\title{
System Analysis of Alternatives for Final Disposition of the Single-Shell Tank System on the Hanford Site
}
E. A. Aitken
D. D. Wanner
M. J. Klem
A. L. Boldt
K. E. Schull
P. A. Salter
F. A. Ruck
K. A. Woodworth

July 1990

Prepared for the U.S. Department of Energy under Contract DE-AC06-76RLO 1830

Pacific Northwest Laboratory Operated for the U.S. Department of Energy by Battelle Memorial Institute 


\section{DISCLAJMER}

This report was prepared as an account of work sponsored by an agency of the United States Government. Neither the United States Government nor any agency thereof, nor Battelle Memorial Institute, nor any or their employees, makes any warranty, expressed or implied, or assumes any legal liabillty or responsibilty for the accuracy, completeness, or usefulness of any information, apparatus, product, or process disclosed, or represents that its use would not infringe prwately owned rights. Reference herein to any specific commercial product, process, or service by trade name, trademark, manufacturer, or otherwise does not necessarily constitute or imply its endorsement, recommendation, or favoring by the United States Government or any agency thereof, or Battelle Memorial Institute. The views and opinions of authors expressed herein do not necessarily state or reflect those of the United States Government or any agency thereof.

PACIFIC NORTHWEST LABORATORY

operated by

BATTELLE MEMORIAL INSTITUTE

for the

UNITED STATES DEPARTMENT OF ENERGY

under Contract DE-ACO6-76RLO 1830 
SYSTEM ANALYSIS OF ALTERNATIVES FOR FINAL, DISPOSITION OF THE SINGLE-SHELL TANK SYSTEM ON THE HANFORD SITE
E. A. Aitkesn (a)
M. J. Klem (b)
K. E. Schupl(b)
F. A. Ruck (b)

D. D. Wanner (b)
A. L. Boldt (b)

P. A. Salter (c)

K. A. Woodworth (b)

July 1990

Prepared for Westinghouse Hanford Company Richland, Washington 99352

Work supported by the U.S. Department of Energy under Contract DE-AC06-76RL0 1830

Pacific Northwest Laboratory Richland, Washington 99352

(a) Associated with Aitken Engineering, Inc.

(b) Associated with Westinghouse Hanford Co.

(c) Associated with Pacific Northwest Laboratory. 



\section{ABSTRACT}

A system analysis of the single-shell tank (SST) system at the U.S. Department of Energy's Hanford Site near Richland, Washington, was initiated as a key step in the planning process for final disposition and ultimate closure of that system. The analys is approach was systematic and structured, using systems engineering principles to provide for traceability and capability for iteration as the Hanford SST disposition program evolves. The disposition function of the system was divided into seven subfunctions that were used to 1) analyze various alternatives on how and how well the functions should be completed to satisfy a myriad of uncertain and conflicting regulatory guides and statutes and 2) establish a baseline for generating and updating planning documents.

A set of 541 candidate requirements was created from the analysis of interfacing needs of the seven subfunctions and from the regulations applicable to the Hanford SST system. The analysis was used to structure and prepare the Hanford Single-Shell Tank System Technical Support Program Plan and other planning documents for the system. 


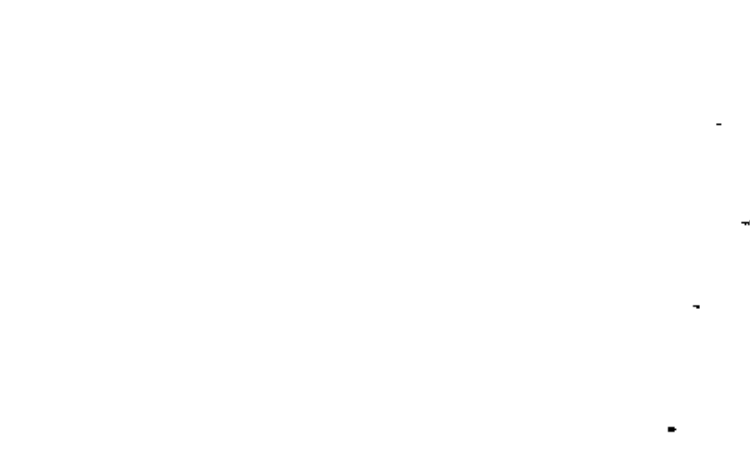




\section{CONTENTS}

ABSTRACT ..........................

DEFINITION OF TERMS ................ ix

SUMMARY. ......................... xi

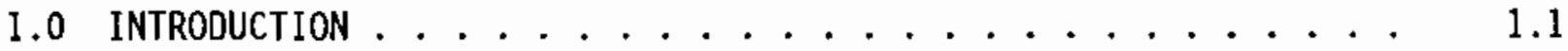

I.1 PURPOSE . . . . . . . . . . . . . . . . 1.1

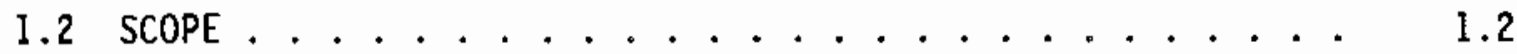

1.3 TECHNICAL APPROACH $\ldots \ldots \ldots \ldots \ldots . \ldots . \ldots . \ldots . \ldots$

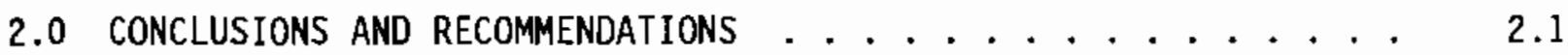

3.0 MISSION STATEMENT . . . . . . . . . . . . . 3.1

4.0 MISSION ASSUMPTIONS . . . . . . . . . . . . . 4.1

5.0 SYSTEM DEFINITION . . . . . . . . . . . . . . . 5.1

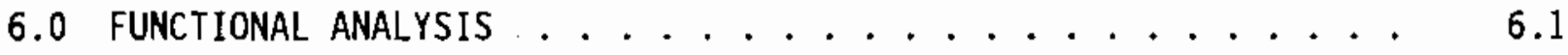

6.1 FUNCTION 1100 - CHARACTERIZE THE SST SYSTEM . . . . . 6.3

6.2 FUNCTION 1200 - PROVIDE INTERIM STABILIZATION/
ISOLATION . . . . . . . . . . . . . 6.4

6.3 FUNCTION 1300 - PROVIDE REGULATORY DOCUMENTS . . . . . 6.4

6.4 FUNCTION I400 - RETRIEVE SYSTEM COMPONENTS . . . . . 6.4

6.5 FUNCTION 1500 - PERFORM PRETREATMENT OF SYSTEM

6.6 FUNCTION 1600 - PREPARE FINAL WASTE PACKAGE $\ldots \ldots . . .6 .5$

6.7 FUNCTION 1700 - PROVIDE LONG-TERM ISOLATION $\ldots \ldots . . .6 .6$

7.0 FUNCTIONAL INTERFACES . . . . . . . . . . . 7.1

8.0 HIERARCHICAL SOURCE ANALYSIS . . . . . . . . . 8.1

8.1 CONSTRAINTS $\ldots \ldots \ldots \ldots . \ldots . \ldots . \ldots . \ldots . \ldots$

8.2 Measurable Performance RequirementS . . . . . . . 8.4 
8.3 DESIGN, QUALIFICATION AND TEST REQUIREMENTS $\ldots \ldots . .8 .4$

8.4 PERFORMANCE CRITERIA . . . . . . . . . . . 8.5

8.5 DECISION CRITERIA FOR SELECTION OF ALTERNATIVES $\ldots \ldots .8 .5$

9.0 REQUIREMENTS ANALYSIS . . . . . . . . . . . . 9.1

9.1 IDENTIFICATION OF ATTRIBUTES ..................... 9.1

9.1 .1 Chemical Attributes (I to 110) . . . . . . . 9.2

9.1.2 Physical Attributes (111 to 182) . . . . . . 9.5

9.1.3 Engineered Enclosures (183 to 443) . . . . . 9. 9.7

9.1 .4 Operating Attributes (444 to 500) ....... 9.15

9.1.5 Site-Selection Attributes (501 to 525) ..... 9.17

9.1.6 Records and Reporting Attributes (526 to 541) . . 9.18

9.2 ALLOCATION OF ATTRIBUTES TO HIERARCHICAL OBJECTIVES . . 9.19

9.3 FORMAT FOR EVALUATION OF ATTRIBUTES . . . . . . . 9.19

9.4 ATTRIBUTE RANKING BY FUNCTION . . . . . . . . . . 9.20

10.0 REFERENCES . . . . . . . . . . . . . 10.1

APPENDIX A - LISTING OF FUNCTIONAL ACTIONS TO BE PERFORMED ON
THE HANFORD SST SYSTEM ....... A.I

APPENDIX B - LINKAGE OF HIERARCHICAL SOURCE STATEMENTS TO ATTRIBUTES DEFINING SYSTEM REQUIREMENTS ........ . B.

APPENDIX C - SOURCE DATA FOR REQUIREMENTS ANALYSIS - SECTION 9.0 . . C.I 


\section{FIGURES}

1.1 Hanford SST Hierarchical Chain of Interests . . . . . . 1.3

1.2 Hanford SST Systems Engineering Approach . . . . . . 1.5

5.1a Hanford Site 200 East Area . . . . . . . . . . . 5.3

5.16 Hanford Site 200 West Area . . . . . . . . . . . . 5.4

5.2 Schematic Representation of Hanford Tank Farm Facilities . . . 5.5

5.3 Underground Single-Shell Tanks at Hanford . . . . . . . 5.6

6.1 Hanford SST Functional Analysis, Illustrations of Functions and Subfunctions .................. 6.2

7.1 SST Functional Interfaces Material Flow ......... 7.3

7.2a SST Functional Interfaces Information Flow To/From $1100 \ldots . . .97$

7.2b SST Functional Interfaces Information Flow To/From $1200 \ldots 7.5$

7.2c SST Functional Interfaces Information Flow To/From $1300 \ldots 7.6$

7.2d SST Functional Interfaces Information Flow To/From $1400 \ldots . . .7 .7$

7.2e SST Functional Interfaces Information Flow To/From $1500 \ldots 7.8$

7.2f SST Functional Interfaces Information Flow To/From I600 . . . 7.9

7.2g SST Functional Interfaces Information Flow To/From $1700 \ldots 7.10$ 


\section{TABLES}

A.l Functional Breakdown - Final Closure of the SST System . . . A.2

B.1 Extracted Statements from Hierarchical Sources Applicable . . B B.3

B.2 Attribute Numbers Arranged by Category Identification

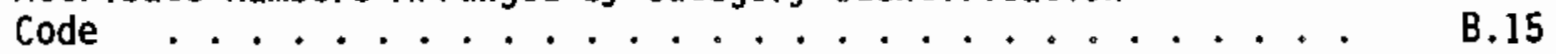

C.1 Listing of Attributes, Units of Measure as Potential Requirements for Final Disposition of the SST System . . . . C.3

C.2 Listing of Rankings of Attributes by Function ....... C.21 


\section{DEFINITION OF TERMS}

Systems engineering terminology is used frequently in this report. To aid the reader unfamiliar with this specialized language, some terms are defined below for quick reference.

- Hierarchy or Hierarchical - A vertical placement of interests, requirements, or authorities that have a stake in single-shell tank (SST) system performance. Looking up the hierarchical chain, the SST system is a subsystem of a larger system involving a broader social, political and technical scope. Looking down the hierarchical chain, the SST system is a synthes is of a set of subsystems with narrower technical scopes.

- Performers - The SST system is comprised of subfunctions that have requirements and methods for completing an action carried out by individuals, teams or organizations. These groups are performers of the function.

- Function - An action involving a transformation of an input to an output subject to certain controls. The transformation may involve information as well as materials. It is the principal means for dividing high level, broad actions into successively smallerscoped specific actions (subfunctions) to simplify management of complex systems such as the single-shell tanks.

- Advocate - A person who develops a set of viewpoints, judgments or decisions from the focused interests of his assigned subfunction. The system analysis maintains these distinctions between subfunctions to resolve conflicts during the development and implementation phases of the SST system.

- Requirements - A set of measures that determine how well a function is to be performed. A requirement, to be capable of measurement, must consist of three elements: a name or attribute, a unit of measure, and a value or procedural description.

- Attributes - A list of identifiers that form one element of a requirement. Identification of attributes is the first step in defining a requirement.

- Unit of Measure - A scale or yardstick to measure performance of an attribute.

- Stringency Level - An attribute may be assigned a range of values depending on the performance desired. The system analysis identifies levels of stringency to show a range from "what is standard practice" to "what is plausible" along a scale defined by a unit of measure. The choice of a level of stringency depends on criteria that balance all interests up and down the hierarchical chain. 
- Constraint - A requirement containing all its elements that has been specified and passed down the hierarchical chain. It is included in the requirements list but not considered as a variable in the impact analysis.

- Assumptions - A set of statements that defines the context in which a system is analyzed. Such statements are considered changeable but their impact on the decisions made is not evaluated.

- Decision Criteria - A basis for making selections from a range of alternative requirements and methods. The decision criteria are not to be confused with performance criteria and requirements.

- Standards - A set of requirements that has achieved a wide leve1 of acceptance. In the context of SST system analysis, all requirements will eventually become standards as the program develops and matures. The requirements 7 ist herein is not a standards list as yet. 
SUMMARY

This system analysis is a key step in the planning process for the disposition program of the U.S. Department of Energy's (DOE) single-shell tank (SST) system at Hanford. The disposition program calls for the ultimate closure of the SST system, and this system analysis provides a systematic and structured approach to meeting this objective, one that is traceable and capable of iteration so that alternatives considered and decisions made are revealed as the program evolves. The system analysis was conducted prior to preparation of the Hanford Single-Shel1 Tank Systems Technical Support Program Plan (SST-TSPP) (Klem et aT. 1990), and the results were used to organize and help establish the baseline information for the SST-TSPP and future updates of this on-going effort. The system analysis was al so conducted during the formulation of the Hanford Federal Facility Agreement and Consent Order (TriParty Agreement between the DOE, the EPA, and the Washington State Department of Ecology) (TPA 1989).

\section{APPROACH AND STRUCTURE}

Because of the uncertainties from conflicting regulations, lack of quantitative decision criteria, and the probable use of variances in the regulatory process, the structured approach described herein is needed to focus the development effort and to provide a bottom-up bas is for a two-way dialogue between Tri-Party agency interests and the implementing organization. The output from the approach is a baseline for generating and updating the planning documents used in the program, such as the Hanford SST-TSPP (Klem et al. 1990).

The key steps in the Hanford SST system analysis were as follows:

1. Formulation of a mission statement defining why actions are needed to change the SST system from its present state.

2. A functional breakdown of what actions are to be performed to the level that permits exposition of requirements and methods for the system as a whole.

3. A requirements analysis of how well the actions are to be performed. A set of reference requirements is selected and is used in the planning. 
4. A methods analysis of how the actions are to be performed. Also, a set of reference methods is selected and used in the planning.

Each of the above steps provides a building-block for a permanent structure that enables change control as new information becomes available. The term "reference" is used to indicate that at any instant in the program, there is a system requirements network that keeps the subsystems from working at crosspurposes.

\section{FUNCTIONS}

From the Mission Statement, the overall function--perform the final disposition of the Hanford SST system--was defined and then divided into seven subfunctions. Each of these subfunctions was assigned to a member of a team who acted as an advocate of the function. The advocacy views provide insights and viewpoints that generate the basis for selecting reference sets of system requirements and methods. Conflicting viewpoints are revealed to highlight the issues needing resolution in the planning process.

By performing the analysis in the sequence described above, a mechanism for understanding the basis for choosing a specific stringency level for a requirement and preferred methods for carrying out the functions is created. The seven functions are:

- characterize the SST system

- provide stabilization/isolation

- provide regulatory documents

- retrieve system components

- perform pretreatment of system components

- prepare final waste package

- provide long-term isolation of waste.

These functions represent a set of actions that are permanent over the development and implementing phases of the SST disposition program and are 
unchanged by the choice of alternatives under consideration. This breakdown becomes the framework for planning as the program transitions from development to implementation.

AT so, as the program matures, each of the seven functions can be divided into lower-level sets of actions revealing more detail. This analysis therefore initiates the functional breakdown sufficient to establish what requirements and methods are appropriate at the top level but does not complete it.

\section{REQUIREMENTS AND METHODS}

A set of candidate requirements was created from an analysis of interfacing information needs of each of the seven functions and from the regulations applicable to the SST system. The team identified 541 attributes as candidate requirements (called attributes) that may be used to set performance standards for the development and implementation of the SST final disposition. The identification of attributes is one element of the requirementsetting process. Each attribute has a range of values or procedures that denotes a degree of difficulty when compared with a defined unit of measure. The requirement is complete when a unit of measure and a particular value or procedure are selected from the range of choices. The system analysis performs the selection based on appropriate criteria for the selection process. This report presents the attributes for this selection process. Several temporary selection criteria were examined for completing the requirementsetting process but their application is being deferred until a more representative set of criteria (recommended in this report) has been evaluated.

Each functional advocate ranked the 541 attributes on a scale from 1 to 10 to reveal the importance of the attribute to performing the function satisfactorily. If several functions ranked an attribute high, then there is a potential for a conflict on the proper choice of the degree of difficulty (level of stringency), since not al1 functions may desire the same degree of difficulty. Rankings of 1 by the functional advocate denote that he is indifferent to the attribute's influence on his function and his involvement in the selection of a degree of difficulty is unnecessary. The rankings reported in 
this document provide the basis for establishing allocation of resources for resolving conflicts and uncertainties between functions during the development phase of the SST program at Hanford.

Several alternative methods were examined by the functional advocate to help guide the requirements setting process. The methods proposed were unique to each of the seven functions. No sharing of a method between functions was evident so that the alternative methods could be selected after completion of the requirements setting using a separate set of selection criteria, if appropriate. Selection of a reference set of methods was deferred until the requirements setting was complete.

There are two paths for disposition of the SST system:

1. Leave the SST waste in place and perform the appropriate actions to satisfy regulatory requirements for long-term isolation of the in situ waste as a contained waste package.

2. Retrieve the SST waste and perform the appropriate actions to satisfy regulatory requirements for long-term isolation of the waste at suitable repository sites at Hanford or elsewhere.

The system analysis has assigned attributes for both options. There may need to be a separate set of requirements for each option, since they may be applied individually to the 149 tanks in the SST system at Hanford.

\section{CONCLUSIONS AND RECOMMENDATIONS}

The options of leaving or retrieving the SSTs have been addressed in the context of: if leaving the tanks is the choice, then how and how well is it to be performed and similarly for the retrieval option? The top-level disposition function can be divided into a subset of seven subfunctions that apply equally regardless of the leave or retrieve option chosen. The flow of information and material between the functions changes, however. Therefore, a separate set of attributes leading to two sets of reference requirements and methods for each option is necessary. The criteria for assigning the stringency level for an attribute have not been developed sufficiently for application to the SST system and must be formalized in discussions with TPA agencies. Furthermore, interfacing requirements for facilities to be shared with other waste systens undergoing environmental restoration at Hanford (such as 
the double-shell tank disposition program) are needed to understand the capacity and potential interference points in the processing network.

Preliminary analysis of the alternatives to determine how well the retrieved waste should be treated by chemical processes before it is accepted for conversion to waste forms (and subsequently to waste packages) shows that potentially enormous cost increments are involved. Further work is recommended to establish credible cost estimates so that they may be factored in as one of the system performance measures in the selection of alternative courses of action.

Recommendations for the further activities that would improve the understanding of the Hanford SST system as a whole and aid in reaching the conclusions about future courses of action toward its disposition are presented as follows:

1. Provide and use a reference set of requirements as the basis for integration with current projects (HWYP, Grout, etc.) that will service the SST disposal project after some non-SST programs are completed.

2. Provide and use a simutation model of the waste process stream between the subfunctions of the SST system to allocate requirements (i.e., inprocess storage capacity, availability, instantaneous processing rates) for integrated development.

3. Provide and use a set of performance measures (i.e., long-term health and risk, short-term risk, cost and schedule) that recognizes the interests of all parties involved in the approval process. These performance measures become the decision criteria for selecting alternative requirements and methods by the implementing organization. 


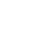




\subsection{INTRODUCTION}

\subsection{PURPOSE}

The U.S. Department of Energy (DOE) has entered into an agreement as part of the Record of Decision (DOE 1988) from its Environmental Impact Statement (DOE 1987) to evaluate the alternatives for the final disposition of the single-she11 tank (SST) system at the Hanford Site. A 1989 Hanford Federal Facility Agreement and Consent Order between DOE, the Environmental Protection Agency (EPA) Region 10, and the Washington State Department of Ecology (Ecology), commonly known as the Tri-Party Agreement (TPA), has set a target date of 2018 to complete closure of the Hanford SST system (TPA 1989). Prior to final disposition (closure) of the system, a supplemental EIS will be approved after a period of evaluations and demonstrations of the appropriate technology for the closure process.

The Westinghouse Hanford Company (WHC) has been assigned by DOE as the operating contractor to perform the Hanford Site reclamation, which includes closure of the SST system. WHC requested that a system analysis be conducted of the Hanford SST complex as a first step toward organizing an extensive evaluation of the alternatives and to direct the development of technology for successfully closing down the single-shell tank system at Hanford. The Pacific Northwest Laboratory (PNL) coordinated the system analysis effort using a muttidisciplined team, each member representing one of seven major functions required to complete the SST closure mission. The team consisted of WHC and PNL personnel.

The regulatory framework surrounding disposal of radioactive waste must be considered in establishing decision criteria for SST waste disposal alternatives. A review of the regulations (Keller et al. 1989) identified the performance, design, permit requirements, and criteria that should be considered. Conciusions from this review are that many regulatory issues need to be resoived and that many of the current statutes and regulations, such as the Resource Conservation and Recovery Act (RCRA), specify general requirements without providing sufficient quantitative criteria to assess performance of the disposition process. 
The purpose of this system analysis is to provide a baseline for the technology planning effort. It provides the initial set of measurable requirements that satisfy the intent of the statutes that lack quantitative criteria. As the development matures and the regulatory dialogue continues, the system analysis provides the systematic and structured framework for traceability and iteration of requirements and methods to guide the decisionmaking process. It also balances the competing interactions between subfunctions to ensure a successful outcome of the system as a whole.

\section{$1.2 \underline{S C O P E}$}

The analysis must consider all facets of the SST system at Hanford. It must also consider all reasonable alternatives consistent with the applicable statutes and regulations. Because of the uncertainty of these regulations and the absence of quantitative criteria, the technical aspects for design, development, and implementation must be conducted as the dialogue with public agencies is carried on. To foster a two-way dialogue in the hierarchical chain of interests, the system analysis must provide a mechanism for showing how and how well the various actions to be performed by the implementing organization (WHC) satisfy the higher order interests in the chain. As shown in Figure 1.1, the desires, intents, and constraints flowing down the hierarchical chain must be transformed into a set of measurable requirements using a systematic and structured system engineering process invoked at the SST system level. From analysis of the alternative requirements and methods, the consequences, risks, and impacts of various choices flow up the hierarchical chain. In this way, a balance between the social and political interests and the technical capabilities can be achieved.

The scope of the system analysis includes formulation of a system engineering process that provides traceability and that is capable of iteration as new information flows up and down the hierarchial chain. The system engineering process involves the following sequence of steps:

1. Formulation of a mission statement defining why actions are needed to change the Hanford SST system from its present state.

2. A functional breakdown of what actions are to be performed to the level that permits exposition of requirements and methods for the system as a whole. 


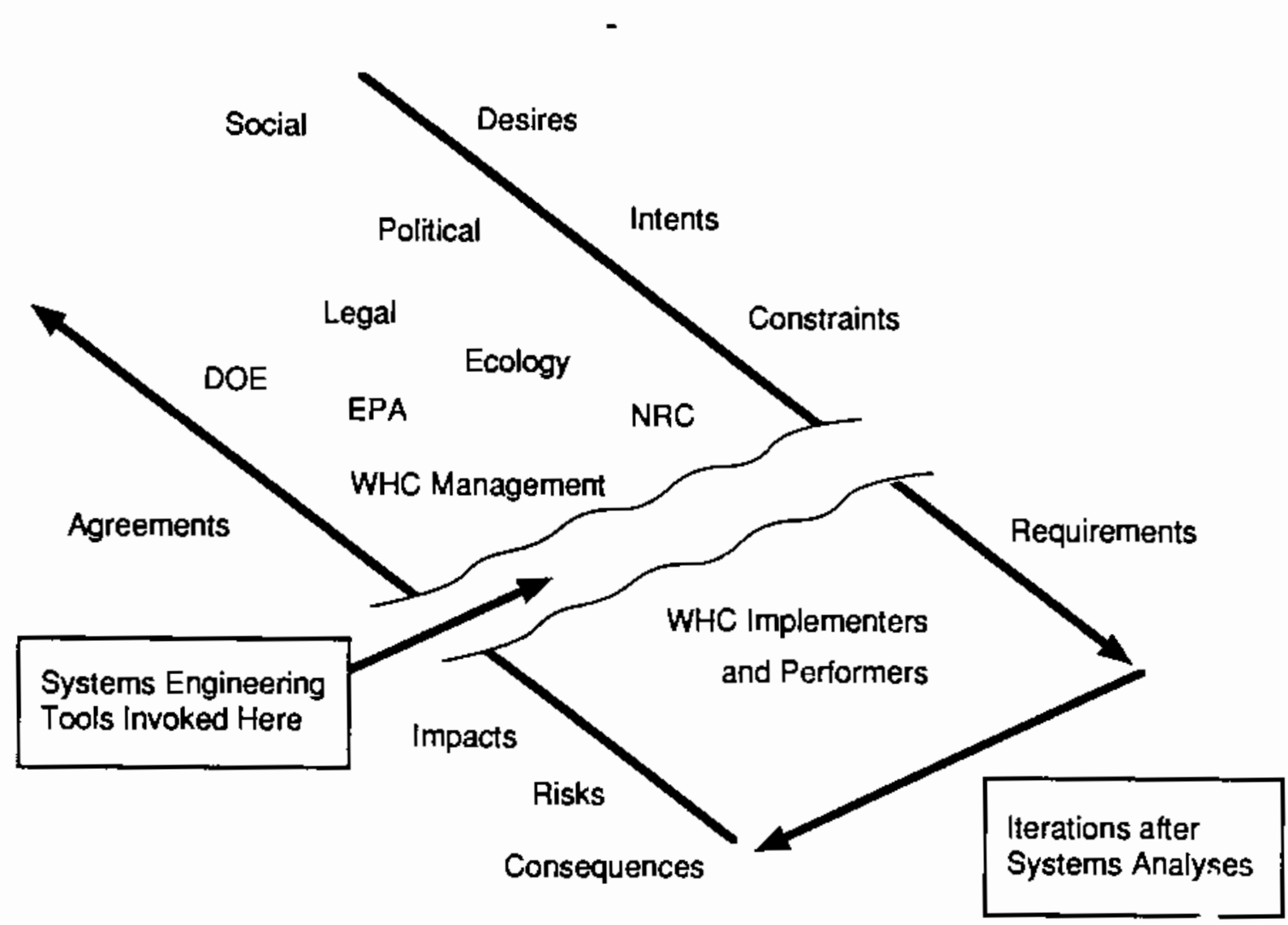

FIGURE 1.1. Hanford SST Hierarchical Chain of Interests

3. A requirements analysis of how well the actions are to be performed. A set of reference requirements is selected and used in the initial planning.

4. A methods anatysis of how the actions are to be performed. ATso, a set of reference methods is selected and used in the planning.

The system analysis provides the baseline at the system Tevel for detailing of the design and development effort so that it is internally consistent among the functional segments of the SST system. This analysis provides the starting point for subsequent interactions and identifies major trade-off issues that need to be resolved early through exploratory development or through resolution by regulatory dialogue. The output from the analysis is to be incorporated into the various planning documents for the project, such as the Single-She1] Tank Systems Technical Support Program Plan (SSTTSPP) (KTem et al. 1990). 


\subsection{TECHNICAL APPROACH}

The overall SST mission is divided into seven major functions and each member of the study team becomes an advocate of his assigned function. Each of the seven functions defines an action that must be performed by a group or organization and the advocate represents their interest in specifying the attributes that determine how and how well the function can be completed. Al1 attributes are assessed by each advocate to identify potential conflicts as to how well a given performance attribute is to be achieved. Attributes passed down from regulations and statutes are included and are treated as constraints not subject to change if they meet the condition of being measurable. If not, then measurable attributes that do meet the intent are generated by the team. This process bridges the uncertainty gap in the "quantitativeness" of regulations raised by Keller et al. (1989) in their review, and surfaces conflicts in the interfaces between the seven major functions.

The attribute list, representing the collective performance of all functions and therefore the system as a whole, is analyzed from the view point of each function as to the importance of the attribute, to the degree of difficulty in achieving a desired level of stringency, and to the cost impact. These viewpoints form the database for making choices and for identifying key conflicting issues that need to be resolved. The database also can be used for a first-cut sensitivity analysis and to set the stage for more detailed trade studies.

This general description of the technical approach is shown schematically in Figure 1.2 in more detail. Three columns of boxes represent activities that focus on generating options, actions/outputs and criteria.

The options and criteria activities are inputs to an analysis box that generates an output in the center column to the next box below. The arrows show the flow of inputs and outputs between the activity boxes. 




FIGURE 1.2. Hanford SST Systems Engineering Approach 
The order of activity is to prepare the mission statement, functional analysis and interfaces first. The mission statement (Section 3.0) generates the top-level function as input to the functional analysis and may also generate appropriate decision criteria. The functional analysis divides the toplevel function into lower-level functions to enable an analys is of interfaces and inputs between functions at the same level. Each of the functions also provides the options for requirements and methods to determine how and how well the function should be completed. The intents and constraints from the applicable regulations and DOE orders are combined with the inputs from the functions to prepare a candidate requirements list.

Similarly, the decision criteria from the regulations and DOE orders are combined with inputs from the mission statement to establish a set of decision criteria for the requirements analysis. The same logic path is used for the methods analysis except that applicable regulations may be involved to a lesser degree.

System engineering principles require determination of reference requirements before determination of reference methods. However, there must be at least one valid and plausible method for a given set of requirements (illustrated in the Figure 1.2 by the broader arrow labeled a test for validity).

The dashed line shows the extent to which this report has completed the technical approach. The boxes above the dashed line identify the applicable sections of this report where the activity is described. The boxes below the dashed line are subsequent activities under way. Because of the long-term development and implementation, it is recognized that several iterations are expected and such is represented in the figure by the arrows to the left returning back to requirements, methods, and tank classification boxes for reanalysis based on new information. The tank classification activity box assigns the appropriate "leave" or "retrieve" option to each of the 149 tanks in the SST system and is included in the figure for future use.

The technical approach provides the visible basis for decisions, the traceability of the evolution of the technology, and the capability for iterations to accommodate and control changes for the very complex SST disposition. 


\subsection{CONCLUSIONS AND RECOMMENDATIONS}

The options of leaving or retrieving the Hanford single-shell tanks (SSTs) have been addressed in the context of: if leaving the tanks is the choice, then how and how well is it to be performed? Similarly, if closing the system (i.e., final disposal of the contained wastes and of the SST system components) is the choice, then how well is that option to be performed? The top-level disposition function can be divided into a subset of seven subfunctions that apply equally regardless of the option chosen. The flow of information and material between the functions changes, however; therefore, a separate set of attributes leading to two sets of reference requirements and methods for each option is necessary. The criteria for assigning the stringency level for an attribute have not been developed sufficiently for application to the SST system and must be formalized in discussions with Tri-Party Agreement (TPA) agencies. Furthermore, interfacing requirements for facilities to be shared with other waste systems undergoing environmental restoration (such as the double-shell tank system at Hanford) are needed to understand the capacity and potential interference points in the processing network.

Preliminary analysis of the alternatives to determine how well the retrieved waste should be treated by chemical processes before it is accepted for conversion to waste forms (and subsequently to waste packages) shows that potentially enormous cost increments are involved. It is concluded, therefore, that cost must be included as one of the system decision criteria, al though a subordinate one, in the selection of alternative requirements and methods. With the milestone from the TPA of 2018 as the completion date for closure of the Hanford SST system, time to accomplish complex closure tasks must also be a decision criterion. From the Resources Conservation and Recovery Act (RCRA) and other applicable statutes, decision criteria al so must be focused on the long-term health and safety risks to the public. DOE orders and other statutes also require near-term exposure to the public and employees from operations performing the closure of the SST system as a consideration for decision criteria. 
Recommendations for further activities to improve the selection of requirements and methods for the Hanford SST system as a whole and to aid in reaching conclusions about future courses of action toward its disposition are presented below.

1. Provide and use a reference set of requirements as the bas is for integration with current projects (HWVP, Grout, etc.) that will service the Hanford SST system after some non-SST systems are completed.

In the anticipation that the double-shell tank (DST) and other waste streams will receive priority for recovery, it is imperative that the needs of the SST system be overlayed with other Hanford Site dispositions where a commonality of facilities and technologies are used. Pretreatment and waste packaging of glass and grout wastes are particularly important. Since SST waste uniquely contains an excess of sodium nitrate, aluminum and silicon compounds, the process system must accommodate this burden. Alternatively the grout and glass waste packages must be reformulated to contain higher concentrations of these relatively low hazard but abundant waste constituents without destroying their long-term waste package performance in the disposal environment.

This step will require strong involvement of SST concerns in the project definition stages of other pretreatment and waste packaging design and construction projects at the Hanford Site. The candidate requirements generated in this report provide the initial instrument for this action.

2. Provide and use a simulation model of the waste process stream between the sub-functions of the SST system to allocate requirements (i.e.. in-process storage capacity, availability, instantaneous processing rates) for integrated development.

The large and diverse quantities of waste accumulated in the Hanford SST system require an analysis of the flow streams if retrieval is attempted. Blending and interim storage of sludge and supernatant liquids will need to be managed if stringent control of certain hazardous chemical constituents is applied. Some constituents cannot be extracted from the waste streams and are subject to large swings in concentration from one tank to the next. The retrieval, pretreatment and waste packaging schedules must be closely matched to achieve an efficient disposition process. Before commitments of major pretreatment and waste packaging projects to DST and other waste recovery plans are finalized, the surge capacity and its strategic placement for SST needs must be recognized.

The simulation study can be readily accomplished early in the program and provides a high leverage in cost savings by minimizing the number of waste packages. The simulation model should be structured using the SST functional breakdown to allocate requirements to each function. The model should be simply applied initially and grow in 
complexity and sophistication as the SST characterization activity defines the SST waste sources more accurately.

3. Provide and use a set of performance measures that recognizes the interests of all parties involved in the approval process. These measures become the basis for selecting alternative requirements and methods by the implementing organizations.

One of the key purposes of a performance assessment is to satisfy (through technical arguments) the interests of all parties involved in the approval process--that is, the TPA agencies. Because of the complexity of the problem, and the multiple performance considerations stipulated by the statutes and the governing agencies as described above, four types of SST performance measures are recommended to establish decision criteria:
a. Long-Term Health Effects/Risk
b. Short-Term Health Effects/Risk
c. Time-to-Complete
d. Cost-to-Complete 



\subsection{MISSION STATEMENT}

Radioactive wastes have been generated since 1944 on the U.S. Department of Energy's (DOE) Hanford Site in Washington State as part of the program required to support national defense activities at Hanford. Liquid radioactive and chemical wastes from the nuclear materials production and research activities were transferred to underground, reinforced concrete, steel-1ined tanks, commonly referred to as single-shell tanks (SSTs), for storage. The SSTs were used to store several types of Tiquid wastes before 1971 .

A total of 149 SSTs, with capacities ranging from 55,000 to 1 million gallons each, were constructed on the 200 Area plateau of the Hanford Site. Waste from several of the SSTs was retrieved in the 1950s for extraction of uranium and in the 1960s and 1970s for extraction of cesium and strontium fission products. During the 1970s, the volume of liquid wastes stored in these tanks was reduced by evaporation of the liquids, leaving moist sludge and saltcake in the SSTs. The evaporation effort also served to reduce the environmental impacts of potential releases from the tanks by minimizing the volume of drainable liquids available to contaminate the soil around the tanks. The SSTs now contain about 37 million gallons of saltcake, sludge, and interstitial and nonpumpable supernatant liquids. The wastes contain radionuc 7 ides and potentialty hazardous nonradioactive chemicals.

Production operations at the Hanford Site have produced approximately 1150 waste management units, as addressed in the Hanford Federal Facility Agreement and Consent Order, more commonly known as the Tri-Party Agreement (TPA 1989). These waste units have been grouped into 78 operable units (excluding four groundwater units) to assist in the management of final disposal activities. The six SST operable units include treatment, storage and disposal (TSD) units and past practices units. The SST TSD units comprise the tanks, currentiy associated piping and soits contaminated by leaks from 66 SSTs. The Resource Conservation and Recovery Act (RCRA) past practice (RPP) units include diversion boxes, a crib, a french drain, and several septic tanks. The cribs and trenches that received discharges from cascade SST operations are included in the other operable units and are not covered by 
this system analysis. Separate remedial investigation and feasibility study work plans are being developed for these waste units.

Interim management activities for the Hanford SST operable units wi11 be continued until a decision is made on the actions required for final closure and waste disposa]. These interim activities include characterization of tank wastes, soil, groundwater and ancillary equipment; stabilization to reduce the volume of liquids contained in the waste solids; surveillance to detect leaks, liquid intrusions and changes in the radiological status of the contaminated solids; heat management to prevent excessive tank temperatures; and tank isoTation (i.e., sealing the tank piping and openings) to deter liquid intrusion and monitoring of the groundwater for radionuclides and chemicals.

Final disposal of SST structures and contaminated wastes was addressed in the Final Environmental Impact Statement for the Disposal of Hanford Defense High-LeveT, Transuranic and Tanks Wastes (DOE 1987). The final HDWEIS presented five alternatives with respect to the SSTs:

1. Geologic Disposal Alternative--Retrieve, separate, process, package and transport to dispose of most of the SST waste in a geologic repository.

2. In-Place Stabilization and Disposal Alternative--Dispose of SST waste in-place, including dome filling and using a protective barrier and marker system. Waste processing will be limited to liquid removal and some SSTs will require interim heat removal equipment.

3. Reference Alternative--The reference alternative is identical to the InPTace Stabilization and DisposaT Alternative for the SSTs.

4. Preferred Alternative--Defer decisions on disposal of waste in the SSTs until additional developnent and evaluation are complete. In the interim, DOE will continue storage and maintenance of the SST wastes. This a]ternative was developed as a response to agency and public review.

5. No-Disposa1-Action Alternative--Continue storage of the wastes in the existing tanks. The SSTs will be monitored and maintained. Ongoing activities, such as reduction of liquids in the SSTs, will continue. This case was analyzed in accordance with the requirements of the Council on Environmental Quality-National Environmental Policy Act (NEPA).

As stated in the final HDW-EIS Record of Decision (DOE 1988). DOE has decided to select the preferred alternative and conduct additional development 
and evaluation before making a final decision on disposal of the SST wastes. This additional development and evaluation will include 1) characterizing radioactive waste and hazardous waste (HW) constituents, 2) demonstrating barrier performance by both instrumented field tests, natural analog studies, and modeling, 3) determining the need and methods for improving the stability of the waste form, 4) determining the need and methods for destroying and stabilizing hazardous waste constituents, and 5) developing and evaluating methods for retrieving, processing and disposing of the wastes. The final HDW-EIS ROD commits to the preparation of a supplemental EIS for the singleshell tank waste at Hanford.

Additional development and evaluation will be integrated with regulatory requirements for permitting and closing hazardous waste (HW) sites. In May 1987, DOE issued a final rule stating that the HW components of DOE radioactive waste that are defined as HW under the RCRA are subject to the RCRA regu1ations. In November 1987, the U.S. Environmental Protection Agency (EPA) authorized the Washington State Department of Ecology (Ecology) to regulate mixed wastes (MW) within the state. Consequently, the SST wastes are jointly regulated by DOE (radioactive constituents) and the EPA and Ecology (hazardous chemical constituents).

The Draft Single-She11 Tank Closure/Corrective Action Work Plan presents a work plan for activities associated with final disposal of the SST operable units. This plan serves as the primary basis for more detailed documentation such as the Hanford Single-Shell Tank Systems Technical Support Program Plan (SST-TSPP) (K1em et a1. 1990). As part of the SST-TSPP preparation, a system analysis activity was initiated as described in this report.

The SST disposa] program mission can be stated as follows:

The overall mission of the SST disposal program is to develop, evaluate and implement methods for ultimate disposal of the SST operable units, in compliance with applicable regulations, standards and permit requirements. The disposal methods must prevent significant adverse impact to the biosphere and must protect the long-term health and safety of the general public and maintain worker exposure to as low as reasonably achievable (ALARA).

For purposes of the system analysis, the primary functional action derived from the mission statement is to perform final disposition of the 
Hanford single-shell tank system. This function is accomplished through many subordinate functions that can be constructed from a functional analysis using the approach described in Section 1.0. 


\subsection{MISSION ASSUMPTIONS}

The major assumptions used to guide the analysis of the Hanford singleshell tank (SST) system are provided in this section. These assumptions were generated during the analysis to clarify situations raised by the team where there was no guidance from existing planning documents. These assumptions are considered temporary and may be modified in the future. However, because of the serious impacts that may be involved, such modification to the assumptions must be accompanied by a reanalysis to ensure that any resulting changes are properly identified.

- All SST barriers as originally designed will fail eventuatly and cannot be used for performance credit in the new concept.

- All tanks will transition from their present state to a stabilization/isolation state before remedial and final disposition actions are performed. This situation provides a uniform reference point for analysis of the interface requirements between the stabilization/isolation function and the other functions.

- A tank farm will have all tanks in the farm stabilized and isolated prior to final disposition. This situation provides a similar uniform reference point for analysis of the sequencing strategies for the leave or retrieve options.

- Offsite repositories will be available to accept the SST waste entities as they are generated. The system analysis does not consider the impacts of interim storage because of delays or upsets outside the SST system.

- Some SST-treated wastes wiTl be disposed of in LLW grout vaults onsite.

- The double-shell tank (DST) system will be available for crossblending and conditioning of SST waste on demand. Final disposal of the DST waste will precede the SST disposition. As a point of reference, cost impacts of pretreatment alternatives will assume that DST technology and capital expenditures are previously incurred costs and will not be allocated to the SST system cost if used by follow-on SST disposition. SST derived technology and provisions for additional DST processing capacity and storage wiTl be included in the analysis of SST system costs. 
- For the purpose of performing the requirements analysis, surveitlance and monitoring of SST waste will be performed within the boundary of the SST system. It is realized, however, that compliance is a site issue and potential overlaps in these activities may occur with other non-SST operable units and allocation of certain requirements may be necessary. 


\subsection{SYSTEM DEFINITION}

The system definition includes the contents of the six SST operable units (OUs) defined in the Tri-Party Agreement (TPA 1989). The inventory of the contents is listed for each $0 U$ in the Hanford Single-Shell Tank Systems Technical Support Program Plan (SST-TSPP) (Klem et al. 1990). For purposes of the system analysis the types of treatment, storage, and disposat (TSD) units are: tank waste, tank structure, associated piping, pumps, ventilation equipment, and contaminated soils from some of the 149 SSTs. Also within the six OUs are Resource Conservation and Recovery Act Past Practice (RPP) units that include: diversion boxes, spills from diversion boxes, a crib, a french drain, and several septic tanks. The contents of the RPP units and the associated piping, pumps, and the ventilation equipment in the TSD units were combined in this report into one category and named "ancillary equipment." The cribs and trenches that received discharges from cascade SST operations are included in the other OUs and are outside the SST system definition. ATso, operational service lines outside the first diversion box in a tank array are not covered as part of the system analysis.

The system definition must include also the facilities (temporary and permanent) that are needed to conduct the closure process. Depending on the alternatives for disposition, the facilities may be located at the SST sites, at designated burial sites at Hanford for LLW disposal, or at a central location for processing and in-process storage of SST waste. The system definition does not include offsite facilities for final disposition of the transported waste that may require further processing and packaging. These facitities are assumed to be available for receipt of waste according to defined acceptance criteria and their services are included in the system anatysis as a unit cost based on the number of units transported.

The system definition al so includes equipment used during the disposition. Depending on the type of method for disposition, various major equipment items should be identified at the system level, such as in situ vitrification assemblies, retrieval assemblies, and transportation casks. However, most of the equipment may be identified later at lower levels in the system 
analysis. The principal concern is that equipment life, decontamination, and disposal may influence the decision about alternative methods and should be recognized early in the system analysis.

Materials consumed or used in the formulation of waste entities for final disposition are also part of the system definition. The SST waste may be divided into several waste forms. The waste form is created by combining the raw waste with host materials in a controlled process that 1 imits release after the containment period has been exceeded. Containment is achieved by incorporating the waste form in a waste package. The waste package consists of one or more material combinations that isolate the waste form from intrusion of destructive elements and from dispersal of its contents during a designated containment period. In the SST system, there are several alternative situations where regulations require containment, including during transport. Therefore, a wide variety of packages are envisaged with their own set of requirements. The system analysis has used the terms "waste form" and "waste package" generally as described here to unify the perspective for examining alternative requirements and methods. The combination of the waste form and the waste package is one class of enclosure. Transportation casks, facility isolation barriers, and intrusion barriers are additional classes of enclosures involved in the SST system definition. All these classes are categorized as engineered enclosures in the system definition.

Figure $5.1 \mathrm{a}, \mathrm{b}$ shows the SST system relative to other waste management systems at Hanford, and a schematic representation of Hanford tank farm facilities is shown in Figure 5.2. Figure 5.3 provides a cross-sectional view of the four types of underground single-shell tanks at Hanford. These figures are from DOE (1987). 


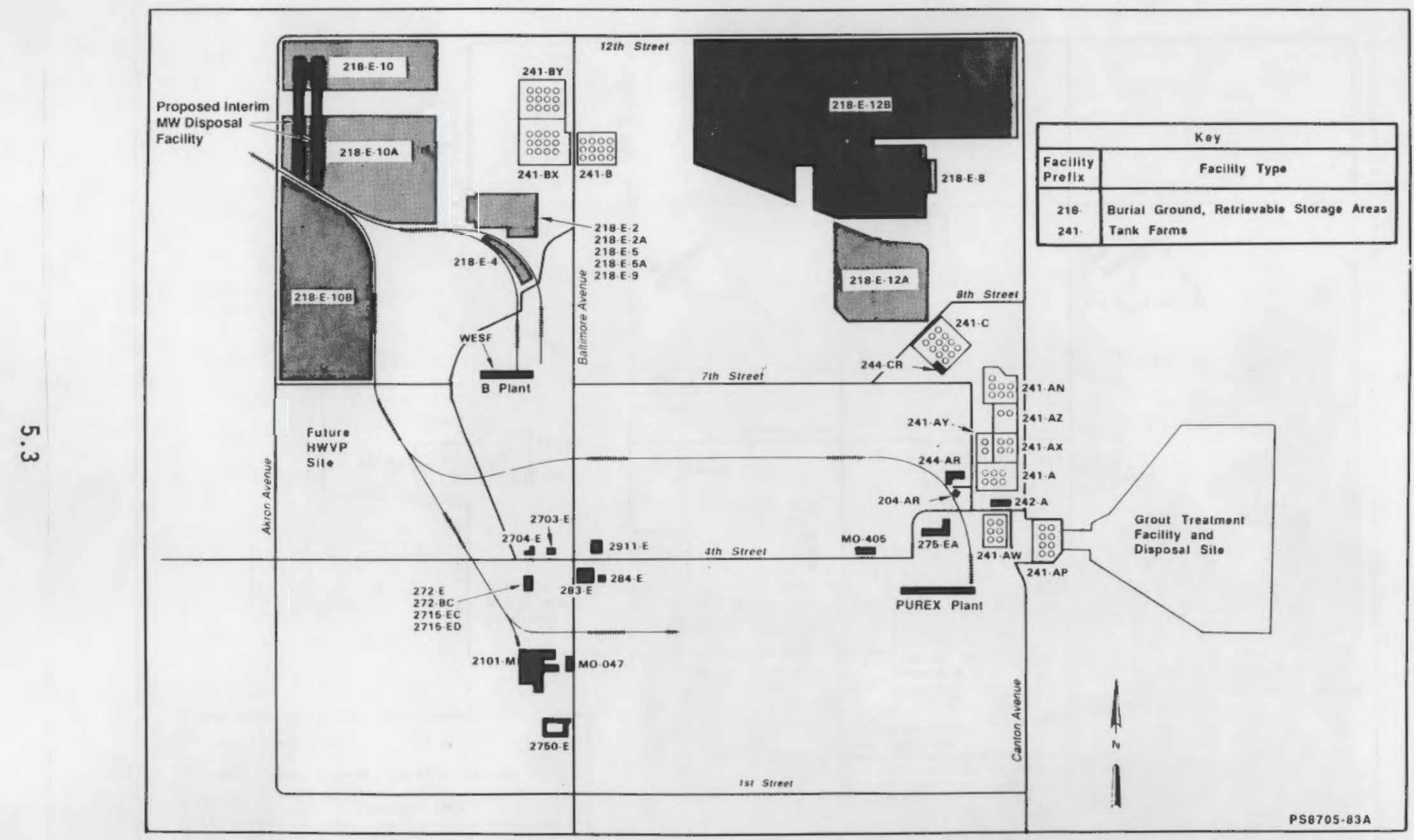

FIGURE 5.1a. Hanford Site 200 East Area 


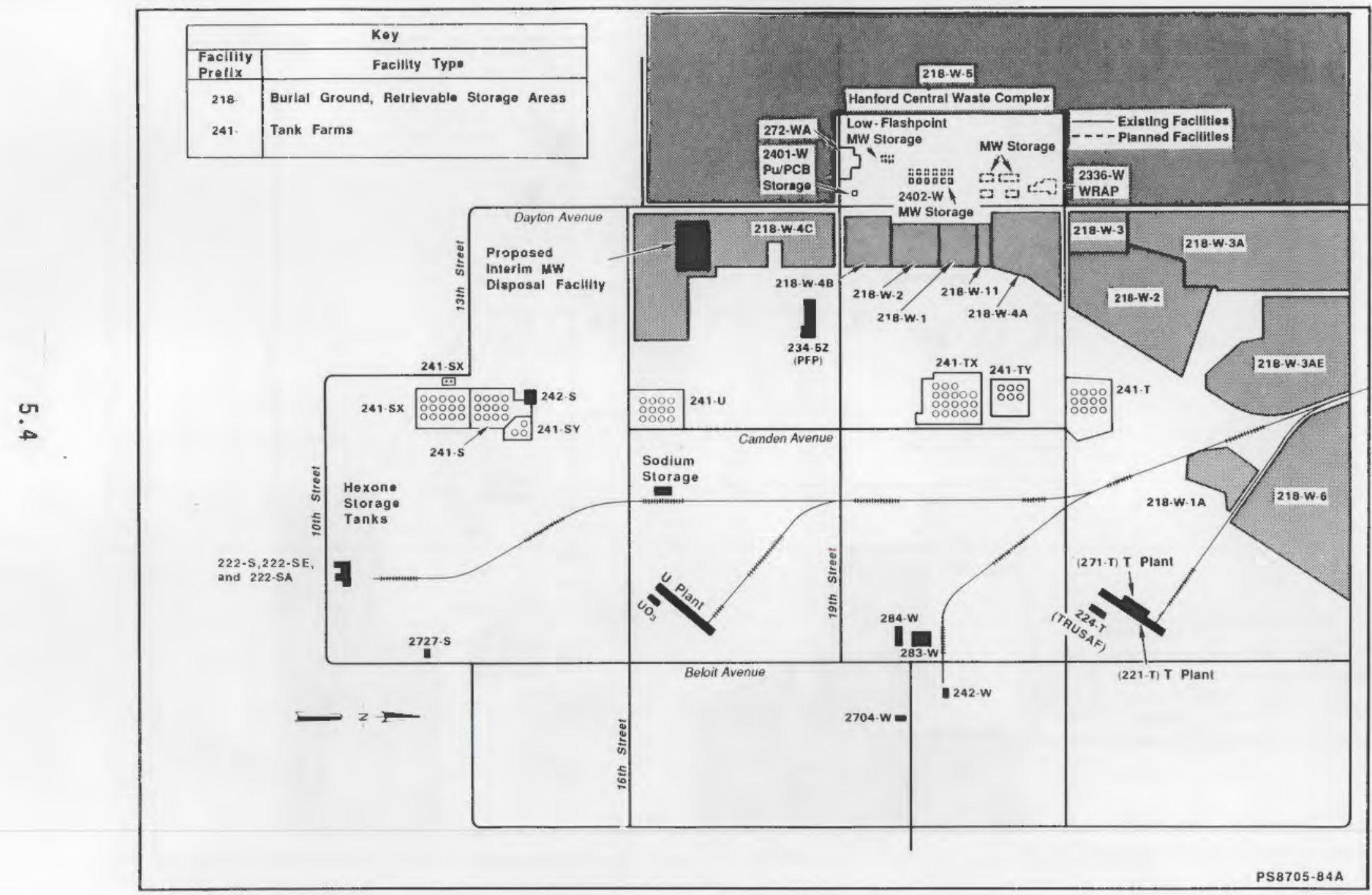

FIGURE 5.1b. Hanford Site 200 West Area 


\section{Existing Underground Waste Tank Farms}

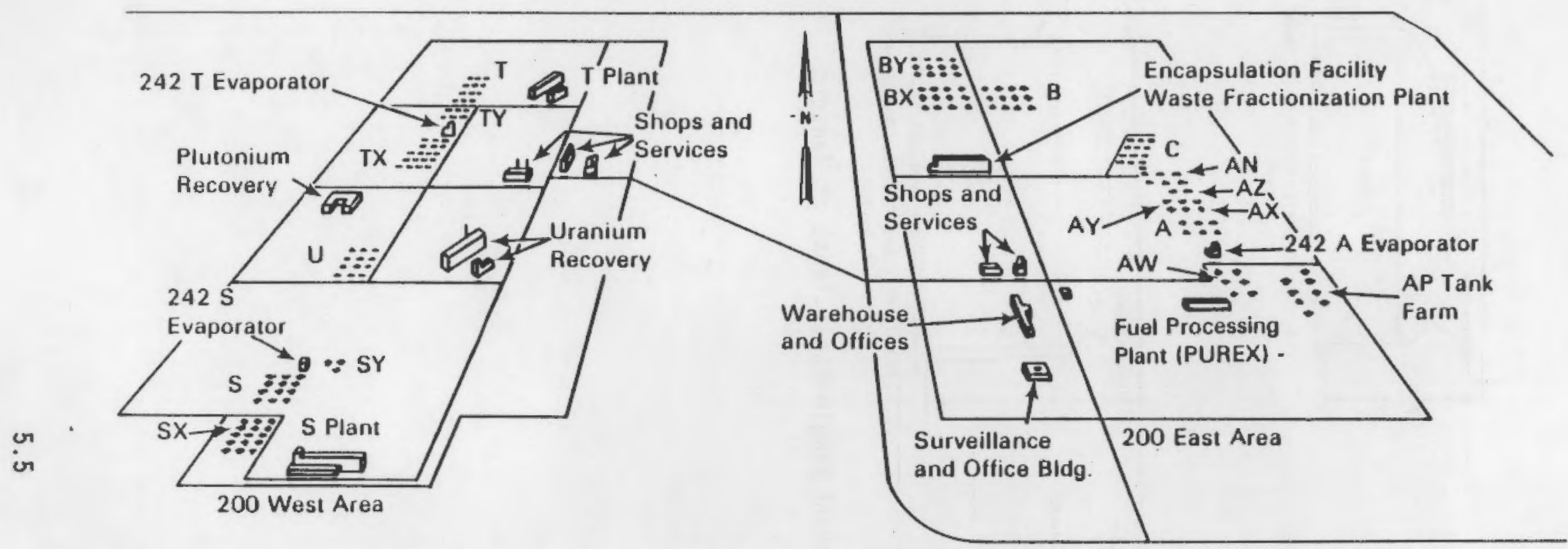

FIGURE 5.2. Schematic Representation of Hanford Tank Farm Facilities (Not to scale. Farms in 200 East and 200 West Areas are about $10 \mathrm{~km}$ apart.) 


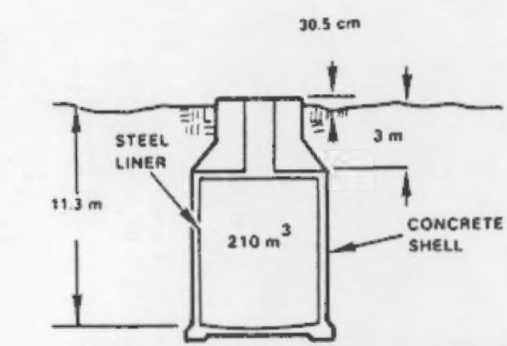

$6.1 \mathrm{~m}$ (20 FT) DIAMETER SINGLE-SHELL TANK TYPE !

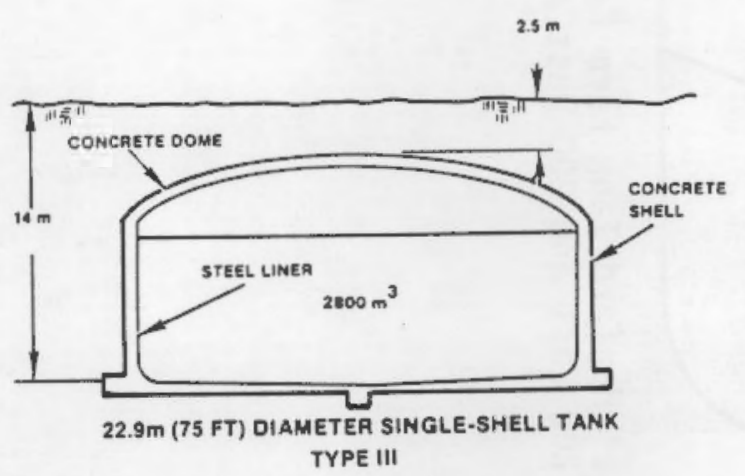

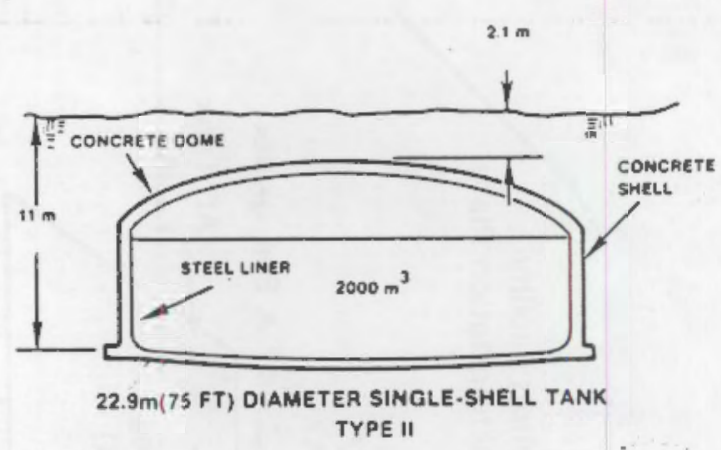

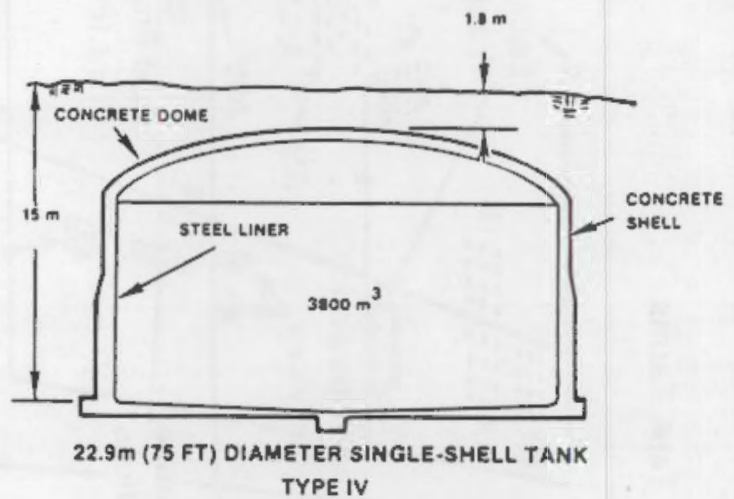
TYPE IV

FIGURE 5.3. Underground Single-She 11 Tanks at Hanford 


\subsection{FUNCTIONAL ANALYSIS}

The results of a functional analysis of the Hanford single-shell tank (SST) system are presented in this section. The functional analysis starts at the primary (zero) function level and continues to the third-level functions. Details of the functional analysis are provided in Appendix A.

In the Mission Statement, the primary function was described as: Perform Final Disposition of the Hanford Single-Shell Tank System. This descriptor reveals little detail but is the starting point for a functional analysis that systematically unfolds the multiplicity of functional actions to be performed. The purpose of this functional analys is is to delineate a layer of subfunctions so that when they are successfully completed, the parent function is also successfully completed. The revelation of functional detail may proceed through many levels. A representative example, extracted from the detailed breakdown in Appendix $A$, is shown in Figure 6.1. The box diagram at the bottom of the figure illustrates the "parent-child" relationship.

At the initial stage of a system analysis it is sufficient to develop a functional breakdown only to the first level, in order to identify major segments that would influence the setting of system requirements and methods. However, it is beneficial to identify provisionally two more levels, in order to organize and justify the requirements and methods from a bottom-up perspective.

One approach to segmenting the primary function is to determine which actions if not performed would render the primary function incomplete. Examination of the regulatory statutes and the DOE orders prescribes a characterization activity to inform the public of the present state of a potential waste source. This provides a data base for judging the hazard level and making decisions for follow-on actions. The regulatory statutes also prescribe a reporting action to justify, through a permitting process, the course of action to be followed toward closure and to monitor performance during the implementation of final closure. Therefore, characterization and reporting are two functions that are essential to achieve final closure. 
Primary Function: Perform Final Closure of SST System

(An Action Satisfying the Mission)

1st Level Function: Provide Final Waste Package

(A Segment of the Top-Level Function)

System Analysis Stopped Here

2nd Level:

Prepare Final Waste Form

3rd Level:

Mix Waste and Stabilizing Agent

Functions Analysis Stopped Here

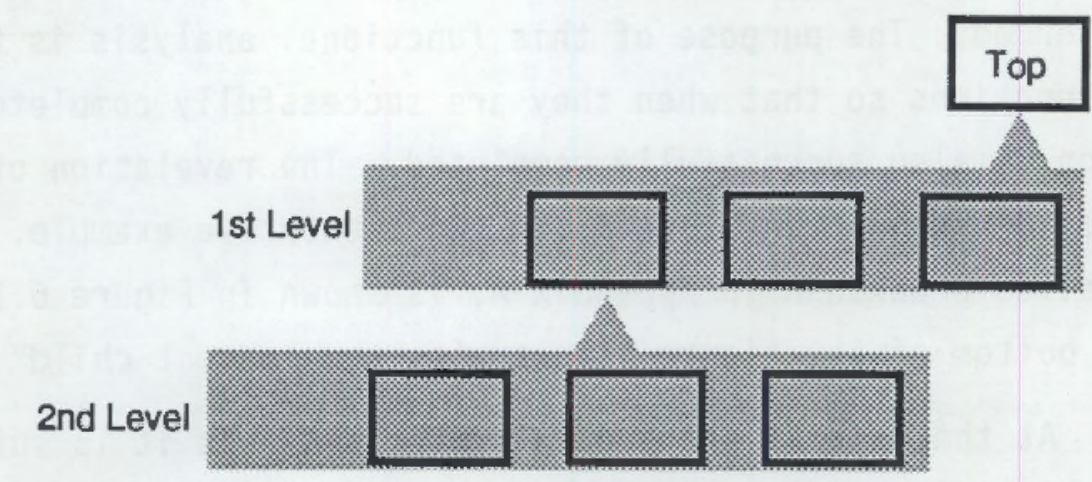

FIGURE 6.1. Hanford SST Functional Analysis, Illustration of Functions and Subfunctions

Because of the complexity of the SST system, there will be a significant period of development before closure is initiated. DOE has committed to a stabilization and isolation action performed on all waste tanks during this interim period. Since the stabilization/isolation of the SSTs may influence other closure actions, it must be included as a function at the first level.

Examination of the known contents and the physical state of the SST waste indicates that up to four distinct types of physical actions are required to complete the final closure process regardless of the choice of disposal option. Each type requires different mechanisms and disciplines, an appropriate condition to designate them as separate functions. These functions are 1) to retrieve SST waste and/or its ancilliary components, 2) to partition the waste materials by chemical pretreatment into specific waste feed streams to optimize the cost within the constraints of regulations, 3) to prepare waste 
packages from the feed streams as a containment vehicle for isolation, and 4) to provide a long-term isolation function to monitor containment and to prevent intrusion of ecological elements that would destroy resistance to dispersat of the waste in the public domain. Elimination of any of these four actions would curtail the opportunity to utilize a number of "leave" or "retrieve" options to perform the mission safely and efficiently.

In all, seven first-level functions are needed to satisfy the mission and its primary function. These include the four physical actions as well as other required actions, e.g., development of regulatory documentation. It is expected that all these functions will be applied to some part of the SST system during implementation of the final closure phase. During the development and assessment phases these functions provide the infrastructure for conducting supporting R\&D. Each of the seven functions are described in more detail below. For purposes of indexing, each function is assigned a fourdigit number. For the primary function, the number is 1000 . For the seven first-level functions, the numbers are 1100 to 1700 . Lower-level functions are indexed by the third and fourth digit.

\subsection{FUNCTION 1100 - CHARACTERIZE THE SST SYSTEM}

This function provides the knowledge of the system state before any $\mathrm{clo}$ sure processing is initiated. Measurements are performed to include all data needed to do assessments for regulatory documentation. Sampling is performed on tank contents and on contaminated soil to determine the hazard level. Sampling may be performed also on uncontaminated soil and groundwater to establish baseline compositions and properties for performance assessments of transport rates. Property determinations of the waste and other components are carried out to provide basic data for handling and transporting the waste. Finally, all measuring techniques are qualified for use in performance assessment and risk analysis evaluations. The output of this function is directed as input to other first-level functions which need the data. The function has been implemented as part of the closure planning process. 


\subsection{FUNCTION 1200 - PROVIDE STABILIZATION/ISOLATION}

As described in the Mission Statement this function has been implemented as part of the interim management activity until a decision is made on the actions for final closure. It is assumed a11 SST tanks will be pumped to a stabilized condition and isolated before final disposition of the tank begins. It is expected that interim management can be performed without any inputs from the other functions, except possibly the characterization function. However, other first-level functions may be dependent on how well this function is performed, in particular the amount of liquid remaining in the tanks after pumping. For subsequent retrieval, pretreatment or conversion to a suitable waste form, conditioning of the tank waste to reduce the remaining free liquids to a lower level may be a necessary action for this function.

\subsection{FUNCTION 1300 - PROVIDE REGULATORY DOCUMENTS}

The outcome of this action is to obtain the necessary pernits and approvals prior to final disposition. Because the regulatory path is complex and unpredictable, it is appropriate to view this step as a primary firstlevel function. This enables the system analysis to evaluate judgments from the regulatory viewpoint on an equal basis with engineering and operational viewpoints, thereby creating an opportunity for safe but lower cost remediation options. The perspective of regulators is essential in the system analysis, since their actions enable many of the other functions to be performed within the interpretation of the regutations. A11 performance assessments needed for preparing documents to satisfy the "permitting" process are subfunctions of this function.

\subsection{FUNCTION 1400 - RETRIEVE SYSTEM COMPONENTS}

Even if in situ entombment is selected, it is necessary to remove, disengage or modify some components in the SST system. This "opening" of the system presents special challenges and represents a unique set of actions that may influence the overall performance of the final disposition such as increasing the risk of short-term health and safety effects for the performers. Retrieval is a field action that must reflect productivity as well as 
operational safety concerns. Containment during operations, transport from the field to a processing facility, storage of in-process waste, and the repeated dismantling and reassembly of the retrieval system are some of the activities involved with this function.

\subsection{FUNCTION 1500 - PERFORM PRETREATMENT OF SYSTEM COMPONENTS}

This function includes all treatments that generate one or more waste streams when applied to the system components, in situ or after retrieval. There is a multiplicity of processes involved, including conditioning of the sludge, salt cake and possibly contaminated soil before chemical processing; partitioning the feed streams for selective control of the disposal paths for various constituents; chemical extraction; and conditioning of the output feedstreams before consolidation in the appropriate engineered enclosure. For retrieved components, the pretreatment may involve a centrally located facility to service all the SSTs. For in situ treatments, field processes would be necessary. An example of an in situ treatment would be conversion of the nitrate species to elemental nitrogen, thereby reducing its toxicity. An example of treatment of the retrieved waste would be to partition the more abundant sodium, aluminum, phosphorous and silicon compounds to the LLW-type engineered enclosure and the less abundant but toxic elements such as chromium, Sr-90, Cs-137 and the transuranics to a HLW-type engineered encTosure.

\subsection{FUNCTION 1600 - PREPARE FINAL WASTE PACKAGE}

A1] hazardous system components must be packaged within an engineered enclosure appropriate for their disposal path. Several disposal paths are possible according to the classification of the waste form. This function receives the waste after conditioning by stabilization, retrieval or pretreatment and converts it to a waste form. Pretreatment may enable a change in classification to reduce the hazard potential and/or reduce the cost of disposal. Preparation of the waste form includes consolidation, sequestering in an isolation media such as glass or grout, or possibly as recycled waste for reuse. Containment of the waste form by one or more engineered enclosures is also part of this function. For HLW or other types of waste forms to be 
shipped offsite, this function provides only that portion of the enclosure required to be performed onsite prior to shipment. For LLW waste forms and for in-place waste forms to be buried onsite, this function performs all the enclosures needed to ensure containment after burial. An example of an inplace waste packaging would be 1) preparation of a waste form by dome-filling and then, if necessary, subsequent sequestering by in situ vitrification or in situ grouting and 2) preparation of an engineered enclosure to provide the appropriate containment. The waste packaging term is used here as a broad description of the functional action and not as a specific design description for a particular class of regulations.

\subsection{FUNCTION 1700 - PROVIDE LONG-TERM ISOLATION}

This function is limited to onsite disposal paths only, of which there are three types:

1. In situ isolation using the existing SST system where this function must provide its own qualification and controls for management of the environmental protection system.

2. Isolation of wastes in grout using an onsite facility where the function must provide its own qualification and controls.

3. Other isolation paths using existing or planned burial grounds serving other disposal sources as well where there is no functional responsibility for management and control.

This function includes providing isolation barriers, markers, and monitoring of the site after final disposition is completed. The term "isolation barrier" is aimed primarily at preventing intrusion of water and other ecological phenomena from destroying control of containment and dispersal rates of the waste packaging system developed under Function 1600. Onsite isolation includes selection and preparation of the sites for waste package receipts, off-loading, and emplacement. Offsite isolation functions managed outside the SST system are included in Functions 1500 or 1600 as a cost of service and are not included in this function.

In summary, these seven first-level functions each represent a particular viewpoint for input to the SST system analysis. Each segment is dependent on the other functions in regards to inputs/outputs, to shared requirements, and 
to the methods used by each segment. The primary purpose of the first-level functional segmentation is to evaluate these interdependencies at the system level before further segmentation to lower levels of functional actions.

Appendix A provides a provisiona1 list of second- and third-level functions for each of the first-level functions. In a few cases, a fourth level was added. This breakdown conveys a perceived set of actions that would successfully complete the parent function. Later, when requirements may need to be allocated, this breakdown of the second and lower levels may be reconsidered and updated.

In genera1, most second-level functions are segmented by components of the SST system and then the third level reveals a set of sequential actions to be performed on each component. The system components are tank waste, tank shell, ancillary equipment, and contaminated soil. Summary highlights of the functional breakdown are as follows:

- 1100 - Characterization is segmented by system components and the third level is segmented by a sequence of steps to gather and evaluate integrity of the components or to obtain and evaluate compositions of components. Evaluation of the compositions is aimed at providing source term data used by other functions.

- 1200 - Stabilization/Isolation is a series of sequential actions followed by a surveillance action and defines the second-level functions. Third-level actions are also sequential. The stabilization segment, however, has two facets, depending on the use of a jet pump or non-jet pump capability.

- 1300 - Preparing Requlatory Documents is segmented at the second level by the responsive actions to satisfying three major statutes: NEPA, RCRA, and CERCLA. In addition, there are actions needed to respond to severa1 auxiliary documents. A11 these documents require performance assessments that are also included at the second level. Each second-level function is segmented to a sequence of actions appropriate for each document.

- 1400 - Retrieval is segmented by system component and each component is segmented at the third level by a sequential set of actions. 
- 1500 - Pretreatment has to consider two environments for processing: inplace or at a processing facility. Each of these segments has the same set of sequential actions. These sequences are very general since the specific methods for the many chemica 7 constituents are varied and complex.

- 1600 - Providing the Final Waste Package involves a sequence of actions assembling the waste package from its components: waste form, container, mass transport barriers, etc. Each of these sequential steps in turn involves a more detailed set of sequences at the third level.

- 1700 - Providing Long-Term Isolation involves three steps: prepare the site, provide an intrusion barrier, and monitoring. Each of these second-level actions has further controlling or monitoring actions to satisfy several constraints for long-term isolation. 


\subsection{FUNCTIONAL INTERFACES}

This section provides an overview of the functional interfaces of the single-shell tank (SST) system at Hanford. These interfaces show the degree of interdependence between the functions and indicate the information needs to complete the overall task. To conduct the interface analysis, advocates for each of the functions defined in the previous section identified key materials and data needed from each other's functions. Flow diagrams were then used to illustrate the linkage patterns, and specific data requests were bundled into an arrow representing a summary statement of the kind of information needed. The specific details were used to generate a 1 ist of attributes as candidate requirements described in the next section.

The principal waste flow streams between the functions are shown in Figure 7.1. All waste streams are input to a function from the left, transformed by the function, and output to the right. As shown in the figure, AND/OR branching is extensive due to the many options being considered in this system analysis. The tank system comprised of its components is the initial input which branches to the Characterization function and Stabilization/ Isolation function. The Characterization function extracts waste samples to obtain information and outputs a sample waste stream to an entity outside the system. The Stabilization/Isolation function transforms the tank system to an interim state. The tank system is output that may be directed to one of three OR branches: Retrieval, Pretreatment, or Prepare Waste Package. This branching is not exclusive as all components and tanks in the system may not each follow the same path. For example, one of the "leave" options is the branch going directly from the Provide Stabilization function to the Prepare Waste Package function. The Prepare Waste Package function transforms the components of the waste received from one of the three sources and distributes the segregated waste to offsite disposal (i.e., HLW, LLW, WIPP) and to onsite facilities such as grout vaults or in-place burial. The onsite waste packages are assigned to the control of the Long-Term Isolation function everafter.

The function, Prepare Regulatory Documents, has no material flow interfaces to and from the other function. Its actions are informational. 
The information flows between the functions are shown in Figures $7.2 \mathrm{a}$ through 7.2g. A diagram is shown for interfaces involving each one of the seven functions separately. Information inputs from the left on the figures represent data needed by the function to complete its set of actions. Information outputs to the right are used by other functions. In the figures, there are two kinds of 1 inkages. Outputs may be linked to another function's input like the material stream. The other kind of linkage is information which is a control on another function's actions, shown by arrows entering from the top of the box. The control is a gate or regulator of the transformation of material or information. In a process system, the controls relate to procedures affecting safety, quality, productivity, etc. One of the functions providing many controls on all other functions is Prepare Regulatory Documents. Based on regulatory requirements, the specifications for design and development are passed to each function. During the development phase, the performance assessments provide for further refinement of the specifications. During the implementation phase, the conditions allowed in the license or permit become outputs to control other functions' actions in the form of procedures. Acceptance criteria is another output/control feedback linkage, particularly when the functional flow is sequential as in the functions: Retrieve, Pretreatment, and Waste Package Preparation.

The illustrations provide a basis for defining what information is needed and how well the information and materials should be detailed to satisfy the needs of all the functions. This foundation is provided to carry out the next step, developing system requirements that are meaningful to the lower-level functions in the functional flow network. When the same information is desired by several functions, its importance can be determined by a ranking that is described in the next Section 9.0. 


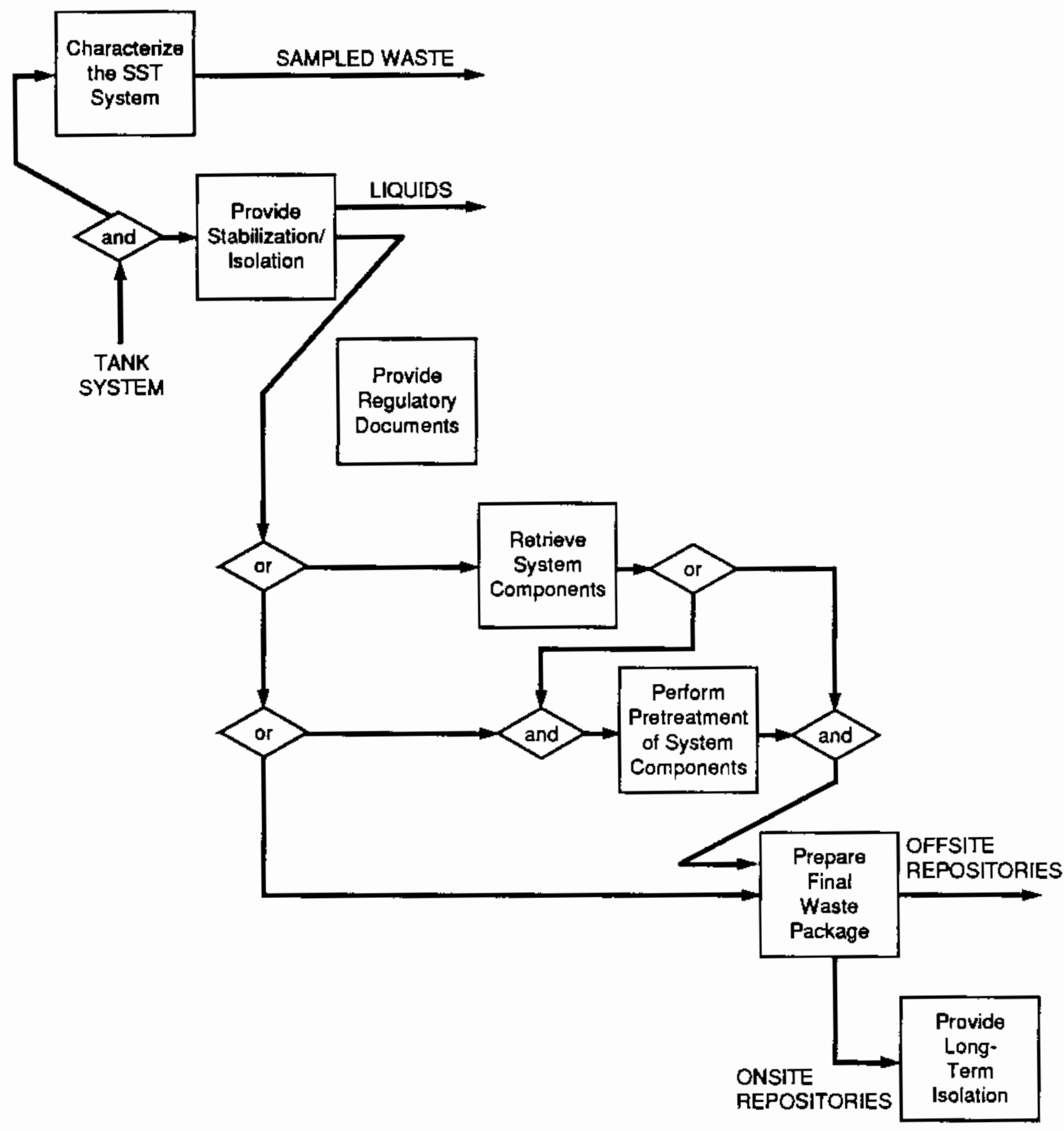

FIGURE 7.1. SST Functional Interfaces Material Flow (During Implementation) 


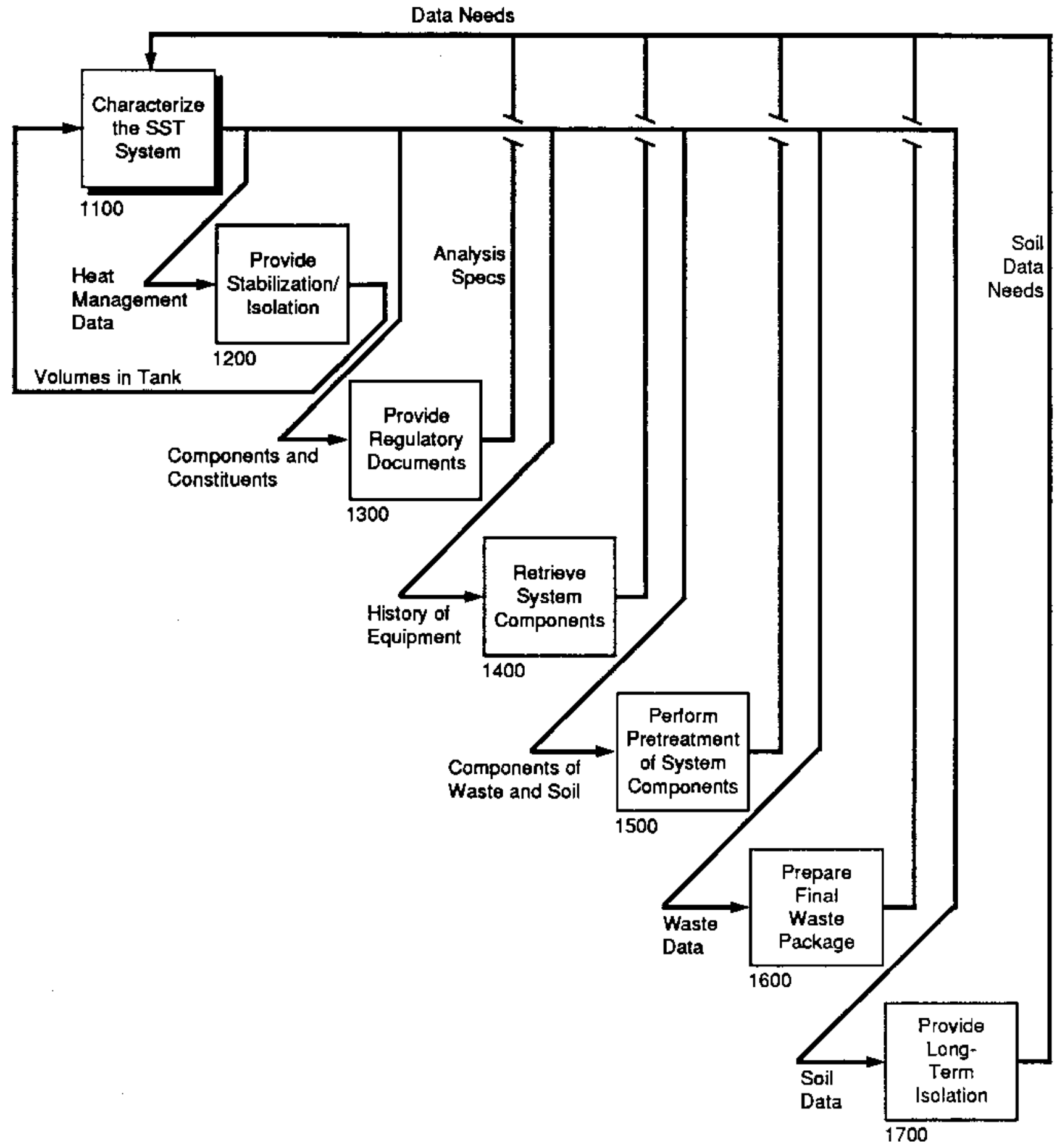

FIGURE 7.2a. SST Functional Interfaces Information Flow To/From 1100 


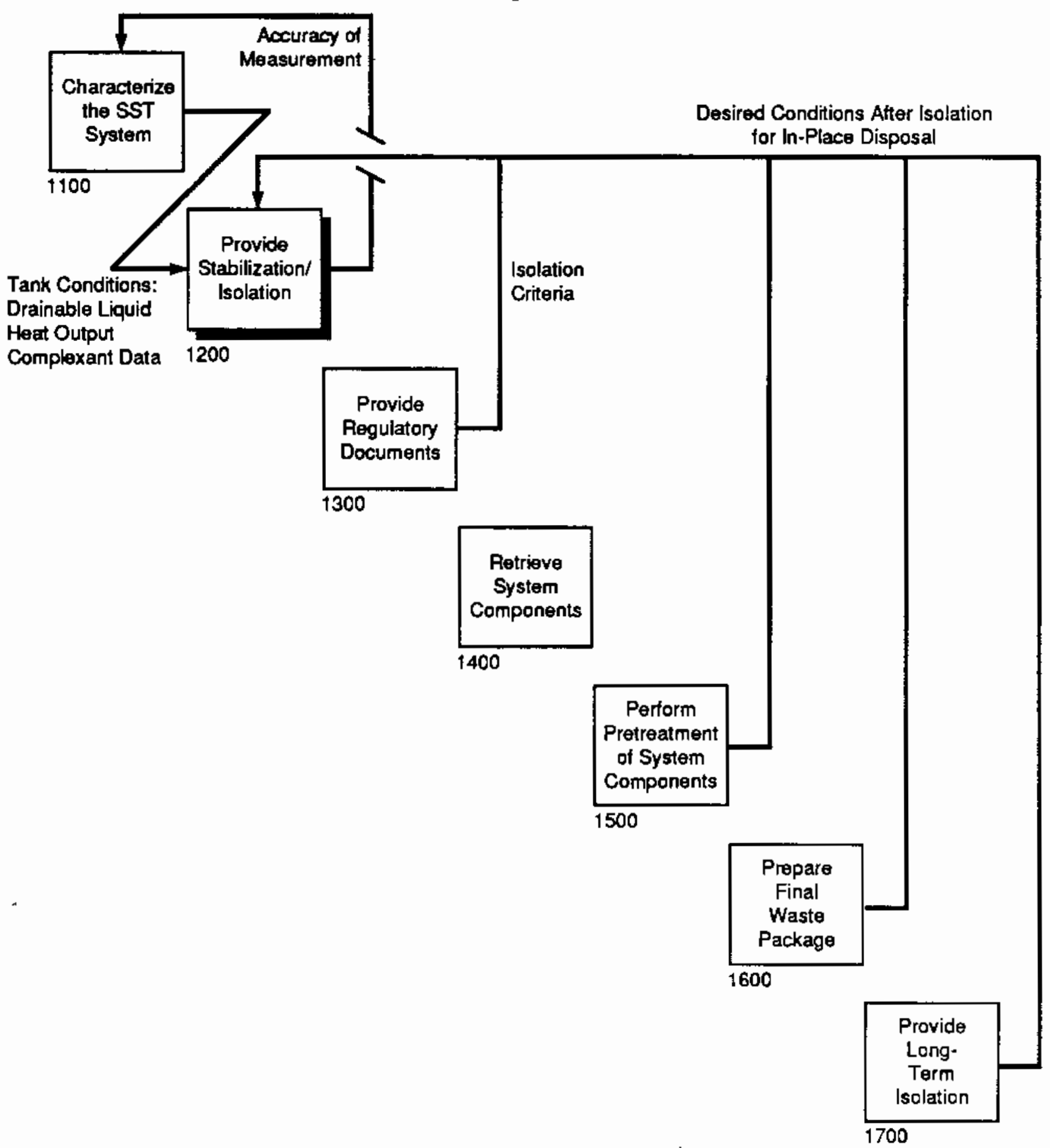

FIGURE 7.2b. SST Functional Interfaces Information Flow To/From 1200 


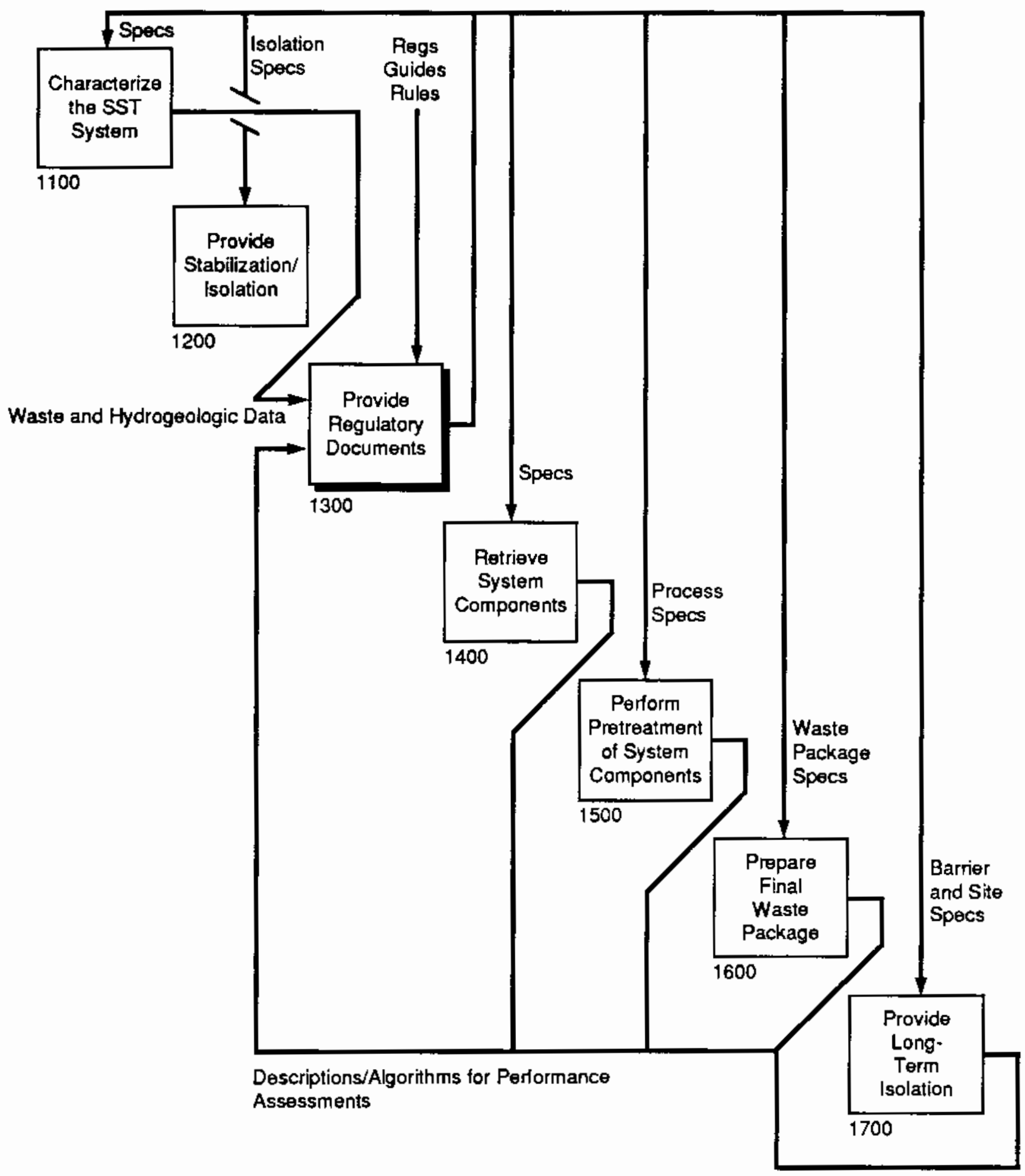

FIGURE 7.2c. SST Functional Interfaces Information Flow To/From 1300 


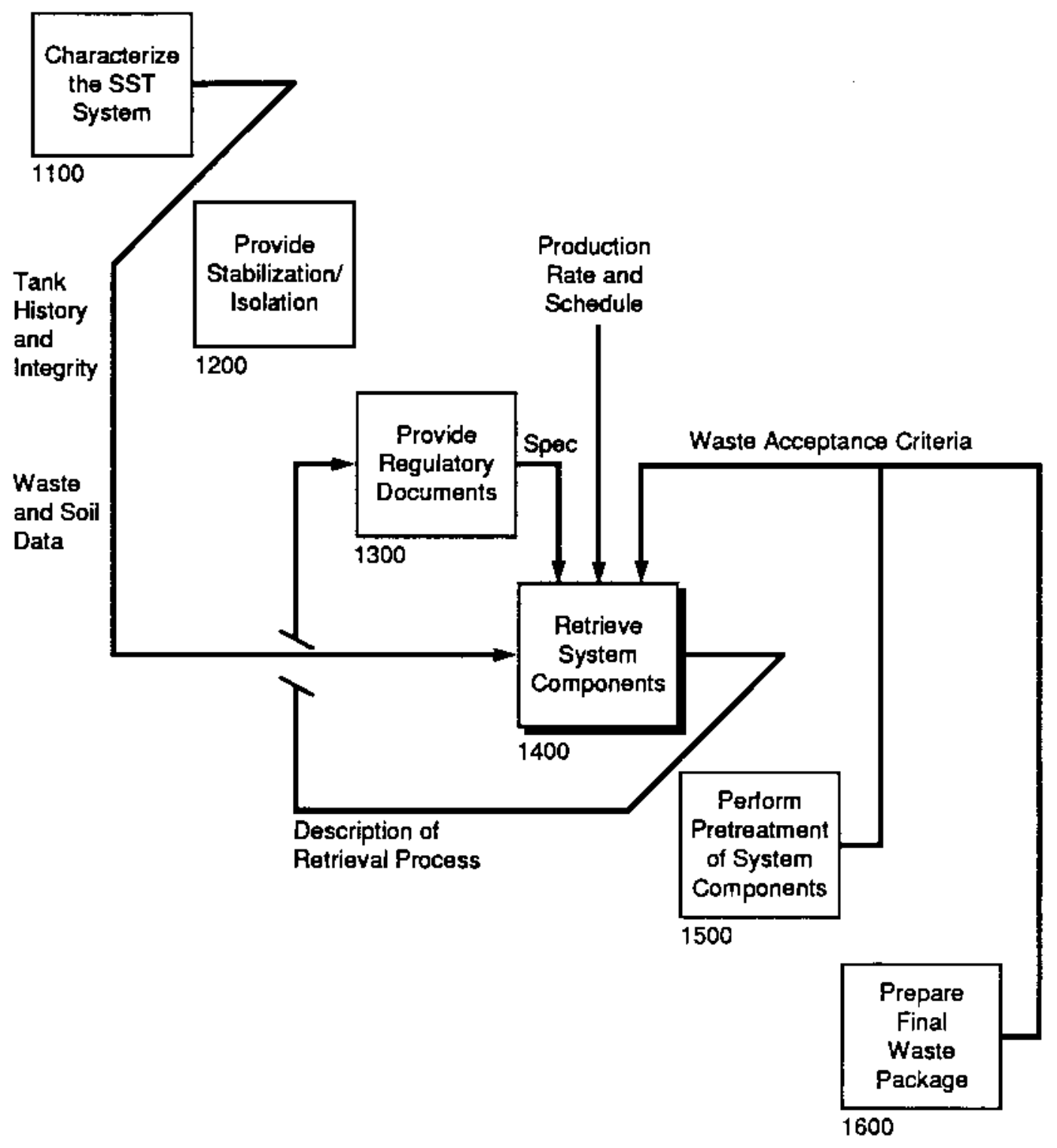

\section{Provide Long- \\ Term Isolation}

FIGURE 7.2d. SST Functional Interfaces Information Flow To/From 1400 


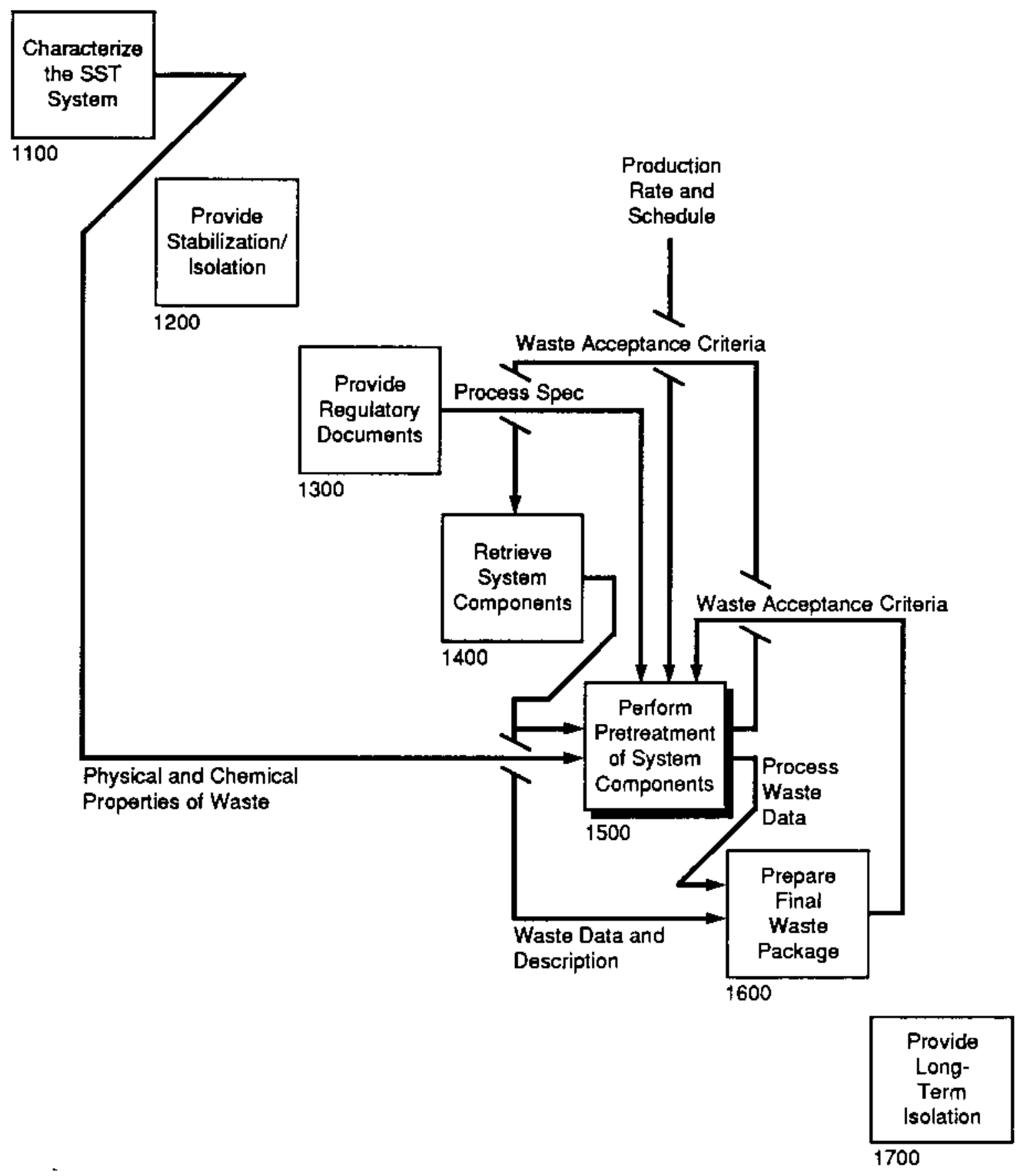

FIGURE 7.2e. SST Functional Interfaces Information Flow To/From 1500 


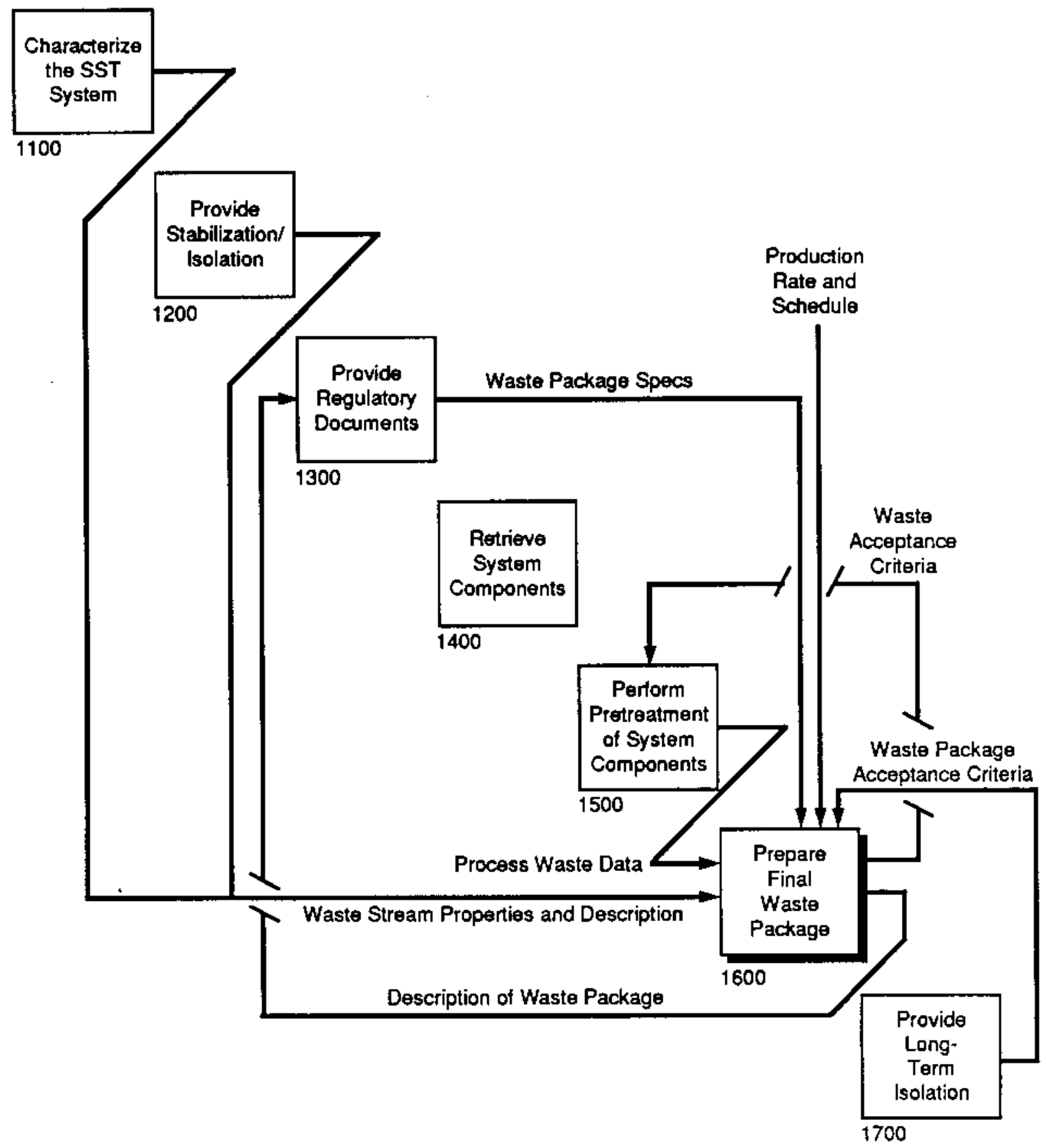

FIGURE 7.2f. SST Functional Interfaces Information Flow To/From 1600 


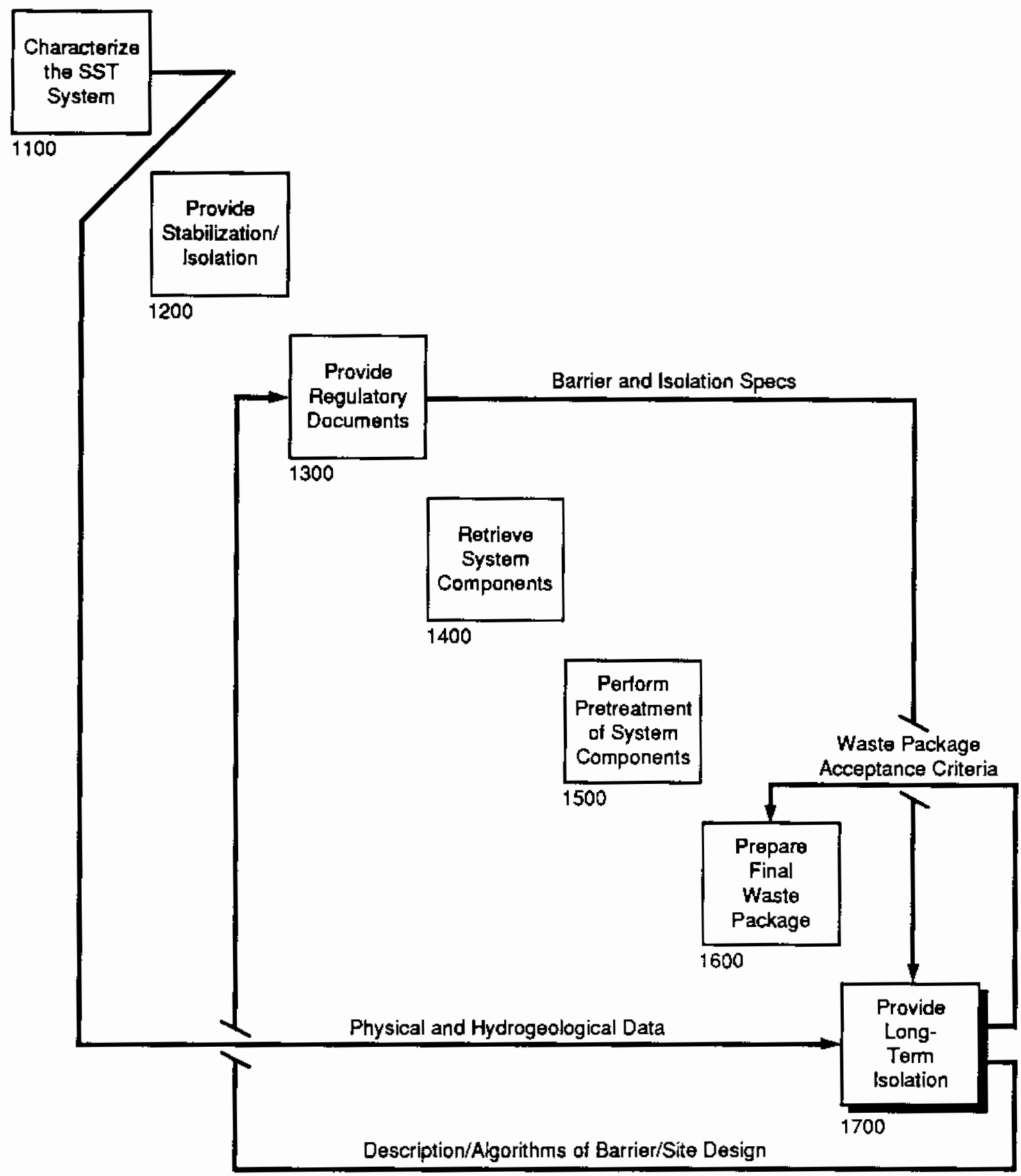

FIGURE 7.2g. SST Functional Interfaces Information F1ow To/From 1700 


\subsection{HIERARCHICAL SOURCE ANALYSIS}

Waste disposal decisions regarding the single-shell tank (SST) waste at Hanford must be made by taking into consideration the regulatory requirements that may impose constraints on implementation of the final disposition of the waste. At present, waste disposal regulations specific to radioactive mixed wastes have not been promulgated. In the absence of such specific guidance, the wastes may come under the purview of a wide range of statutes and regulations related to radioactive waste disposal, hazardous waste disposal, and water and air protection--collectively referred to in this analysis as the "hierarchy" or "hierarchical chain" of regulatory requirements. A comprehensive review of the environmental pollution control and radiation protection statutes and regulations that are relevant to Hanford SST waste characterization and management was completed by PNL (Keller et al. 1989) for DOE. The review identifies the performance, design, and permit requirements and criteria that should be considered in 1) evaluating SST waste disposal options and 2) designing an efficient waste characterization scheme that provides the information necessary to make this evaluation.

The system analysis performed herein used Keller et al. (1989) as the starting point for developing candidate requirements from these hierarchical sources. Specific statements that identified a significant control or concern about actions taken in the SST disposition were extracted from all sources reviewed. Each extracted statement was assigned to one or more of 14 categories, as shown in Table B.l of Appendix B. Each category represented a specialized activity used by the functions for disposing of the SST waste. About 120 statements were extracted and assigned to the following categories:

- CO Constraints from the hierarchical source

- AIR Atmospheric release

- CA Corrective actions

- DC Design and construction

- ES Employee safety and health

- H20 Water release 
- L Landfill

- MA Maintenance and surveillance

- MC Monitoring and Characterization

- OP Operations

- PS Public safety and health

- RE Reporting

- RAC Remedial actions after closure

- RBC Remedial actions before closure

These categories enabled a cross-comparison of the statements generated from the many statutes and regulations issued. In some cases, the extracted statements were identical from several sources. However, they were mostly statements of performance objectives and intents rather than specific requirement values capable of measurement. Nevertheless, the exercise revealed the complexity of satisfying all regulating bodies. Those statements that prohibited certain actions or contained measureable performance requirements were categorized as constraints and were treated as unaiterable during the system analysis. The constraints were incorporated into the attribute list generated in Section 9.0, "Requirements Analysis." The remaining statements were used in the system analysis by the functional advocates as "guiding statements" in developing attributes that would satisfy their intent. After completion of the attribute list, each attribute was assigned to one or more of the 14 categories described above. The attributes that are applicable to the regulatory statements can be examined through these 14 categories. This approach allows the statements that are presented in legal documents to be transformed to measurable requirements that can be acted on by technically performing groups.

\subsection{CONSTRAINTS}

The primary constraint applicable to the Hanford SST system is the stipulation in 40 CFR 264.314 and WAC 173-303-665(9) that placement of bulk liquids in landfills is prohibited. For all future actions for SST disposition, only limited amounts of bulk liquids are to be added to the existing tanks. 
The primary source of liquids would come from decontamination of retrieved components or from process water used in retrieving and in pretreatment of waste to selectively remove certain constituents. In addition, there will be some interstitial liquid remaining, because the interim stabilization efforts stop when pumping rates reach $0.05 \mathrm{gal} / \mathrm{min}$. Also, it may be necessary to leave some moisture in the tank waste in order to maintain stability with respect to the tanks containing ferrocyanide (FeCN). Inasmuch as some residual liquid in the single-shell tanks exists already, it remains to be determined under the intent of the statutes if it is a bulk 1iquid. This aspect of the regulation cannot be treated as a constraint since 1 iquid is already in the tank. Therefore, the system analysis must examine the levels of stringency that might be representative of the "no bulk liquid" stipulation. Three possible technical interpretations are:

- No "bulk liquid" is present when it cannot be pumped at a flow rate $>.05 \mathrm{gal} / \mathrm{min}$. (present practice for tank stabilization)

- No "bulk liquid" is present when the analyses of a set of samples is below 10 vol\% of the residual solids. (i.e., below slurry flow condition)

- No "bulk liquid" is present when the sample releases less than 1 vol\% of the solid as water vapor upon heating from $70^{\circ} \mathrm{F}$ to $300^{\circ} \mathrm{F}$. (partial dehydration).

A second primary constraint is the allowed contaminants in discharges to sources of drinking water that have been defined consistently by several regulatory agencies. The maximum concentration leve1s (MCLS) defined in WAC173-303-645 were used as constraints for the system analysis. The list of chemical species was incorporated in the attribute list generated in Section 9.0.

Additional constraints from the governing statutes have been incorporated in the attribute list and designated as such in Section 9.0. Additional constraints have been included to cover acceptance criteria such as for HLW repositories receiving glass containers. These constraints are passed indirectly to the SST system to satisfy licensing requirements for the $\mathrm{HLW}$ repository. 


\subsection{MEASURABLE PERFORMANCE REQUIREMENTS}

The statutes and DOE orders list several requirements that can be measured. These are:

- Exposure to public (at the site boundary) shatl not exceed $25 \mathrm{mrem} / \mathrm{yr}$ to the whole body and no more than $75 \mathrm{mrem} / \mathrm{yr}$ to any organ from atmospheric release.

- High-grade Class II groundwater consumed by an individual cannot result in an increase of $4 \mathrm{mrem} / \mathrm{yr}$ on a 2 liter/day consumption rate.

- Exposure to radiation by SST personne1 shall be maintained within 10 CFR 20 and EPA limits through final disposition and closure.

- Any single waste package for final disposition as LLW or MW shall have a TRU content $<100$ nanocuries/gm.

- The criticality state of all credible water-moderated process environments shall be below a $k$ (eff) of 0.95 .

These measurable requirements have we 17 -established precedence and are applied routinely and should be assigned as constraints. However, the principle of ALARA has been incorporated in these statutes and orders and this requires that operations be conducted such that a lowering of the total dose to a work force must be constantly applied. As a result, the system analysis must view measurable dosage requirements for personnel as a maximum allowed (constraint), but the real requirement influencing the choice of alternatives for performing the final dispostion should be a target reduction value to be determined by the system analysis. Retrieval and pretreatment of waste material has an increased exposure potential and must be monitored in ALARA terms throughout the task of disposing of 149 single-shell tanks.

\subsection{DESIGN, QUALIFICATION AND TEST REOUIREMENTS}

There are several categories where the statutes emphasize design, qualification, and test requirements. Characterization, monitoring, surveillance, and analytical procedures are listed without specific rules or measurable targets. The system analysis of the Hanford SST system develops many attributes that respond to the intent of the statutes and are measurable. 
Specific design requirements are: no ignitable, reactive, and incompatible wastes be used in land burial. The guidance is to reduce the waste volume through processes such as destruction, separation, etc., as much as possible.

There are reporting requirements for unplanned releases and for recovery plans for remedial action. The system analysis develops specific sets of measurable attributes that are responsive to this class of requirements.

\subsection{PERFORMANCE CRITERIA}

Most of the statements in the statutes contain criteria for performance and areas to be considered rather than specific requirements. The goals of maximizing safety to the public and maintaining a quality of performance preserving the environment are dominant themes in the statutes. The challenge is to translate these goals into measurable requirements that define successful outcomes for the SST disposition. The system analysis provides a backfill of requirements that can satisfy the goals stated in the statutes. This aspect is developed in the Requirements Analys is section.

\subsection{DECISION CRITERIA FOR SELECTION OF ALTERNATIVES}

Many of the statutes regulating the disposition of the Hanford SST system acknowledge that performance goals and cost benefits should be considered in selecting various alternatives. For the SST system analysis there are alternative requirements and alternative methods. A requirement may be assigned different levels of stringency depending on what is reasonable when all hierarchical interests are considered. Unfortunately, the mechanism for establishing a quantitative set of criteria for deciding on the alternatives is undefined. Inspection of the statutes and DOE orders shows four general performance goals applicable to the SST system: safety, quality, productivity, and cost. There is a need to maximize the first three elements and minimize the fourth. A given alternative probably will not satisfy all four goals simultaneously; therefore, a weighting must be established.

Examination of the regulations reveals concerns about the ability to complete an intended action at a margin of safety declared adequate at the outset 
of the SST disposition. In addition, quality of the activity is highlighted by the need to report and verify that an intended action was carried out. Safety and quality should probably receive a preferred weighting in selecting a]ternatives over productivity and cost. Cost is the only one of the four which can be scaled easity for quantitative evaluation of alternatives. The SST system analysis considered preliminary evaluations using these four decision criteria elements, but the activity was deferred until there was further dialogue with the Tri-party agencies.

Decision criteria based on validated computational models may be considered also for quantitative evaluation of alternatives. Four models have been proposed to cover the hierarchical interests and are recommended for further development in this report. These models are discussed in turn below.

To meet the primary concerns for public safety and health risks, a quantitative model to calculate long-term health and safety risks for the surrounding population after closure is recommended. This type of modeling evaluates the potential hazard for contaminating the ecological systems. Some elements of this activity are under way now at the Hanford Site.

A second primary concern is the short-term health and safety risks during the final disposition. This involves models that calculate risk assessments of potential exposures to personne] performing the task as well as the public as a result of performing alternative methods.

Because of the TPA milestone to complete the final disposition (closure) by the year 2018, a third calculational mode1 is recommended that evaluates the impact of various alternative requirements and methods on the Time-ToComplete the final disposition.

Similarly, because the funds must be supplied through one of the TPA agencies, a fourth modeT that evaluates the impact of alternatives on the Cost-to-Complete the final disposition is recommended.

Taken together, these models can provide the basis for making quantitative decisions on the alternatives. 


\subsection{REQUIREMENTS ANALYSIS}

This section initiates the development of system-level requirements by identifying attributes that describe how well the single-shell tank (SST) closure function at Hanford should be performed.

The section is organized as follows: Section 9.1 describes the creation of 541 attributes and groups them into six main categories. Section 9.2 shows how the attributes are linked to the statements extracted from the applicable statutes discussed in Section 8.0. In Section 9.3, a format for evaluating the attributes is described. In Section 9.4, the attributes are ranked by each of the first-level functions as a measure of importance to the function. The basis for selecting a level of stringency for each attribute has been deferred until the criteria for the selection are established.

\subsection{IDENTIFICATION OF ATTRIBUTES}

A requirement, to be useful, must be definable as a measurable attribute. Therefore, identifying the attributes is the first step in establishing SST system requirements. Each attribute must have a defined unit of measure or scale on which to assign a level of performance. The second step is to assign a value somewhere on the scale for each attribute. The location of a value on the scale may be fixed by constraints from the statutes or there may be several choices based on a desired level of stringency. Before assigning values, the purpose of this section is to collect all the attributes considered appropriate from the analysis of statutes and orders (Section 8.0) and from the advocates representing each of the first-level functions described in Sections 6.0 and 7.0. In Section 7.0, the interfaces between the first-level functions identified the types of data and information needed by each function from each other. These needs are also a principal source for defining the appropriate attributes.

This approach identified 541 attributes as being potentially significant to the successful performance of one or more of the first-level functions and may be considered as candidates for inclusion as system requirements for the overall SST closure function. Each advocate drew upon other disciplines 
involved in completion of his function as additional sources for identifying appropriate attributes. Sources performing analytical chemistry, developing performance assessment models, conducting chemical processing operations at the Hanford Site, and performing design and testing studies provided key information. The attribute list is shown in the second column of Table C.l of Appendix C. Each attribute has been assigned a number for reference purposes and this number is shown in the first column. The 1 ist was organized such that the attributes could be grouped under six major headings with subgroupings as appropriate. The corresponding units of measure for each attribute are shown in the third column of Table C.I. Values will be assigned later after the criteria for selecting the appropriate level of stringency are established. The six categories are discussed below. The applicable attribute numbers in each of the categories are identified in the parenthes is in the subheading.

\subsubsection{Chemical Attributes (1 to 110)}

The SST waste contains many constituents accumulated from a variety of processes and support functions used before 1970 at Hanford in the reprocessing of fue 1 . New regulations require characterization of the waste before initiating an implementation program. This category collects all properties related to the quality of chemical measurements, such as detection, accuracy, and sampling. Chemical properties defining the concentration limits or thresholds for performance of waste enclosures or waste processing streams have been placed in other categories.

The chemical attributes category inciudes the detection level required for all the perceived constituents in the SST waste. These detection levels have been subdivided further into radioisotopes compounds and/or ionic species. The method of detection depends on these two subdivisions and also on the degree of interference by one constituent upon another. Samples submitted for detection will include core drillings as part of the SST waste characterization function, control of pretreatment waste streams, qualification (leaching tests) of waste forms prior to $p$ lacement in engineered enciosures, and surveillance of SST groundwater monitoring wells. There are about 
80 elements and radionuclides of interest to the SST system. This list of species subject to characterization and surveillance arises from the need to demonstrate that all possible constituents are known based on confirmatory evidence or past records. Many of the non-radioactive constituents appear as a result of fuel reprocessing chemistry; however, other constituents were included as laboratory discards and are only a very minor constituent. Because of the inhomogeneous nature of the tank waste, identifying minor constituents will be a major challenge. The organic content of the tank waste should be very low since most of the sensitive hazardous contaminants like organic chlorides and hydrocarbons would have evaporated before discharge as waste. The principal organic species are the complexants that are water soluble. The complexants have not been listed individually but are considered as a group: "Total Organic Carbon" (TOC). The general groundrule adopted for the system analysis is that if TOC exceeds a certain stringency level, then an organic compound identification (TOC Identification) attribute would be triggered with its own stringency level for qualitative detection of the TOC species to the specified percentage.

The radioactive species listed may be divided into two parts:

1. Species that are dominant due to their abundance as fission products and their short-term activity content. A high level of stringency for these species may require special treatment to satisfy low-level waste burial criteria. A low level of stringency may require higher certainty in the performance assessment if the engineered barriers were to become ineffective prematurely.

2. Species that are less abundant but longer-lived. These species can be expected to be the radioactive source after engineered barriers have exceeded their design life. Characterizing these isotopes in a background of higher activity is a major challenge.

The desired detection level depends on the source of the samples and the combination of chemical and radionuclides in the sample. Samples from groundwater monitoring wells will require the most stringent level of detection and as a minimum must satisfy the maximum concentration levels (MCLs) listed in the Washington State Water Quality Standards cited in Section 8.0 (see also attributes 380-396 in Table C.1). Since groundwater samples are expected to be relatively abundant, detection levels can be made very sensitive by 
evaporation to concentrate the samples sufficiently to achieve the appropriate level of chemical mass or radionuclide activity to register on the appropriate instruments with confidence. On the other hand, samples containing high concentrations of ionic species or radionuclides can mask other species such that extraction and/or concentration is necessary before detection by an instrument. As a general rule, if any of the constituents exceed 1000 ppm (parts per million), it is difficult to detect any other constituent much below the $1000 \mathrm{ppm}$ level. Conversely, if pristine water is analyzed, subppm detection levels of many elements are readily achieved. A similar situation occurs in the detection of radionuclides. A given counting instrument can detect very low levels of radioactive species ( -25 picocuries). However, the ability to detect specific isotopes depends on interference from more abundant species such as uranium and on difficult decay characteristics. Chemical separation to extract the species preferentially may be used; however, higher personnel exposures are often encountered as a result.

The accuracy of some of the chemical constituents of key subsystem components was included as part of the chemical attributes category. By choosing high levels of stringency, these attributes reduce uncertainties and in turn improve the quality of the performance assessments that use the data. Reducing the uncertainty, however, may tax the available resources to achieve this level of stringency, raising the probability that the task might not be successful. Attributes related to accuracy of the chemical measurements, listed under subcategory 1.2, were considered important for establishing the interface requirements between some of the functions.

Detection and accuracy attributes, however, may be of little system value if variances due to sampling are not controlled also. Samples to be characterized range from retrieved waste (moist s]udge and salt cake), pretreatment process streams, contaminated soil, and pristine groundwater. Because many waste components are highly inhomogeneous mixtures, sampling density and frequency are important attributes that may determine the uncertainty of the SST 
tank waste, leaks or spills. Each of these attributes have been further subdivided to delineate a particular stage in the waste processing sequence where a level of accuracy is needed.

\subsubsection{Physical Attributes (111 to 182)}

This category identifies the physical attributes of various components of the SST system. Subcategories of the physical attributes are spatial properties, physical properties, and decontamination factors. Every component requires physical definitions that determine its effectiveness to be handled, modified, or characterized in the overall system. Spatial properties define dimensions and shapes important for fitting components into standardized casks or for manipulation by machinery. Most of the dimensions relate to retrieved packages of disassembled SST components such as tank wastes, contaminated soils, the tanks themselves, and ancillary equipment. One level of stringency may use dimensions that are compatible with a large specialized container while another level may be based on a standard 55-gallon drum size. The range of spatial properties for SST retrieval packages should determine the performance and cost sensitivity between using casks common to other environmental restoration tasks at the Hanford Site versus specialized casks for the SST system only. Similarly, the sensitivity between casks common to all SST components versus special configurations for each SST component should be determined. The purpose of the spatial attributes listed here is to evaluate configuration options and handing strategies at the system level. Precise detailing of dimensions and tolerances would be done later at subfunction levels of the SST system.

There are three kinds of containers to be considered for disposal of retrieved SST waste: two of them are for offsite disposition, the other is for onsite disposition as a grout waste package. The attributes of the HLW glass waste container have been fixed by existing guides and regulations for compatibility with commercial HLW waste packages; therefore, the HLW container spatial dimensions are assigned as constraints, as noted by the letter " $C$ "

placed next to the attribute number in Table C.1 of Appendix C. Similarly, containerized TRU wastes for offsite disposal at WIPP have a set of spatial attributes, defined by DOE orders, which have been designated as constraints. 
Because there are two types of TRU wastes: contact-handled (CH) and remotehandled (RH), each type has a separate set of dimensions. For onsite disposal of the grout container (vault), there are no dimensional limits pertinent to the SST system analysis except the maximum free volume inside the grout container. The free volume may be an important performance consideration for the integrity of the grout disposal system.

Many physical properties of the SST system are required for characterization and performance assessments. Physical attributes that can not be controlled but require a precision on the measurement of the property of the tank waste are identified under category 2.2 of the attribute list. These precision attributes are important to know the margins for safely managing the heat and the flowability of the tank waste during the closure process. They apply to the retrieval option where the tank waste is moved by sluicing and pumping as a slurry.

In category 2.3, the physical properties of SST components that should be controlled during the closure function are Tisted. These properties include temperature limits and heat generation rates for HLW and grout waste forms. Properties for other engineered materials used in the disposal process to confine the waste are listed also. Strength, load compliance parameters, and temperatures are some of the design attributes for the waste containers, soils/clays, and concrete when used as a structure/barrier. Permeability is also an important attribute for design of non-metallic containment materiais such as soils and cements. The physical properties were included in the attribute list for the requirements analys is only if they could be preset and controlled within established 1 imits during design and operation of the SST closure function. Other properties may be measured and used as input data to performance assessments and process control decisions but they cannot be assigned a level of stringency for evaluation by a system analysis.

The final category of physical attributes is the contamination levels acceptable for completion of a task within a function. These acceptance levels determine release criteria to the next function. Higher stringency leveis will require greater attention and care in the design and procedures, particularly for retrieval tasks and would affect the productivity. Most 
attributes related to smears on packages should have stringency levels at or below DOT standards for shipment in the public domain.

The residues in the tank and in the ancillary equipment are key attributes for the system as all functions are impacted by the choice of stringency level. There is a large uncertainty how well the residues in the tank can be retrieved, and specialized development activities will be needed if the tank system is to be cleared of activity sufficient to dismantle the liner as some regulations would indicate.

\subsubsection{Engineered Enclosures (183 to 443)}

This category identifies the attributes for the broad class of engineered enclosures used during and after closure of the SST system. Six types of engineered enclosures have been identified. An engineered enclosure consists of one or more sets of diverse and redundant mechanisms for preventing spread of hazardous material at unsafe levels to the environment. In some cases the enclosure consists of a waste form to limit the rate of dispersal after a containment vessel has reached its design lifetime. The combination of a waste form and a containment vessel along with additional barriers (i.e., special soils) to sequester the hazardous constituents or slow the dispersal rates is defined here as a waste package. A waste package applies to disposition of any of the SST waste components, including in-place disposition. In addition to waste packages, additionat engineered enclosures necessary for the conduct of the SST closure function are enclosures to prevent intrusion of water to the vicinity of the waste package, enclosures to prevent dispersat when the waste is being processed (i.e., HWVP or B plant facilities) and enclosures to prevent dispersal when the waste is being transported.

For purposes of dividing almost half of the 541 attributes listed for defining how well these types of enclosures should perform, six subcategories are defined as follows.

1. Transport containers for retrieval of waste components and movement to a facility for processing.

2. Waste packages for burial of the HLW in glass at a commercial repository or in the Waste Isolation Pilot Plant (WIPP). 
3. Vaults for permanent placement of the grouted LLW waste form.

4. In-place waste packages for the single-shell tank.

5. Earthen barriers to prevent intrusion of surface water to any of the onsite buried waste packages.

6. Site facilities for retrieving, transporting, or processing waste.

Attributes for the transport containers (item 1) are grouped as cate-

gory 3.1 ; all waste packages (items $2,3,4$ ) are grouped as category 3.2 . The intrusion barrier and site facilities are grouped as categories 3.3 and 3.4 respectively. Each category may be subdivided further into a set of performance attributes and a set of design or process attributes. Performance attributes define how well the enclosures (waste form, waste package, intrusion barrier, etc.) must resist damage or degradation due to all external influences (i.e., physical, chemical, and environmental). Design and/or process attributes define how well input data for design and control during processing and packaging of the waste form must be stated to ensure that the performance attributes can be achieved.

The six subcategories for the engineered enclosure attributes are discussed below.

\section{Iransport Containers (183 to 184)}

Only two performance attributes were identified, relevant primarily to the retrieval function, since most of the physical attributes for the containers were described in Subsection 9.1.2 (category 2). It is often required to qualify a container by performing a drop test and evaluating its integrity afterwards. The level of stringency for its integrity may range from a simple retention of its containment function to a more complex rigidity specification. The second performance attribute defines the longevity of the container, which may range from a one-time-use to several thousand times similar to a cask.

Waste Packages - Glass, Grout, In-Place (185 to 369)

The performance attributes for the three types of waste package disposal units are 1 isted in category 3.2.I and include rifetime of containment, 
release rate after loss of containment, and a closure specification such as a leak test or equivalent. These attributes are intended to meet the performance goais listed by many of the applicable statutes described in Section 8.0. The design attributes for the waste package units are 1isted in category 3.2.2 and include the limiting feed stream concentrations of various ionic and radioactive species after pretreatment but before transformation to waste forms and waste packages. The feed streams concentrations are not expected to be specified by statutes, but the ability to meet the performance requires control of the waste concentrations as they are transformed to a waste form. There are many chemical species involved in the SST system; however, some species will have more relevance to meeting performance goals of the statutes than others. The attributes for these species will require a higher level of stringency.

The attributes defining the lifetime of the various types of enclosures to provide isolation and/or containment of the waste were obtained from performance goals in the applicable statutes. The minimum desired lifetimes range from 300 to 10,000 years depending on the regulation. HLW, LLW, Grouted Vaults and In-Place waste packages each require a containment design life.

Release Rates from Glass Waste Package. A second set of performance attributes is needed to define the allowed rates of release of a number of potential species from the HLW, Grouted Vault and the In-Place waste forms. The list of over 50 radioactive and potentially hazardous species was obtained from all closure subfunctions involved in meeting the performance goals. No attempt was made to limit the number of species of concern at this stage of the system analysis.

Explicit release rates specified as a mass dissolution rate (micrograms of the waste form $/ \mathrm{cm}^{2} /$ day) have been defined in regulations applicable to defense waste for burial in commercial $H L W$ repositories for glass compositions containing $\mathrm{Cs}, \mathrm{U}, \mathrm{Si}, \mathrm{B}$ and $\mathrm{Na}$. These constituents are expected to be dissolved in a molten mixture of solids from the pretreated waste stream slurry and from the sodium borosilicate frit used as a solvent. The release rates for these constituents were treated as constraints. A major SST constituent, sulfate, has been added to the list and further analysis has indicated that 
phosphate and chromium may need to be added as well since they may be present in high concentrations in the slurry waste stream and could affect the overall release rate. The mass fraction of the waste form due to solids in the feed stream has been included as an attribute also as part of the recipe established in regulations for an acceptable HLW glass waste form and has been included on the attribute list.

Release Rates from Grout Waste Package (Vaylt). The key performance attributes for the grouted waste form are the release rates represented by a leachability index per ANSI 16.1 for each species under evaluation. A large number of hazardous chemicals and radionuclides have been included in the attribute list to cover the range of concerns about both short- and long-term isolation. There have been no specific statements in the regulations about release rates from grout; however, these leachability attributes are necessary to satisfy performance goals and to test the validity of performance assessment mode1s. A detailed approach for using the leachability index for SST grouted waste has been developed as part of the SST program. The leachability indices may be selected from observations on selected constituents in the Hanford grouts, estimates of solubilities or mobilities in groundwater, and an NRC requirement that the leachability index should be $\geq 6$ for all radioactive species listed. The leachability index has the units of $\log$ of the effective diffusion coefficient specified in $\mathrm{cm}^{2} / \mathrm{sec}$. This term is determined experimentally using the formulations stated in ANSI 16.1 .

Some additional attributes for the grouted waste package have been included to cover possible degradation mechanisms that could increase mobility of hazardous material. These are the Total Organic Content (TOC), Residual free water content, Gel strength after 10-minute setting periods, critical flow rate, and ASTM test for withstanding 30 thermal cycles and biodegradation.

Release Rates from In-Place Waste Package. Performance attributes for the in-place tank waste package, in principle, should be based on criteria similar to that set for the grouted vault waste package. This waste form however cannot be pretreated and isolated as with glass or grout. There are few 
choices for selectively partitioning or recovering some of the waste constituents. The performance attributes for controlling the release rate from an In-Place waste package should include all the identifiable hazardous constituents in the SST system. The initial step for establishing performance for these constituents in this analysis was to specify minimum concentration levels (in units of $\mathrm{g} / \mathrm{m}^{3}$ or $\mathrm{ci} / \mathrm{m}^{3}$ ) below which the hazard is acceptable. The levels for acceptance could be based on the dispersal rate defined by appropriate methods for sequestering the SST waste in situ. Eventually, as the methods are qualified, the sequestered system could be evaluated as a waste package similar to the grouted waste package described previously.

Similar to the grouted waste package, the In-Place waste package should have performance attributes for the residual free water (volume \% water released up to $300^{\circ} \mathrm{F}$ heat) and for the TOC. An additional attribute for the In-Place waste package is the $\mathrm{pH}$ after pretreatment as this could influence the degradation of any sequestering mechanisms used.

Containment Attributes for Waste Packages. Most waste packages are expected to have some form of containment that prevents spread of hazardous material for a specified period. Attributes that define the closure property depend on the method used. For glass waste forms seaied in metal containers, an ANSI standard for a leak rate has been used as the attribute. For grout or In-Place waste packages, a sealed containment does not appear feasible and some other attribute is needed. But, as yet, the appropriate unit of measure has not been found and must be reconsidered later.

Process Attributes for Glass and Grout Waste Streams. To support the performance goals and attributes cited above, a set of design or process , attributes must be defined for the waste feed stream concentrations prior to conversion to the their respective waste forms. A set of attributes is listed for the grout feed stream and the glass feed stream. There is no feed stream for the in-place waste package. The feed stream concentrations are important interfaces between the pretreatment function (1500) and the waste package (1600) function. To meet the desired performance goals for some of the hazardous SST constituents, either the feed streams must be pretreated and adjusted to concentrations acceptable to conversion to the waste form or the 
waste form and/or enclosures must be upgraded and qualified to accommodate higher concentrations of certain SST hazardous constituents. Either approach is a challenge.

The acceptance level for concentrations of certain hazardous constituents in the grout feed stream and the glass feed stream highlights the opposing positions of the pretreatment and the waste package functions. Acceptance of a high concentration level would place the greatest burden on the waste package function to assure that the total waste package will be protective and may need additional engineered enclosures or modifications of the waste form to contain larger concentrations to meet the waste package release rates. Acceptance of a low concentration level would place the greatest burden on the pretreatment function to develop a qualified extraction or partition process to meet the desired performance without any alteration in the enclosure design. If no such process is feasible, then ditution, producing a larger number of waste packages, is the only alternative. Preliminary analysis indicates that the greatest variability in SST system cost is associated with this set of attributes. Careful analysis and evaluation of the levels of stringency should be carried out with a well-established set of criteria before making a selection.

The key constituents for $\mathrm{HLW}$ glass waste feed stream are listed under category 3.2.2.a. These attributes are specified as the weight percent of the constituent as a dry solid after removal of the aqueous portion of the slurry. This unit of measure is convenient for the formutation of the glass waste form which will be constrained by qualifying tests on glass samples prior to production in a glass melter. The constituents were selected based on their potential ability to influence glass degradation and dissolution rates after loss of containment. Most constituents must be maintained below a maximum weight percentage set by the qualification tests. However, $\mathrm{Fe}_{2} \mathrm{O}_{3}$ and $\mathrm{Na}_{2} \mathrm{O}$ should be maintained within a specified concentration band to provide control of the melting process. The particle size of the solids in the slurry must al so be controlled to ensure that the solids will be dissolved in the glass 
melter before pouring. The total organic carbon (TOC) also is included as an attribute due to its potential for generating carbonaceous off-gasses that may upset the melting process.

The SST waste may contain constituents in excess of concentrations evaluated for other defense wastes qualified for disposal as a glass waste form in commercial repositories and may require reformulation and requalification of a new glass waste form. High concentrations of phosphates, sodium, aluminum, and silicon may be present as a complex compound requiring a new formulation. Cyanide exists as a complex anion with iron but its characteristics in the glass melt should be similar to other carbon compounds and is included in the TOC determination. Other constituents listed may influence the melting process or the properties of the glass waste form.

Process attributes which define the feed stream concentrations for grouted waste forms are 1 isted under category 3.2.2.b. This waste stream has a large number of attributes since both hazardous chemical and radiochemical constituents are involved. The convenient units of measure are $\mathrm{g} / \mathrm{m}^{3}$ or $\mathrm{ci} / \mathrm{m}^{3}$. The cyanide is identified as the free ion concentration because of its potential high toxicity and mobility. In contrast to the glass waste form, TOC is identified separately from the cyanide because of differences in chemical behavior in grout. Some constituents listed for the grout waste stream may have no toxicity standards established as yet and may be dropped 1ater. High concentrations of the sodium and nitrate species could have a large effect on the stability of the grout system and also on the amount of grout needed. The $\mathrm{pH}$ and the volume percent of solids in the grout stream need to be specified also for control of the grout solidification process.

Additional design attributes were identified for the in-place tank waste package, which consists primarily of the as-found stabilized waste form, carbon steel liner, and a reinforced concrete enclosure. The liner and concrete enclosure would be subject to deformation if certain operations were carried out without controls. Attributes which ensure against damage are excessive hydrostatic loads, heat generation, and pressure differences relative to the 
ambient and are listed as constraints since the single-shell tanks already have specified as-built design conditions.

Intrusion Barriers (370 to 433 )

Another major enclosure is the barrier to prevent intrusion of surface water to the buried waste package. Several performance and design attributes, involving mainly soil and environmental parameters, have been identified (see category 3.3). In addition, attributes identifying data uncertainty levels for some key environmental parameters have been listed to provide reliability of the performance assessments needed.

The performance attributes identified for the barrier include lifetime, drainage rate, storage capacity of fine soil, fine content in the soil, permeability of the soil, and allowed subsidence and thickness changes from erosion/deposition. Washington State regulations for control of the state's water usage also list constraints for specific constituents (i.e., As, Cd, $\mathrm{Cr}$, $\mathrm{Pb}, \mathrm{Hg}$ and chlorinated hydrocarbons) in the groundwater and constraints on the monitoring frequencies of the groundwater or vadose zone. The maximum concentration levels (MCL) which have been designated in the regulation could be applied to the 5ST operable units (OUs) only or to all Hanford waste OUs collectively. In the latter case, the allowed MCL values may be partitioned among the oUs. The Washington State regulations also include a provision to add chemicals to the list for specific permits. Specific details cannot be determined as yet; however, it is anticipated that three attributes that define MCLs for the activity emanating from TRU elements and certain radionuclides and MCLs for the concentration of a justified chemical such as the nitrate ion will be included after the performance assessments are completed.

Twenty-one design attributes were identified for intrusion barriers . Several attributes define the physical characteristics of the composite of soils and markers that are part of the barrier design. Each of the attributes have units of measure that are appropriate for the design bas is calculations of performance. Attributes for animal intrusion, plant growth intensity, and rain and wind intensity have been included. 
Thirteen attributes were identified which specify uncertainty limits for key environment parameters for $\mathrm{climatology,} \mathrm{hazards} \mathrm{probability,} \mathrm{and} \mathrm{void} \mathrm{size}$ in the barrier that could influence the accuracy of the performance assessment of the barrier system. Many of these attributes have been discussed in prior planning documents for barrier development. The units of measure have been difficult to define for some of the attributes and after further analysis they may be deleted.

\section{Site Facility Enclosures (434 to 443 )}

Many site facilities are engineered enclosures which protect the public and employees from exposure to hazardous materials during processing of the SST waste. Typical examples are the structures and environmental control system for the HWVP or the mobile structure and control system surrounding retrieval operations at a SST OU. The principal performance attributes for this type of enclosure are to control gaseous oxides of nitrogen (NOX) and of sulfur (SOX) and particulate effluents released to the atmosphere. At present, emission constraints have been established with the local tri-county emissions control organization. Attributes for the amount and the form of the liquids discharged from the site facility may have very tight limits such that all liquid side-streams would be transformed to solid or gaseous substances before discharge.

There are a large number of attributes for design of facilities that are defined by standard building codes; however, for purposes of the system analysis, only five were considered appropriate for identification at this stage of the analysis. The design basis for seismic events should be specified for permanent and temporary structures used during SST closure. Facility operating life, post-closure life, and maximum wind speed for operating permanent or temporary facilities may need to be specified also.

\subsubsection{Operating Attributes (444 to 500 )}

This category identifies attributes important for the continuity of the flow of material between various processes involved in the SST system at Hanford. These attributes include system level process rates, personnel qualifications, and design standards and practices for operating systems. The 
attribute for overal1 processing rate of the SST system determines the capacities and availabilities of subfunctions for SST closure. The TPA (1989) has set the target for completion of ciosure for the year 2018. If a11 149 tanks were involved, the mean rate would be about 10 tanks per year after start of implementation. However, the system analysis must evaluate a range of processing rates to understand the cost/risk benefits of delays and interruptions in the closure process.

For the retrieval option, if the SST closure process sequence is to operate efficiently, then in-process storage may be required. Some statutes have performance objectives of minimizing this storage period. The range of inprocess storage times could be from 90 days to no limit. Statutes also have set objectives to minimize the amount of process water associated with recovery of waste. Three attributes have been identified to satisfy this objective, one for each of the three main processing functions involved in SST closure. Each function may independently set its own water utilization target based on a unit of measure in terms of a ratio of the liquid water in the output stream relative to the amount of water in the input stream.

In Section 9.1.3, attributes were identified for the maximum concentrations of various constituents in the grout and glass feed streams. If no pretreatment process was available to meet these iimits, then dilution of the feed streams would be the only option. In this category, a set of process design attributes is identified to determine how well a given constituent should be extracted when one or more pretreatment methods are available. There are three potential pretreatment situations: removal of constituents from the glass feed stream, removal of constituents from the grout feed stream, and removal of constituents in situ. The goal is to minimize the waste volume so that dilution becomes unnecessary. The unit of measure is the ratio of concentration of the output after treatment to the concentration of the input before treatment. A low stringency level would be a value of one, i.e., no reduction of the output relative to the input. A high level of stringency would be as low a fraction as is practical for large-scale processing systems. Species identified for control in the glass stream are: $\mathrm{Na}$, $\mathrm{Fe}, \mathrm{Al}, \mathrm{Si}$ and $U$ (and possibly $\mathrm{Bi}$ and Phosphate) to minimize the quantity of 
waste. ATso, total organic carbon (TOC), which includes the cyanide in the sludge, is controlled to prevent unfavorable reactions in the glass melter. Species identified for control in the grout stream are: TRU, Sr-90, TC-99 and Cs-137 to improve the quality of the grout vaults for burial of the low-level and hazardous waste.

Pretreatment of the waste in the tank was considered in the early stages of this system analysis. Stringency levels for meeting concentration limits for in-place tank waste packages require very large reduction of many key species, especially the TRU elements. These attributes would be an enormous challenge. Several potential processes were considered, such as in situ nitrate destruction, but all had shortcomings of potential uncontrolled reactions or required excessive heat applications in a system not designed for such. The species listed for in-place pretreatment, however, were retained on the attribute list for future reexamination, but there is little prospect for a feasible, safe, and efficient method for in-place pretreatment.

The final set of attributes in this category identifies personnel practices and public protection practices that enable an operating system to function in a safe manner. The degree of training is an important attribute in this regard also. Higher levels of training impact the efficiency of implementation and lead to higher qualification costs. Mockup testing of field operations is a feature that may be appropriate for qualification of equipment and personnel. Exposure limits for personnel are constrajnts set by statutes. However, under the principle of ALARA, it is appropriate to set stringency levels below those allowed for safe operation. Because of the hazardous nature of retrieving waste from buried tanks not designed for retrieval, the exposure potential is high. A high stringency Tevel could be a target percentage reduction of $10 \%$ in the overall exposure to the working teams for every thirty tanks processed. This would reduce the team exposure by onehalf between the first tank processed and the last tank if all 149 tanks were retrieved.

\subsubsection{Site-Selection Attributes (501 to 525)}

As part of the SST closure function, sites for grout burial must be established. The performance measures and design attributes for defining how 
well this activity may be carried out are 1isted in this category. Many of these attributes apply to qualifying the in-place burial of tank waste as wel1. Several design attributes are constraints from existing statutes. Accuracies for key data important to the performance assessment associated with the site selection have been listed in this category as well. Three principal attributes are the accuracies of measurements for the groundwater depth, the groundwater or vadose travel time, and the groundwater mass flow.

\subsubsection{Records and Reporting Attributes (526 to 541)}

Inspection of several statutes shows a high frequency for reporting requirements such as notification of unplanned events and for documentation to initiate the final disposition and to initiate remedial actions. This category was created to list attributes which would respond to the reporting requests raised in the statutes. The attributes may be assigned a range of stringency levels to evaluate the potential impact. The impact may involve more issues than just administrative detail since the operating system may not be able to synchronize its response to some time constraints and suffer a major loss of productivity. The method and contents of the reporting have been identified as constraints by the Resource Conservation and Recovery Act (RCRA). Also, annual reports on the volume of solids and total volume of water in the SST system are constraints from DOE orders.

Also included in this category are attributes defining how well a performance assessment is performed relative to the quality of input data and the quality of algorithms used in the calculation of margins for overall public and employee safety or risk. The origin of the algorithm may have a different margin if it is based on first principles of science instead of an empirical relationship. In general, a high level of stringency for these attributes would require large margins in the outcome of the assessment to offset reliance on less accurate or low quality inputs. Attributes with specific margins for temperature calculations, escape rate from the waste forms, and transport rate in the surrounding soil (carrier system) have been identified for acceptability requirements of the performance assessment itself. 


\subsection{ALLOCATION OF ATTRIBUTES TO HIERARCHICAL OBJECTIVES}

In Section 8.0, "Hierarchical Source Analysis," the applicable statutes were reviewed for statements that revealed performance objectives, goals, or constraints. As described, 120 statements were extracted and grouped in one or more of 14 categories useful for technical application. To provide a connection between these statements and the attributes identified in this section, one or more of the 14 categories was assigned to each of the 541 attributes. In this way, the statements may be reviewed directly with the attributes in the same category.

The results of this exercise are shown in Appendix B. The categories assigned to the attribute are listed in the last column of Table $C .1$ of Appendix C. As described in Section 8.0, Table B.I of Appendix B shows the 1 ist of statements and the assigned categories. Table B.2 lists all the attributes by their assigned number under each category. Those attributes which are constraints as defined and discussed in Section 8.0 are identified by the letter " $C$ " in the status column of Table $C .1$ of Appendix $C$.

The major purpose is to show how the responses from the viewpoints of the first-level functions as to "how well" they should perform are linked to the performance objectives and constraints from the hierarchical interests. This transformation from general intents to specific requirements can be used for further dialogue in regulatory interactions.

\subsection{FORMAT FOR EVALUATION OF ATTRIBUTES}

A system requirement is not complete until an appropriate value is assigned to the attribute. This value should be assigned in a systematic manner to provide traceability and justification. Some attributes can be assigned a range of possible values on the scale and selection of the appropriate value (level of stringency), but this requires inputs on the sensitivity of a value on each of the seven first-level functions. Some functions may have little or no sensitivity to the choice of the stringency level, others may have conflicting or opposing sensitivities. Completion of the requirements analysis (i.e., selecting a specific value within a range of plausible values) has been deferred until there is a set of selection criteria 
which can be applied systematically to each of the 541 attributes. In preparation for the selection, the following tasks were performed on the attribute 1 ist.

1. Each attribute was examined for its application to the "In-Place" or the "Retrieve" option. Some attributes apply to only one of the two options and others apply to both. The fourth and fifth columns of Table C.1 in Appendix C indicate a YES or NO label for these options. This enables one to narrow the scope of the requirements analysis depending on the choice of the closure option. 100 attributes are singularly identified with the "In-Place" option, 260 are singularly identified with the "Retrieve" option, and 181 are identified with both options.

2. Each attribute was ranked as to its importance to each of the firstlevel functions. The ranking is scaled between 1 and 10 where 10 represents the highest importance and 1 represents complete indifference by the function. Each function must have a 10 for at least one attribute, and no zero rankings are allowed. The rankings for the seven functions are shown in Table C.2 of Appendix C. This task identifies which functions have a high stake in the selection of the stringency level and which do not. Those that do not should not be involved in the selection process. Functions having an intermediate ranking should have a proportionate weighting as to their influence in the selection process. Analysis of the rankings is provided in Section 9.4.

\subsection{AITRIBUTE RANKING BY FUNCTION}

Examination of the ranking of the attributes by each function shown in Table C.2 of Appendix $C$ reveals an overall balance of interest in the attributes. The character of the rankings may be analyzed from the viewpoints of the average ranking by each function and of the number of ones chosen for each attribute by the functions.

The average of the 541 rankings (top row of Table C.2) shows the overal1 level of importance by each function. The highest average levels of importance were from the Provide Regulatory Documents (1300) and Provide Waste Packages (1600) functions. These two functions provide the confidence in the performance assessment (Function 1300) and the quality of the waste package containment (Function 1600) for a large number of the chemical and radioactive constituents 1 isted as attributes and therefore would show a high level of importance. Converseiy, Functions 1200 (Stabilization) and 1400 (Retrieval) 
show the lowest average rankings because of their lesser scope of interest in the chemical content of the tank waste in performing those functions. Pretreatment (Function 1500) has the next lowest average ranking, primarily because only a limited number of constituents is involved in the process control of preparing feed streams to the various waste forms used. Characterization (Function 1100) and Long-Term Isolation (Function 1700) have the second highest average in the rankings.

The overall order of average ranking among the functions is:

$$
1300=1600>1700=1100>1500>1400>1200 .
$$

The number of ones shown in the last column of Table C.2 reveals the breadth of interest in an attribute among the functions. If there is a large number of ones for an attribute, then the breadth of interest is narrow and the choice of stringency level for that attribute involves only a few functions. If there are no ones or a few ones, then the breadth of interest is extensive and the choice of stringency level for the attribute may require a consensus of views among the functions. The distribution of the number of ones is as follows:

$\begin{array}{ccc}\begin{array}{l}\text { Number } \\ \text { of Ones }\end{array} & \text { Frequency } & \text { Percent } \\ 0 & 14 & 2.6 \\ 1 & 57 & 10.6 \\ 2 & 97 & 18.0 \\ 3 & 79 & 14.7 \\ 4 & 196 & 36.4 \\ 5 & 57 & 10.6 \\ 6 & 39 & 7.2\end{array}$

The distribution is slightly asymmetrical. The broadest range of interest $(0)$ is less than the narrowest range (6) by about $5 \%(2.6 \%$ versus $7.2 \%$ of the attributes). The median for the breadth of interest is about 3.3. This distribution indicates that potential conflicts in choice of stringency level may require a consensus of judgments involving four or more functions for about $46 \%$ (247) of the attributes. Some of these attributes, however, may be constraints (52) where the level of stringency is already selected by the 
statute or orders, or the choice of stringency level may be unanimous by the functions involved, reducing the number requiring a consensus.

Finally, the purpose of this analysis is to identify pathways for iteration of requirements as the SST closure function evolves from the development stage to the implementation stage. Research and development of the methods of performing SST closure functions and dialogues with the regulatory and sponsoring agencies may require changes in the SST system requirements. The rankings enable the SST project managers to know where the changes should be applied in the subfunctions of the SST closure process. 


\subsection{REFERENCES}

Keller, J. F., A. J. Schmidt, K. B. Selby, M. G. Woodruff, and P. L.

Hendrickson. June 1989. Regulatory Requirements Important to Hanford SingleShel1 Tank Waste Management Decisions, pp. iv-v, 2.1-2.9, PNL-6821, Pacific Northwest Laboratory, Richland, Washington. .

Klem, M. J., C. E. Golberg, R. D. Gibby, K. A. Giese, F. A. Ruck, J. C. Sonnichsen, D. D. Wanner, N. R. Wing, K. A. Woodworth, J. F. Fletcher. June 1990. Single-She11 Tank Systems Technical Support Program Plan. WHC-EP-0288, Westinghouse Hanford Company, Richland, Washington.

U.S. Department of Energy (DOE). December 1987. Final_Environmental Impact Statement, Disposal of Hanford Defense High-Level, Transuranic and Tank Waste, Vol. 1, p. xi, Pp. 3.36-3.38, D0E/EIS-0113, Washington, D.C.

U.S. Department of Energy (DOE). April 1988. Disposal of Hanford Defense High-LeveI. Transuranic and Tank Wastes, Hanford, WA; Record of Decision (ROD). 53 Federal Register, Apri] 14, 1988, pp. 12449-12453.

Washington State Department of Ecology, United States Environmental Protection Agency, and United States Department of Energy. Tri-Party Agreement (TPA). May 1989. Hanford Federal Facility Agreement and Consent Order, p. 1, Washington State Department of Ecology, OTympia, Washington. 

APPENDIX A

LISTING OF FUNCTIONAL ACTIONS TO BE

PERFORMED ON THE HANFORD SST SYSTEM 
APPENDIX A

\section{LISTING OF FUNCTIONAL ACTIONS TO BE PERFORMED ON THE HANFORD SST SYSTEM}

This appendix lists (in Table A.1) the descriptions of the functional actions to be performed on the single-shell tank system at Hanford. A numerical code is used to identify each function at the appropriate level. Subsystem functions comprise a complete set which reveals the functional content of the parent or higher-level function. This analysis does not detail the functional contents below the third level except in a few instances where a fourth level has been used. The numerical code is as foltows:

$\begin{array}{ll}1000 & \text { Zero Level } \\ 1 \times 00 & \text { First Leve1 } \\ 1 \times X 0 & \text { Second Level } \\ 1 \times X X & \text { Third Leve } 1 \\ 1 \times X X . X & \text { Fourth Leve] }\end{array}$

"X" represents a serial digit from 1 to 7.

See Section 6.0 of the main report for a brief summary of these descriptions. 
TABLE A.1. Functional Breakdown - Final Closure of the SST System

tOOO PERFORM FINAL CLOSURE OF THE SST SYSTEM

1100 CHARACTERIZE SST SYSTEM

11 t0 DETERMINE INTEGRITY OF TANK SUBSYSTEM

1111 EVALUATE WASTE ACCUNLATION HISTORY

1112 EVALUATE FAILURE HISTORY

1113 EVALUATE RELEVANT SURVEILLANCE DATA

1114 DETERMINE PROJECTED LIFE OF TANK SUBSYSTEM

1120 DETERMINE COMPOSITION OF IN-TANK WASTE

1121 IDENTIFY CONSTITUENTS AND PROPERTIES

1122 VALIDATE SAMPLING SYSTEM

1123 SAMPLE TANK CONTENTS

1124 AUALYZE TANK SAMPLES

1125 EVALUATE SAMPLING INTEGRITY

1126 DETERMINE SOURCE TERM

1130 DETERMINE IHTEGRITY OF ANCILLARY EQUIPMENT

1131 DETERMINE FAILURE HISTORY OF EQUIPWENT

1132 DETERMINE STATUS OF TRANSFER PIPING

1133 DETERMINE STATUS OF VENTILLATION PIPING

1134 DETERHINE STATUS OF INSTRUNENT PIPING

1135 DETERMINE STATUS OF DIVERSION BOXES

1136 DETERKINE STATUS OF IN-TANK EQUIPHENT

1140 DETERMINE EXTENT OF SOIL CONTAMINATION NEAR LEAKS

1141 IDENTIFY PLUME CONFIGURATION

1142 IDENTIFY CONSTITUENTS BY LDCATIONS

$\$ 143$ VALIDATE SAMPLING SYSTEM

1144 SAMPLE SOIL AS NEEDED

1145 ANALYZE SOIL SAMPLES

1946 DETERMINE SOURCE TERM

1147 ASSESS MOVEMENT OF PLUME

1150 [DETERMINE EXTENT OF SOIL CONTAMINATION IN CRIB/TRENCH] disabled

1151 [IOENTIFY PLUME CONFIGURATION ]

1152 [IDENT:FY CONSTI TUENTS BY LOCATIONS ]

1153 [VALIDATE SAMPLING SYSTEM ]

1154 [SAMPLE SOIL AS NEEDED ]

1155 [AMALYZE SOIL SAMPLES ]

1156 [DETERMINE SOURCE TERM ]

1157 [ASSESS MOVEMENT OF PLUME ]

1180 DETERMINE SOIL INTEGR!TY OF ENVIRONS

1161 VALIDATE SOIL DATA BASE

1162 ASSESS NEW DATA BASE NEEDS

1163 INSTALL NEW BORE HOLES AS NEEDED

1164 VALIDATE MEASUREMENT EOUIPMENT

1165 DETERMINE SOIL SEDIMENT CHARACTERISTICS

1166 DETERMINE HYOROLOGIC PROPERTIES

1167 DETERMINE GEOCHEMICAL PROPERTIES 


\section{TABLE A.1. (contd)}

\begin{tabular}{|c|c|c|}
\hline \multirow[t]{11}{*}{1200} & \multirow{2}{*}{\multicolumn{2}{|c|}{$\begin{array}{l}\text { INTERIM STABILIZATION/ ISOLATION } \\
\text { PRONIDE STABILIZATION (REDUCE LIOUID VOLUME) }\end{array}$}} \\
\hline & & \\
\hline & \multirow[t]{4}{*}{1211} & PRONIDE STABILIZATION FOR NOH-JET PLAPED TANKS \\
\hline & & 1211. 1 EVAL. TAIK CONDITION FOR INTERIM STABILIZATION \\
\hline & & 1211.2 PRONIDE PUMPING CAPABILITY FOR SUPERNATE \\
\hline & & $\begin{array}{l}1211.3 \text { VERIFY TANK CONDITION AFTER PUIPING } \\
1211.4 \text { OBTAIN APPRONAL FOR INTERIM STABILIZATION }\end{array}$ \\
\hline & \multirow[t]{5}{*}{1212} & PRONIDE STABILIZATION FOR JET PLMPED TANXS \\
\hline & & 1212.1 EVAL. TANK CONDITION FOR IHTERIM STABILIZATION \\
\hline & & 1212.2 PRONIDE JET PUAPING CAPABILITT \\
\hline & & 1212.3 VERIFY TANK CONDITION AFTER PUMPING \\
\hline & & 1212.4 OBTAIN APPRONAL FOR INTERIM STABILIZATIOW \\
\hline \multirow[t]{7}{*}{1220} & \multicolumn{2}{|c|}{ PRONIDE ISOLATION (ENCAPSULATE TANKS) } \\
\hline & 1221 & SEAL OPENINGS TO PREVENT WATER INTRUSION \\
\hline & 1222 & PRONIDE FOAM COVER \\
\hline & 1223 & PROVIDE RADIATIOU SHIELDING FOR RISERS \\
\hline & 1224 & PRONIDE VENTILATION \\
\hline & 1225 & PRONIDE EAUIPHENT OISPOSAL IF NEEDED \\
\hline & 1226 & OBTAIM APPRONAL FOR INTERIM ISOLATION \\
\hline \multirow[t]{4}{*}{1230} & \multicolumn{2}{|c|}{ PROVIDE SURYEILLANCE AFTER ISOLATIOA } \\
\hline & 1231 & MONITOR TEMPERATURE \\
\hline & 1232 & MONITOR LIOUID LEVEL \\
\hline & 1233 & MONITOR ORY-WELL, RADIATION LEVEL \\
\hline
\end{tabular}


TABLE A.1. (contd)

1300 PROVIDE RECULATORY DOCUMENTS

1310 PREPARE PERFORMANCE ASSESSMENT

1311 ESTABLISH DATA RASE

1312 DEVELOP COMPUTER MOOELS AND COOES

1313 ANALYZE GENERATED DATA

1314 DEVELOP CAPABILITY TO ANALYZE UNCERTANITY

1315 DEVELOP AND IMPLEMENT OUALITY ASSURANCE PLAK

1320 PREPARE NEPA DOCLNENTATION

1321 ISSUE NOTICE OF INTENT DOCUMENTS

1322 DEFINE SCOPE OF DOCUMENT DOCLNENTS

1323 PREPARE DRAFT DOCUMENT

1324 INCORPORATE CONMENTS FOR FIMAL DOCURENT

1325 PREPARE RECORD OF DECISION(ROD)

1326 IMPLEMENT RECORD OF DECISION(ROD)

1330 PREPARE RCRA DOCUMENTS

1331 SUEMIT PART A PERHIT

1332 PREPARE CLOSURE PLAN

1333 SUBMIT CLOSURE PLAN

1334 RECEIVE APPRONAL FOR PLAN

1335 IMPLEMENT CLOSURE PLAN

1340 PREPARE CERCLA DOCUMENTS

1341 CONDUCT REMEDIAL INVESTIGATION

1342 PREPARE FEASIBILITY STUDY

1343 PREPARE AND ISSUE ROO

1344 PREPARE REMEDIAL DESIGN

1345 IMPLEMENT REMEDIAL DESIGN

1350 PREPARE ADDITIONAL REGULATORY DOCUMENT

1351 PREPARE HECESSARY DOCUMENTS

1351.1 COMPLY WITH RCRA SUBTITLE I

1352.2 COMPLY WITH CLEAN WATER ACT

1352.3 COMPLY WITH CLEAN AIR ACT

1352.4 CONPLY HITH NRC

1352 PREPARE APPROPRIATE DOCUMENTS

1353 ISSUE DOCUMENTS

1354 RECEIVE APPROVAL. FOR DOCUMENTS 
TABLE A.1. (contd)

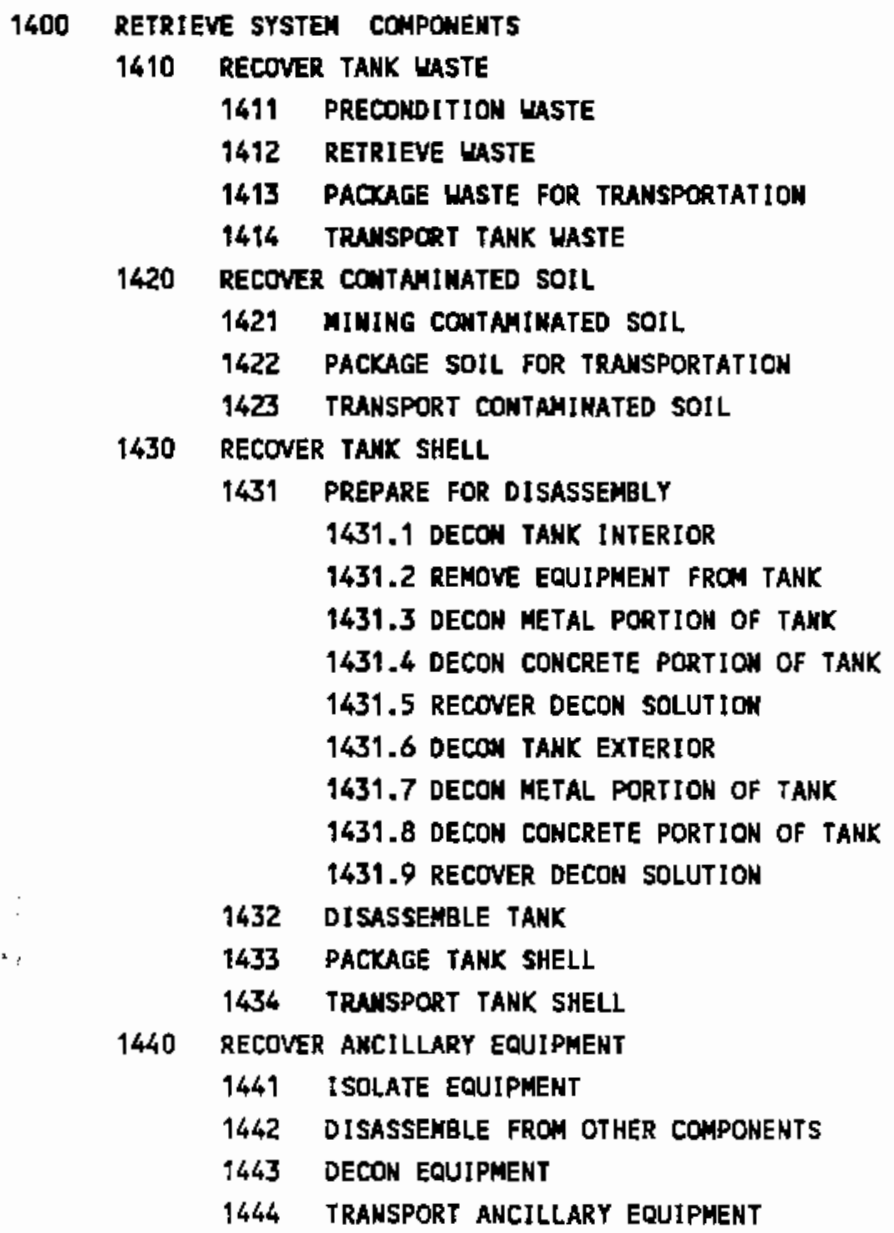




\section{TABLE A.1. (contd)}

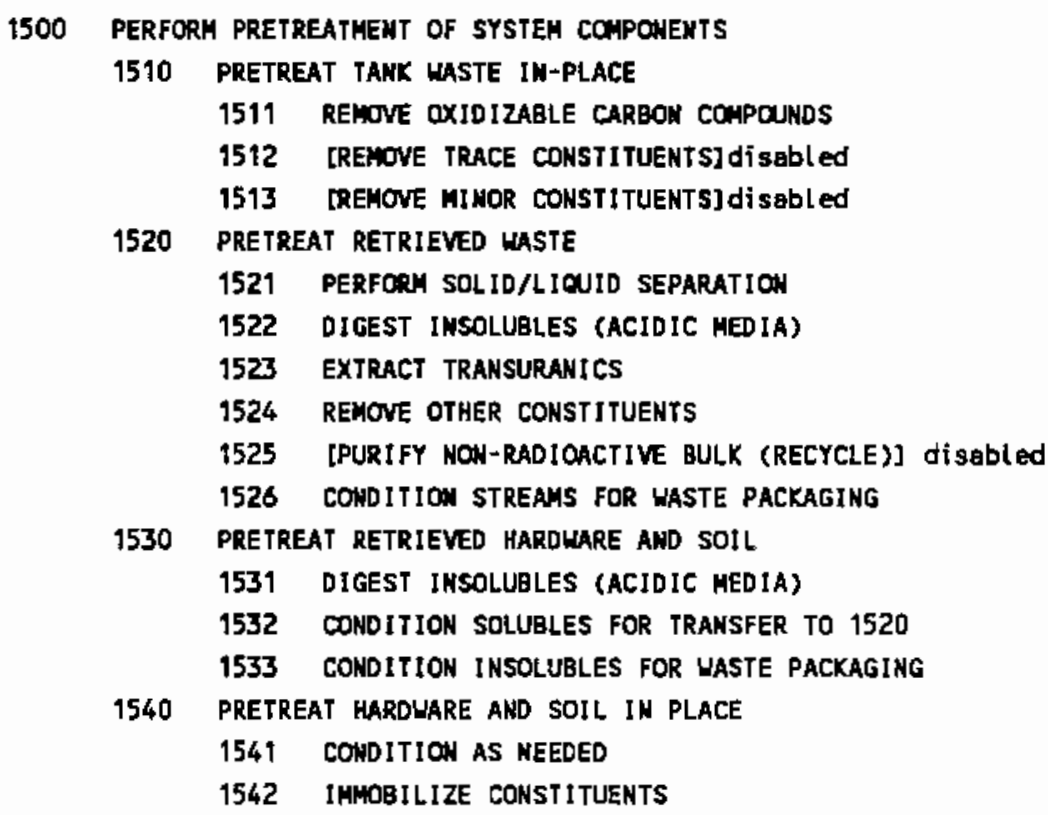


IABLE A.1. (contd)

\begin{tabular}{|c|c|c|c|}
\hline \multirow[t]{14}{*}{1600} & \multicolumn{3}{|c|}{ PROVIDE FIHAL UASTE PACKAGE } \\
\hline & 1610 & \multirow{2}{*}{\multicolumn{2}{|c|}{$\begin{array}{l}\text { RECEIVE WASTE } \\
\text { PREPARE FINAL WASTE FORM }\end{array}$}} \\
\hline & \multirow[t]{4}{*}{1620} & & PREPARE FINAL WASTE FORM \\
\hline & & 1621 & PROVIDE STABILIZING AGENT \\
\hline & & 1622 & MIX WASTE AMD STABILIZING AGENT \\
\hline & & 1623 & COADITION WASTE FORM \\
\hline & \multirow[t]{4}{*}{1630} & PLACE & HASTE FORM IN CONTAINER \\
\hline & & 1631 & PROVIDE CONTAINER \\
\hline & & 1632 & FILL CONTAIMER \\
\hline & & 1633 & SEAL CONTAINER \\
\hline & \multirow[t]{3}{*}{1640} & \multicolumn{2}{|c|}{ PROYIDE MASS TRANSPORT BARRIER(S) } \\
\hline & & 1641 & OBTAIN BARRIER MATERIALS \\
\hline & & 1642 & FABRICATE BARRIER(S) \\
\hline & 1650 & TRAWSPO: & ORT FINAL WASTE PACKAGE \\
\hline \multirow{19}{*}{1700} & \multicolumn{3}{|c|}{ PROVIDE LONG TERM ISOLATION } \\
\hline & \multirow[t]{4}{*}{1710} & SELECT & SITE \\
\hline & & $17 t 1$ & IDENTIFY POTENTIAL SITES \\
\hline & & 1712 & COLLECT DATA ON POTENTIAL SITES \\
\hline & & 1713 & EVALUATE POTENTIAL SITES \\
\hline & \multirow[t]{3}{*}{1720} & \multicolumn{2}{|c|}{ PROVIDE COMPLIAHT BARRIER } \\
\hline & & 1721 & BACKFILL AND GRADE SITE \\
\hline & & 1722 & CONSTRUCT GARRIER \\
\hline & \multirow[t]{2}{*}{1730} & \multicolumn{2}{|c|}{ CONTROL RELEASE FROA SITE } \\
\hline & & 1731 & CONTROL BIOINTRUSION INTO BARRIER \\
\hline & \multirow[t]{4}{*}{ : } & 1732 & CONTROL UATER INFILTRATION AND GASEOUS RELEASES \\
\hline & & 1733 & CONTROL EROSION AND DEPOSITION \\
\hline & & 1734 & MAINTAIN STRUCTURAL STABILITY \\
\hline & & 1735 & CONTROL HUMAN INTRUSION \\
\hline & \multirow[t]{5}{*}{1740} & \multicolumn{2}{|c|}{ MONITOR SITE AFTER BARRIER CONSTRUCTION } \\
\hline & & 1741 & MONITOR SUBSIDENCE \\
\hline & & 1742 & MONITOR LINER/ LEACHATE COLLECTION SYSTEM \\
\hline & & 1743 & MONITOR GROUNDUATER \\
\hline & & 1744 & MONITOR SUBSIDENCE \\
\hline
\end{tabular}

\section{A. 7}



APPENDIX B

LINKAGE OF HIERARCHICAL SOURCE STATEMENTS TO ATTRIBUTES DEFINING SYSTEM REQUIREMENTS 
APPENDIX B

\section{LINKAGE OF HIERARCHICAL SOURCE STATEMENTS TO ATTRIBUTES DEFINING SYSTEM REQUIREMENTS}

The hierarchical statements shown in Table B.l of this appendix were extracted from a review (Keller et al. 1989) of the applicable regulations and statutes that may influence the final disposition (closure) of the Hanford single-she11 tank system. About 125 individual statements were extracted and assigned to one or more of 14 categories (see belaw) to link the 541 attributes identified in the requirements analysis as important to meeting the performance objectives.

Each of the 541 attributes was also assigned to one or more of the 14 categories as appropriate. Table B.2 shows the attribute numbers by category which connect to the attribute descriptions shown in Appendix $C$. With the aid of the category codes, the transformation of the hierarchical source statements to system requirements can be traced in either direction.

The categories selected were as follows:

\begin{tabular}{ll} 
ID & \multicolumn{1}{c}{ Description of Cateqory } \\
CODE & Constraint from hierarchical source \\
AIR & Atmospheric release \\
CA & Corrective action \\
DC & Design and Construction \\
ES & Employee Safety and Health \\
H20 & Water release \\
L & Landfill \\
MA & Maintenance and Surveillance \\
MC & Monitoring and Characterization \\
OP & Operations \\
PS & Public Health and Safety \\
RE & Reporting \\
RAC & Remedial Actions after Closure \\
RBC & Remedial Actions before Closure
\end{tabular}


CA

Placement of bulk Tiquids in landf $i 1$ is in prohibited. See 48 CFR 264.314 and WAC 173-363-665(9). Disposal sites having a reasonable expectation as a future resource of minera is should be avoided. Discharge of any pollutant in navigable waters is prohibited.

Discharge of oil or hazardous substance in navigable waters is prohibited.

Discharge of radiological, chenical or biological marfare agents in navigable waters is prohibited.

Prevent degradation of air quality.

Radionuclides released to the air from DOE facilities shall not exceed $25 \mathrm{mrem} / \mathrm{yr}$ to the whole body and $75 \mathrm{mrem} / \mathrm{yr}$ to the critical organs of a public member.

Radionucides released to the air from DOE facilit ies should be as low as reasonably achievable (ALARA).
Exposure shall not exceed an effective dose equivalent of $25 \mathrm{mran} / \mathrm{yr}$ to the whole body of an individual public menber and no more than 75 mrem to any organ from an atmospheric re lease.

Pernit must contain a corrective action specification and must be institute: regardless of the age of the waste emplacement.

Completion of corrective actions nust be supported by assurances of financial responsibility.

l'pon re lease of hazardous waste, inmediate not if ication of authorities is required.

Must take action to protect human hea lth and the environment upon a release.

After a release, a facility riay be required to clean up, treat, store or dispose of all contaminated materials, water or soil.

After a re lease grotind water monitoring is required.

If the compliance point specified by the permit is exceejed, corrective action is required.

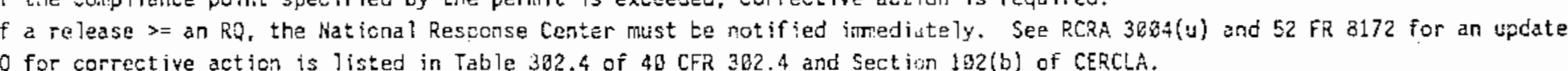



DC

DC KAC 173-353-438(3)(d) HAC $173-393-438(3)(\mathrm{f})$ WAC 173-383-438(3) ( $\mathrm{h}$ ) 48 CFR 264.17 RCH 78.185. 858 48 CFR $398.78(b)$ 48 CFR 380.79(b) 48 CFR 191.13(a) 4Q CER $191.13(a)$ 48 CFR 191.13(a) 48 CFR 191.13(a) 4B CFR 191.13(a)

48 CFR 191.14(d) 4Q CFR 191.14(e) 1B CFR 68.113(a)ii(A) 10 CFR 68.113(a)i i (B)(2) 46 CFR $141.46-.43$ HAC 173-218-19, 4I CFR 146. I1-.73

5488.1, Poircy(a)

DC, PS, ES DOE Order $5820.2 \mathrm{~A}$ Ch.I.3.a(1)(a) COE Order $5828.2 A$ Ch.I. $3 \mathrm{a}(1)(\mathrm{c})$ COE Order 5828.2A Ch.I.3a.(1)(c)
Prevent destruction of flora and fauna outside facility boundary.

作

that do not treat, detoxify, recycle, reclaim, and recover waste.

Facility design requirerents. See 4Q CFR 264.17: ignitable, reactive, incompat ible wastes.

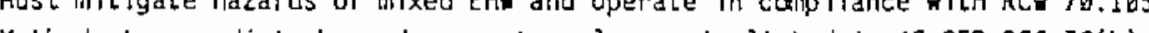

Methods required are: a a ir emission, surface water, grounctuater controls,

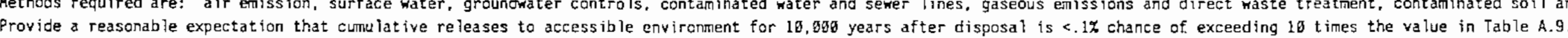

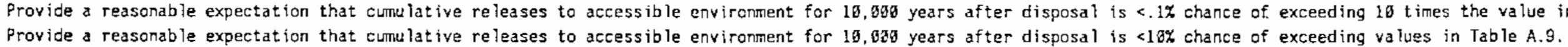

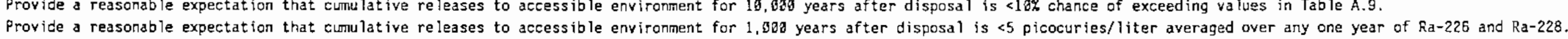

Provide a reasonable expectation that cumulative releases to accessible environment for 1,880 years after disposal is < 15 picocuries/liter averaged over any one year of alpha emitting isotopes.

Provide a reasonable expectation that cumulative re leases to accessible environment for 1,80 e years after disposal is $<4$ millirens/year from 2 liters/day consumption by an individual.

Provide a reasonable expectation that crmlative releases to accessible environent for 1 ang years after disposal will not increase increentally by more than the limits established exen if groundiat sources are already above the limit.

Disposal systens shall use different types of barriers to isolate the wastes from the accessible environment.

Disposal sites having a reasonable expectation as a future resource of minerals should be avoided.

After permanent closure, hilk must be substantially conta ined $x$ ith in the waste package barriers for at least 380 years.

Pre-xaste emplacement grouncrater travel time shall be at least 1 , agg years.

Special monitoring regulations and prohibition on lead use (Subpart $E$ of 40 CFR 141) shall apply.

Underground injection can not be used in a nanner that al lows the movement of fluid cortaining any contaminant into underground drinking water.

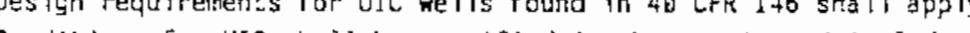

Conditicns for UIC shall be specified in the permit and inciude all kncwn methods for prevention, control and treatment. Applicable requirements :4E, $1(a)$ in 45 CFR 124, 144 , and 146 shall apply.

H. Wesigns must assure protection of the public and coerating personnel.

PrLW designs must incorporate retrievable capability.

HLW designs must conply with COE 6438.1, Hanford Plant Standard and Specifications and 48 CFR 264

revent endangernent of employee health.

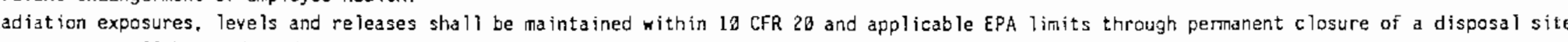
Ul 

WAC 173-363-436(3)(a) WAC $173-393-436(3)(\mathrm{c})$

CERCLA Sec 184(c)(6) 48 CFR 191.13(a) 4 CFR 191.13(a) 49 CFR 191.13(a) Oraft Proposed $4 a$ CFr 193 Subpart C

Oraft Proposed 4I CFR 193 Subpart C

193 Subpart $C$ C 46 193 Subpart C
WAC 248-54-175(2) 4 CAC $248-54-175(2)$ 48 CFR 141.11-.16 4 CFR $141.58-.52$ 48 CFR $141.68-.63$ CHA Sec 482(a)(1)

48 CFR 264.361(a) HAC $173-383-605(2)(a)(1)$ 48 CFR $264.331(i)$ 48 CFR $264.381(\mathrm{i})$ 40 CFR 20̂.251(a)(2) 4B CFR 264.301(a)(2) 40 CFR 264.301(c) 46 CFR $264.381(\mathrm{c})$ RCRA Sec $3004(c)(1)$ 43 CFR 264.31F(a)(1) 48 CFR 264.318(a)(2) 48 CFR 264.31:(a)(3) 48 CFR 264.316(a)(4) 4 CFR $264.316(\mathrm{~b})(1)$ WAC $173-3 * 3-665(6)$ (b)( iv)
Prevent degratation of groundwater and surface water quality.

Renedial action is completed when ground and surface water is restorad to a quality level that assures protection of human hea ith and environient.

Provice a reasonable expectaticn that cLnulative releases to accessible environnent for 1.630 years after disposal is $<5$ picocuries/1iter averaged over any one year of Ra-225 and Ra-228. Provide a reasonable expectation that cumulative releases to accessible environnent for 1.660 years after disposal is $<15$ picocuries/liter averaged over any one year of alpha enitting isotopes. Provide a reasonable expectation that cumulative releases to accessible environnent for 1,036 years after disposal is $<4$ millirems/year from 2 liters/day consumption by an individual. Provide a reasonable expectation that cumulative releases to accessible environnent for 1,28 years after disposal will not increase increnentally by more than the 1 imits established even if groundrater sources are already above the 1 imit.

Class I groundwater cannot result in an increase in radioactivity level fron disposal of LLW.

High yieid Class II grouncrater cannot result in an increase in radioactivity level from disposal of LLW by nore than 4 mrem/year based on 2 liter/day consumption by an individual. Connected groundwater cannot result in an increase in radioactivity level from disposal of LLW that is determined by the class to which it is hydrodynamically connected.

State of Hashington regulations require that conpliance with secondary standards be enforced based on DSHS discretion as the public interest warrants.

Monitoring and analyt ical requirenents in Subpart C of 48 CFR 141 shall apply.

Maximum contaminant levels in Subpart B of 40 CFR 141 shall apply.

Maximem contaminant level goals in Subpart $F$ of $4 B$ CFR 141 shall apply.

Mexinum contaminant levels for prifrary drinking water in Subpart $G$ of $48 \mathrm{CFR} 141$ shall apply (currently being developed).

Discharges to navigable waters rust be permitted under the MPDES program.

Regulated units must have a 1 iner for all portions of the unit.

No migration of waste out of unit during active iife.

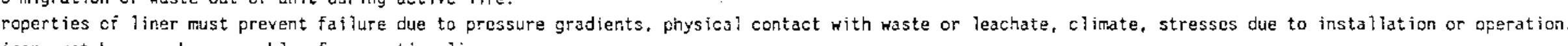

An above liner to collect leachate and remove it.

New, replaced, expanded landfills must have two or more liners.

Ner. replaced, expanded landfills must have a leachate system above and between the liners.

Placenent of bulk liquids in landfills is prohitited. See 48 CFR 254.314 and WAC 173-373-665(9).

Landfilts cover must minimize long term migration of liquids from closed lardf $i 11$.

Landf ill cever must function with minimum ma intenance.

landfill cover must pronote drainage and minimize erosion or abrasion of the cover

Landfill cover must maintain its integrity after sett $t$ ing or subsidence.

andfill cover permeability <= perneability of bottom liner or natural sub-soils present.

A groundwater monitoring program is required to monitor effectiveness of final cover. 

40 CFR $264.111(a)$ AQ CFR 264.318(b) (1)

46 CFR 191.14(a)

48 CFR 191.14(b)

40 CFR 191.14 (c)

DOE Order 5480.1

Policy(a), pg.6 WAC 173-393-655(6)(b)(iv)

CERCLA Sec 192(b)

46 CFR 191.13(a)

4 CFR 191.13(a)

46 CFR 191.14(a)

46 CFR $191.14(\mathrm{~b})$

40 CFR 191.14(c)

10 CFR $66.113(a) i\{(B)(2)$

49 CFR $141.21-36$

C.WA Sec $492(a)(1)$

WAC $462-89-876(4)$

WAC $402-88-888(2)$

WAC $482-88-886(3)$

YAC $402-888-986(8)$

DOE Order $5826.2 \mathrm{~A}$

Ch.1.3.b.(1)(a)

DOE Order $5820.2 A$

Ch. II.3(a) (i)
Must minimize further maintenance after closure.

Must control, minimize or eliminate escape after closure to surface and groundwater. Waste, constituents, leachate contaminated runoff. decompos it ion products.

Must perform maintenance to enșure and correct the effects of settling. subsidence and erosion.

Performance assessments shall not consider contributions from institutional controls for more than 186 years after disposal.

Disposal systems shall be monitored after disposal to detect substant fal and detrimental deviations without jeopardizing the isolation mechanisms.

Disposal sites shall be designated by the most permanent markers, records and other passive controls practicable.

Radiation exposures, levels and re leases shall be mainta ined within 16 CFR 28 and applicable EPA 1 imits through permanent closure of a dispasal site.
DOE activities shall assure protection of the environment.

Analysis must completely describe the chemical and physical characteristics of the waste for petitions for exclusion.

A grouncwater mortoring progran is required to non itor effectiveness of $f$ of the wast cover.

RQ for corrective action is listed in Table 382.4 of 48 CFR 382.4 and Section 192 (b) of CERCLA.

Compliance for a completed remedłal action must attain Max Conta inment Level Goals of the SWDA and water quality criter ia under Sect ions 304 or 383 of the CWN

Provide a reasonable expectation that cumulative releases to accessible eny/ronment for 10,806 years after disposal is <.1\% chance of exceeding 18 times the values.

Provide a reasonable expectation that cumulative releases to accessible environment for 18,606 years after disposal is <16\% chance of exceed ing values in Table A.9.

Performance assessments shall not consider contributions from institutionai controls for more than 106 years after disposal.

Disposal systems shall be monitored after disposal to detect substantial alid detr imental deviations without jeopardizing the isolation mechan isms.

Disposal sites shall be designated by the most permanent markers, records and other passive controls practicable.

Pre-waste emp lacement groundwater travel time shall be at least 1,600 years.

5pecial nonitoring regulations and prohibition on load use in Suppart E of AG CFR 141 shall apply.

Discharges to navigable waters must be permitted under the NPDES progran.

Best available radionuclide control shall be used to provide maximut reduction of emissions in the air.

Stack sampling, ambient air monitoring or other testing is required under tishs.

Continuous monitaring is encouraged; otherwise alternative monitoring and reporting procedures will be established.

Spectal sampling ports or platforms must be provided for use by OSHS for special emission tests.

Liquid and solidified HLW must be characterized to determine its hazardous waste components

Material suspected to be contaminated with TRU shahl be evaluated and determined to be recoverable scrap, tRU waste, LLW as soon as practical to zvoid intermingling 

49 CFR 264.17 49 CFR 264.251 (a) (2) 40 CFR 264.361(a)
RCY 78.165 .953 40 CFR 264.113(a) 40 CFR 264.111(c) 18 CFR 68.111(a) 10 CFR 61.43 WAC 713-218-180 CWA Sec $181(a)(1)$ CHA Sec $311(b)(1)$ CNA Sec $381(f)$ WAC 482-80-683(8)

DOE 5489.1 Policy(a), pg.0

52 FR 15937-15948 48 CFR 191.93(a)(2) 46 CFR 191.63(a)(2) 48 CFR $191.63(b)$ 48 CFR 191. .44(a)(1) Oraft Proposed $48 \mathrm{CF}$ Oraft Proposed Oraft Proposed $48 \mathrm{C}$ 193 Subpart B 16 CFR 61.41 10 CFR 61.92 VAC 173-488-850(1) VAC 402-88-870(4) DOE Order 5496.5 Ch.II.A. DOE Order 5466.5 Ch.II.1.C DOE Order 5499.5 Ch.II.1. DOE Order $5496.5 e$ Ch.II. DOE Order 5408.5 ch.1.4
Facility operating requirenents, see 46 CFR 254.17 : ignitable, reactive, incompatible wastes.

EPA specif ies operat ing conditions to ensure leachate depth does not exceed $38 \mathrm{~cm}$

Yust mitigate hazards of mixed EHW and operate in compitiance with RCW 76.195

Must minimize further ma intenance after closure.

Must control, minimize or el ininate escape after closure to surface and groundwater. Waste, constituents, leachate contaminated runoff, decompos ition products.

Radiation exposures, levels and releases shall be ma intained within 16 CFR $2 \mathfrak{g}$ and applicable EPA 1 inits through permanent closure of a disposal site.

Operations shall be conducted in compliance with the 18 CFR 28 radiation protection standarts.

Underground injection can not be used in a manner that allows the movenent of fluid containing any contaminant into underground drinking water.

Discharge of any pollutant in navigable waters is prohibited.

Discharge of orl or hazardous substance in navigable waters is prohibited.

Discharge of radiological, chenical or blological warfare agents in navigabie waters is prohibited.

Spectal sum radill

DOE activities shall assure protecticn of the envirenment.

RCRA yields to AEA then inconsistencies arise. ALARA > Waste characterizat, on.

Whole body dose shath not exceed 25 millirems.

NRC: Dases to the thyroif shall not exceed 75 millirems and to other critical organs shatl not exceed 25 gillirems.

Non-NRC OOE op 'de. Doses to any artical organ shall not ex to other

doses shall not exceed 168 mrens/yr dose equivalent, and infrequerit coses of 580 mrems in a year from all sources, not natural or medical.

Managenent and storage of LLW should not exceed $25 \mathrm{mr}$ of exposure to any menber of the public nearby.

Disposal of LLW should not exceed $25 \mathrm{mr}$ of exposure to any nember of the purlic nearby.

Doses to the thyroid shall not exceed $75 \mathrm{mren} / \mathrm{year}$ and $25 \mathrm{mrem} / \mathrm{yr}$ to the whole body or any other organ

Releases of radioactivity in effluents to the general environments should be ALARA.

Radionuclides released to the air from DOE facilities shall not exceed $25 \mathrm{mr} m / \mathrm{mr}$ to the whole body and $75 \mathrm{mren} / \mathrm{yr}$ to the $\mathrm{cr}$ itical organs of a public member.

Radionuclides released to the air from DOE facilities should be as ALARA.

Best available radionuclide control shall be used to provide maximum reduction of emissions in the air.

Exposure shall not exceed an effective dose equiva ?ent of $25 \mathrm{mrem} / \mathrm{yr}$ to the whole body of an individual public member and no more than 75 mrent to any organ from an atmospheric re lease.

exposure shall not exceed an effective dose equiva lent of $25 \mathrm{mrem} / \mathrm{yr}$ to the whole body of an individual public member and no more than 75 mrem to $2 n y$ organ from management or storage of HLL.

Exposure shath not exceed $4 \mathrm{mrem} / \mathrm{yr}$ from any person consuling drinking water. 


- +




\section{Q CFR 264.112(b)(5)} 48 CFR 141.31-.35 RE Ch. (IV)

RE DOE Order 5825.2A Chapter 1.3.b(1)(b) COE Order 5481.18 Chapter I. (3)(a)(3) DOE Order $5481.1 \mathrm{~B}$ Ch. I. (3)(a)(5)

RAC, H2B CERCLA SeC 184(C)(E) RAC CERCLA Sec 121(b)(1) RAC, MC CERCLA Sec 121(d)(2)(A)(ii) RAC 43 CFR $3 \times 3.55(b)(1)$ RAC 43 CFR 3.3.

kBC

REC RCRA Subtitle I RBC. OC $\quad 40$ CFR 3BQ.78(b)
Subnit a closure plan for describing how performance standards mill be sat isf ied.

Reparting, Public Not if ication and Recorckeeping in Subpart $D$ of 48 CFR 141 shall apply.

Environnental monitoring plans must be submitted and include design criteria, frequency of neasurenents and procedures for analyses.

Characterization data must be used in a Safety Analysis Report.

A safety analysis shall be ferforned to icentify and demonstrate conformance with applicable guides, codes and standards.

A safety ana lysis shail be perforned to denonstrate there is reasonable assurance that operations will protect the public, emplayees and the environnent at a low risk.

Renedial action is completed then grcund and surface water is restored to a quality level that assures protect ion of human health and environment. Remedial action treatnents that recuce volume, toxicity, or mobility of hazardous waste is preferred over treatments not involving such treatment.

Remedial action trat

Compliance for a completed remedial action must attain Max Contaminant Level Goals of the SVDA and water quality criteria under Sections 363 or 387 of the ChA.

Any release deemed a threat by EPA must be abated, minimized, stabilized, mitigated, or eliminated.

Removal actions shall meet or exceed applicable federal, public health and environmental requirenents.

All tanks taken out of service permanently nust be emptied and either fanoted

Methods to renediate hazardous waste releases is listed in $48 \mathrm{CFR} 386.78(\mathrm{~b})$.
Methods required are: air enission, surface water, groundwater controls, contaminated water and semer lines, gaseous emissions and direct waste treatment, conteminated soil and sedinent. 

IABLE B.2. Attribute Numbers Arranged by Category Identification Code

\begin{tabular}{|c|c|c|c|c|c|c|c|c|c|c|c|c|c|c|}
\hline COOE---> & co & AIR & CA & $D C$ & ES & ห20 & $L$ & MA & MC & $O P$ & PS & RE & RAC & RBC \\
\hline TOTAL -.> & 63 & 4 & 10 & 220 & 22 & 111 & 50 & 114 & 7 & 185 & 22 & 18 & 7 & 42 \\
\hline \multirow[t]{41}{*}{ LIST---S } & ATT \# & ATT & ATT \# & ATT * & ATT \# & ATT \# & ATT \# & ATT \# & AIT " & ATT \# & ATT & AT \# & ATI & ATT \# \\
\hline & 88 & 434 & 95 & 101 & 172 & 1 & 167 & 1 & 526 & 88 & 380 & 91 & 524 & 44 \\
\hline & 89 & 435 & 96 & 102 & 173 & 2 & 168 & 2 & 527 & 89 & 381 & 92 & 525 & 445 \\
\hline & 93 & 436 & 97 & 103 & 174 & 3 & 169 & 3 & 528 & 90 & 382 & 526. & 526 & 446 \\
\hline & 98 & 500 & 533 & 104 & 175 & 4 & 170 & 4 & 529 & 91 & 383 & 527 & 527 & 447 \\
\hline & 99 & & 534 & 105 & 176 & 5 & 288 & 5 & 530 & 92 & 384 & 528 & 528 & 448 \\
\hline & 100 & & 535 & 126 & 177 & 6 & 289 & 6 & 531 & 93 & 385 & 529 & 529 & 451 \\
\hline & 126 & & 536 & 127 & 178 & 7 & 370 & 7 & 532 & 94 & 386 & 530 & 530 & 452 \\
\hline & 127 & & 537 & 128 & 179 & $a$ & $37 !$ & 8 & & 111 & 387 & 531 & & 453 \\
\hline & 128 & & 538 & 129 & 180 & 9 & 372 & 9 & & 112 & 388 & 532 & & 454 \\
\hline & 129 & & 539 & 130 & 181 & 10 & 373 & 10 & & 113 & 389 & 533 & & 455 \\
\hline & 130 & & & 131 & 182 & 11 & 374 & 11 & & 114 & 390 & 534 & & 456 \\
\hline & 131 & & & 132 & 183 & 12 & 375 & 12 & & 115 & 391 & 535 & & 457 \\
\hline & 132 & & & 133 & 184 & 13 & 376 & 13 & & 116 & 392 & 536 & & 458 \\
\hline & 133 & & & 134 & 488 & 14 & 377 & 14 & & 117 & 393 & 537 & & 459 \\
\hline & 134 & & & 135 & 489 & 15 & 378 & 15 & & 118 & 396 & 538 & & 460 \\
\hline & 135 & & & 150 & 490 & 16 & 379 & 16 & & 119 & 395 & 539 & & 461 \\
\hline & 153 & & & 151 & 491 & 17 & 400 & 17 & & 120 & 396 & 540 & & 462 \\
\hline & 154 & & & 152 & 492 & 18 & 401 & 18 & & 121 & 397 & 549 & & 463 \\
\hline & 189 & & & 153 & 495 & 19 & 402 & 19 & & 122 & 398 & & & 464 \\
\hline & 190 & & & 154 & 496 & 20 & 403 & 20 & & 123 & 399 & & & 465 \\
\hline & 191 & & & 155 & 497 & 21 & 404 & 21 & & 124 & 499 & & & 466 \\
\hline & 192 & & & 156 & 498 & 22 & 405 & 22 & & 125 & 500 & & & 467 \\
\hline & 193 & & & 157 & & 23 & 406 & 23 & & 136 & & & & 468 \\
\hline & 246 & & & 161 & & 24 & 407 & 24 & & 137 & & & & 469 \\
\hline & 366 & & & 162 & & 25 & 408 & 25 & & 138 & & & & 470 \\
\hline & 367 & & & 163 & & 26 & 409 & 26 & & 139 & & & & 471 \\
\hline & 368 & & & 164 & & 27 & 410 & 27 & & 140 & & & & $4 \pi 2$ \\
\hline & 369 & & & 165 & & 28 & 411 & 28 & & 141 & & & & 473 \\
\hline & 380 & & & 166 & & 29 & 412 & 29 & & 142 & & & & 474 \\
\hline & 381 & & & 169 & & 30 & 473 & 30 & & 143 & & & & $4 \pi$ \\
\hline & 382 & & & 170 & & 31 & 414 & 31 & & 144 & & & & 476 \\
\hline & 383 & & & 171 & & 32 & 415 & 32 & & 145 & & & & 477 \\
\hline & 384 & & & 183 & & 33 & 416 & 33 & & 146 & & & & 478 \\
\hline & 385 & & & 185 & & 34 & 417 & 34 & & 147 & & & & 479 \\
\hline & 386 & & & 186 & & 35 & 418 & 35 & & 148 & & & & 480 \\
\hline & 387 & & & 187 & & 36 & 419 & 36 & & 149 & & & & 481 \\
\hline & 388 & & & 188 & & 37 & 420 & 37 & & 158 & & & & 482 \\
\hline & 389 & & & 189 & & 38 & 421 & 38 & & 159 & & & & 483 \\
\hline & 390 & & & 190 & & 39 & 422 & 39 & & 160 & & & & 484 \\
\hline & 391 & & & 191 & & 40 & 423 & 40 & & 172 & & & & 485 \\
\hline
\end{tabular}




\section{TABLE B.2. (contd)}

\begin{tabular}{|c|c|c|c|c|c|c|c|c|c|c|c|c|c|c|}
\hline COOE--.> & $\mathrm{co}$ & AIR & CA & DC & ES & H2O & $L$ & MA & $\mathrm{MC}$ & OP & PS & RE & RAC & RBC \\
\hline TOTAL $\leadsto$ & 63 & 4 & 10 & 220 & 22 & 111 & 50 & 114 & 7 & 185 & 22 & 18 & 7 & 42 \\
\hline LIST--.> & $\begin{array}{r}\text { ATT } \\
392\end{array}$ & ATT \# & АТT & $\begin{array}{r}\text { ATT * } \\
192\end{array}$ & АТт \# & $\begin{array}{r}\text { ATT \# } \\
41\end{array}$ & $\begin{array}{r}\text { ATT } \\
424\end{array}$ & $\begin{array}{r}\text { ATT } \# \\
41\end{array}$ & ATT \# & $\begin{array}{r}\text { ATT \# } \\
173\end{array}$ & ATT \# & ATT \# & ATT \# & $\begin{array}{r}\text { ATT } \\
486\end{array}$ \\
\hline & 393 & & & 193 & & 42 & 425 & 42 & & 174 & & & & 487 \\
\hline & 394 & & & 194 & & 43 & 426 & 43 & & 175 & & & & \\
\hline & 395 & & & 195 & & 44 & 427 & 44 & & 176 & & & & \\
\hline & 396 & & & 198 & & 45 & 428 & 45 & & 177 & & & & \\
\hline & 397 & & & 197 & & 46 & 429 & 46 & & 178 & & & & \\
\hline & 398 & & & 198 & & 47 & 430 & 47 & & 179 & & & & \\
\hline & 434 & & & 199 & & 48 & 431 & 48 & & 180 & & & & \\
\hline & 435 & & & 200 & & 49 & 432 & 49 & & 181 & & & & \\
\hline & 436 & & & 201 & & 50 & 433 & 50 & & 182 & & & & \\
\hline & 495 & & & 202 & & 51 & & 51 & & 184 & & & & \\
\hline & 499 & & & 203 & & 52 & & 52 & & 291 & & & & \\
\hline & 500 & & & 204 & & 53 & & 53 & & 292 & & & & \\
\hline & 509 & & & 205 & & 54 & & 54 & & 293 & & & & \\
\hline & 510 & & & 206 & & 55 & & 55 & & 294 & & & & \\
\hline & 511 & & & 207 & & 56 & & 56 & & 295 & & & & \\
\hline & 512 & & & 208 & & 57 & & 57 & & 296 & & & & \\
\hline & 513 & & & 209 & & 58 & & 58 & & 297 & & & & \\
\hline & 514 & & & 210 & & 59 & & 59 & & 298 & & & & \\
\hline & 538 & & & 211 & & 60 & & 60 & & 299 & & & & \\
\hline & 539 & & & 212 & & 61 & & 61 & & 300 & & & & \\
\hline & 540 & & & 213 & & 62 & & 62 & & 301 & & & & \\
\hline & 541 & & & 214 & & 63 & & 63 & & 302 & & & & \\
\hline & & & & 215 & & 64 & & 64 & & 303 & & & & \\
\hline & & & & 216 & & 65 & & 65 & & 304 & & & & \\
\hline & & & & 217 & & $\infty$ & & 66 & & 305 & & & & \\
\hline & & & & 218 & & 67 & & 67 & & 306 & & & & \\
\hline & & & & 219 & & 68 & & 68 & & 307 & & & & \\
\hline & & & & 220 & & 69 & & 69 & & 308 & & & & \\
\hline & & & & 221 & & 70 & & 70 & & 309 & & & & \\
\hline & & & & 222 & & 71 & & 71 & & 310 & & & & \\
\hline & & & & 223 & & 72 & & $\pi$ & & 311 & & & & \\
\hline & & & & 224 & & 73 & & 73 & & 312 & & & & \\
\hline & & & & 225 & & 74 & & 74 & & 313 & & & & \\
\hline & & & & 226 & & 75 & & 75 & & 314 & & & & \\
\hline & & & & 227 & & 76 & & 76 & & 315 & & & & \\
\hline & & & & 228 & & 77 & & $\pi$ & & 316 & & & & \\
\hline & & & & 229 & & 78 & & 78 & & 317 & & & & \\
\hline & & & & 230 & & 79 & & 79 & & 318 & & & & \\
\hline & & & & 231 & & 80 & & 80 & & 319 & & & & \\
\hline
\end{tabular}


IABLE B.2. (contd)

\begin{tabular}{|c|c|c|c|c|c|c|c|c|c|c|c|c|c|c|}
\hline $\cos E \cdots$ & $\infty$ & AIR & $\mathrm{CA}$ & $D C$ & ES & $\mathrm{HZO}$ & $\mathbf{L}$ & MA & MC & $Q P$ & PS & RE & RAC & RBC \\
\hline TOTAL- -> & 63 & 4 & 10 & 220 & 22 & 111 & 50 & 114 & 7 & 185 & 22 & 18 & 7 & 42 \\
\hline \multirow[t]{41}{*}{ LIST.... } & ATT \# & ATT \# & ATT \# & ATT \# & ATT \# & ATT \# & ATT * & ATT & ATT & ATT \# & ATt & ATT & ATT * & ATT \\
\hline & & & & 232 & & 81 & & 81 & & 320 & & & & \\
\hline & & & & 233 & & 82 & & 82 & & 321 & & & & \\
\hline & & & & 234 & & 83 & & 83 & & 322 & & & & \\
\hline & & & & 235 & & 84 & & 84 & & 323 & & & & \\
\hline & & & & 236 & & 85 & & 85 & & 324 & & & & \\
\hline & & & & 237 & & 86 & & 86 & & 325 & & & & \\
\hline & & & & 238 & & 87 & & 87 & & 326 & & & & \\
\hline & & & & 239 & & 106 & & 88 & & 327 & & & & \\
\hline & & & & 240 & & 107 & & 89 & & 328 & & & & \\
\hline & & & & 241 & & 108 & & 90 & & 329 & & & & \\
\hline & & & & 242 & & 109 & & 91 & & 330 & & & & \\
\hline & & & & 243 & & $1 t 0$ & & 92 & & 331 & & & & \\
\hline & & & & 244 & & 380 & & 93 & & 332 & & & & \\
\hline & & & & 245 & & 381 & & 94 & & 333 & & & & \\
\hline & & & & 246 & & 382 & & 95 & & 334 & & & & \\
\hline & & & & 247 & & 383 & & 96 & & 335 & & & & \\
\hline & & & & $24 B$ & & 384 & & 97 & & 336 & & & & \\
\hline & & & & 249 & & 385 & & 98 & & 337 & & & & \\
\hline & & & & 250 & & 386 & & 99 & & 338 & & & & \\
\hline & & & & 251 & & 387 & & 100 & & 339 & & & & \\
\hline & & & & 252 & & 388 & & 101 & & 340 & & & & \\
\hline & & & & 253 & & 389 & & 102 & & 341 & & & & \\
\hline & & & & 254 & & 390 & & 103 & & 342 & & & & \\
\hline & & & & 255 & & 391 & & 104 & & 343 & & & & \\
\hline & & & & 256 & & 392 & & 105 & & 344 & & & & \\
\hline & & & & 257 & & 393 & & 106 & & 345 & & & & \\
\hline & & & & 258 & & 394 & & 107 & & 346 & & & & \\
\hline & & & & 259 & & 395 & & 108 & & 347 & & & & \\
\hline & & & & 260 & & 396 & & 109 & & 348 & & & & \\
\hline & & & & 261 & & 397 & & 110 & & 349 & & & & \\
\hline & & & & 262 & & 398 & & 415 & & 350 & & & & \\
\hline & & & & 263 & & & & 416 & & 351 & & & & \\
\hline & & & & 264 & & & & 419 & & 352 & & & & \\
\hline & & & & 265 & & & & 420 & & 353 & & & & \\
\hline & & & & 266 & & & & & & 354 & & & & \\
\hline & & & & 267 & & & & & & 355 & & & & \\
\hline & & & & 268 & & & & & & 356 & & & & \\
\hline & & & & 269 & & & & & & 357 & & & & \\
\hline & & & & 270 & & & & & & 358 & & & & \\
\hline & & & & 271 & & & & & & 359 & & & & \\
\hline
\end{tabular}


TABLE B.2. (contd)

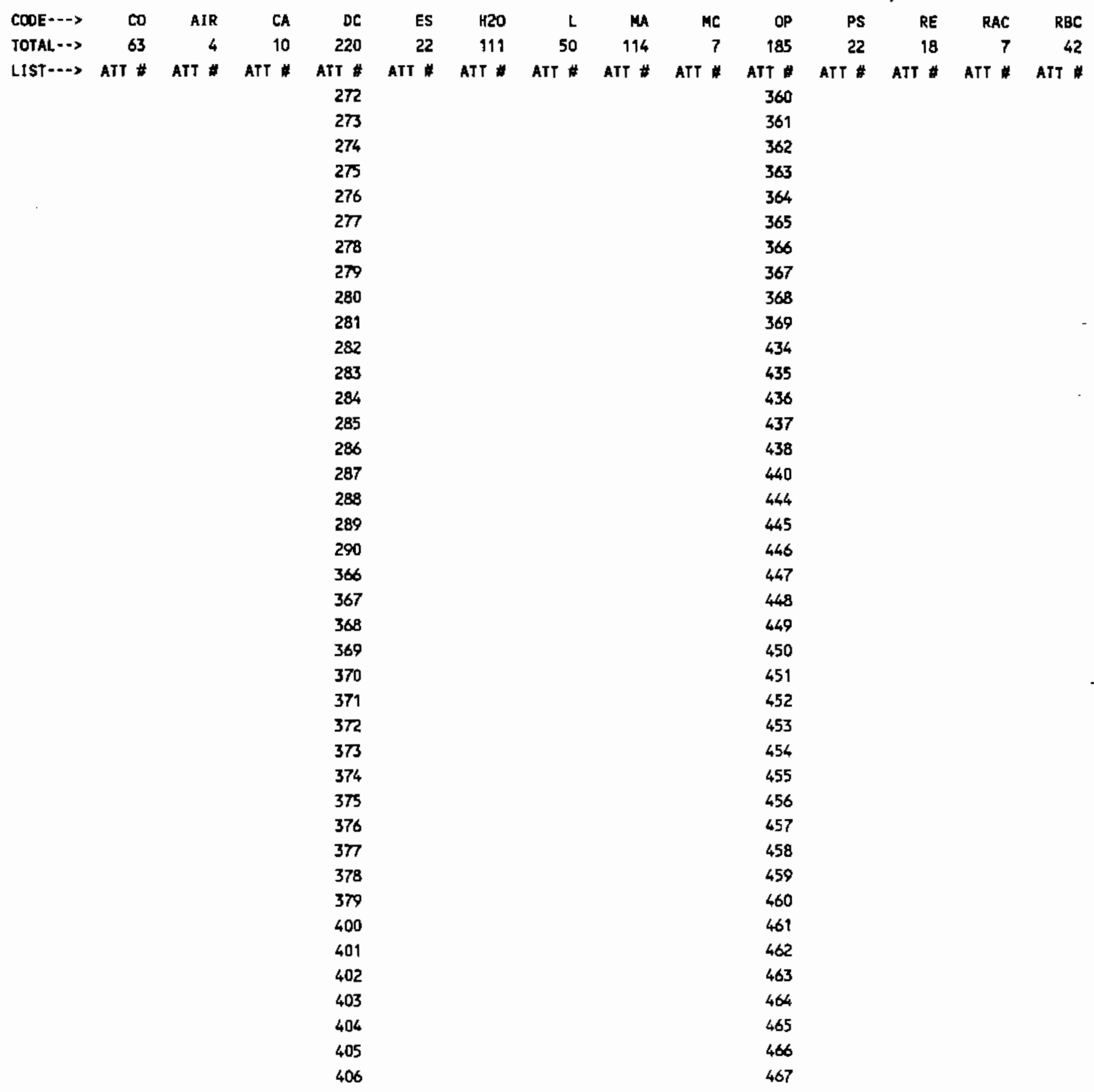


TABLE B.2. (contd)

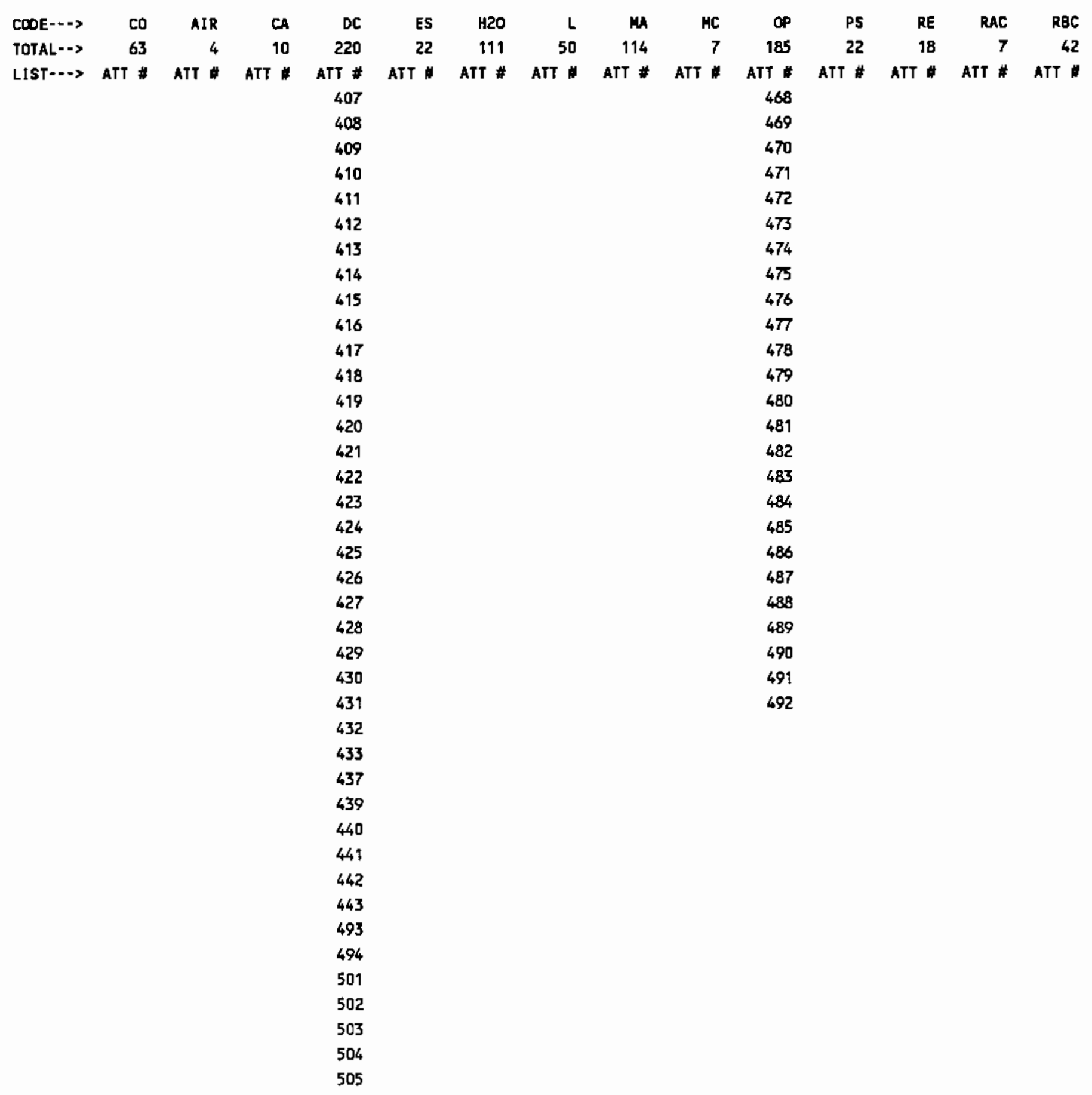




\section{TABLE B.2. (contd)}

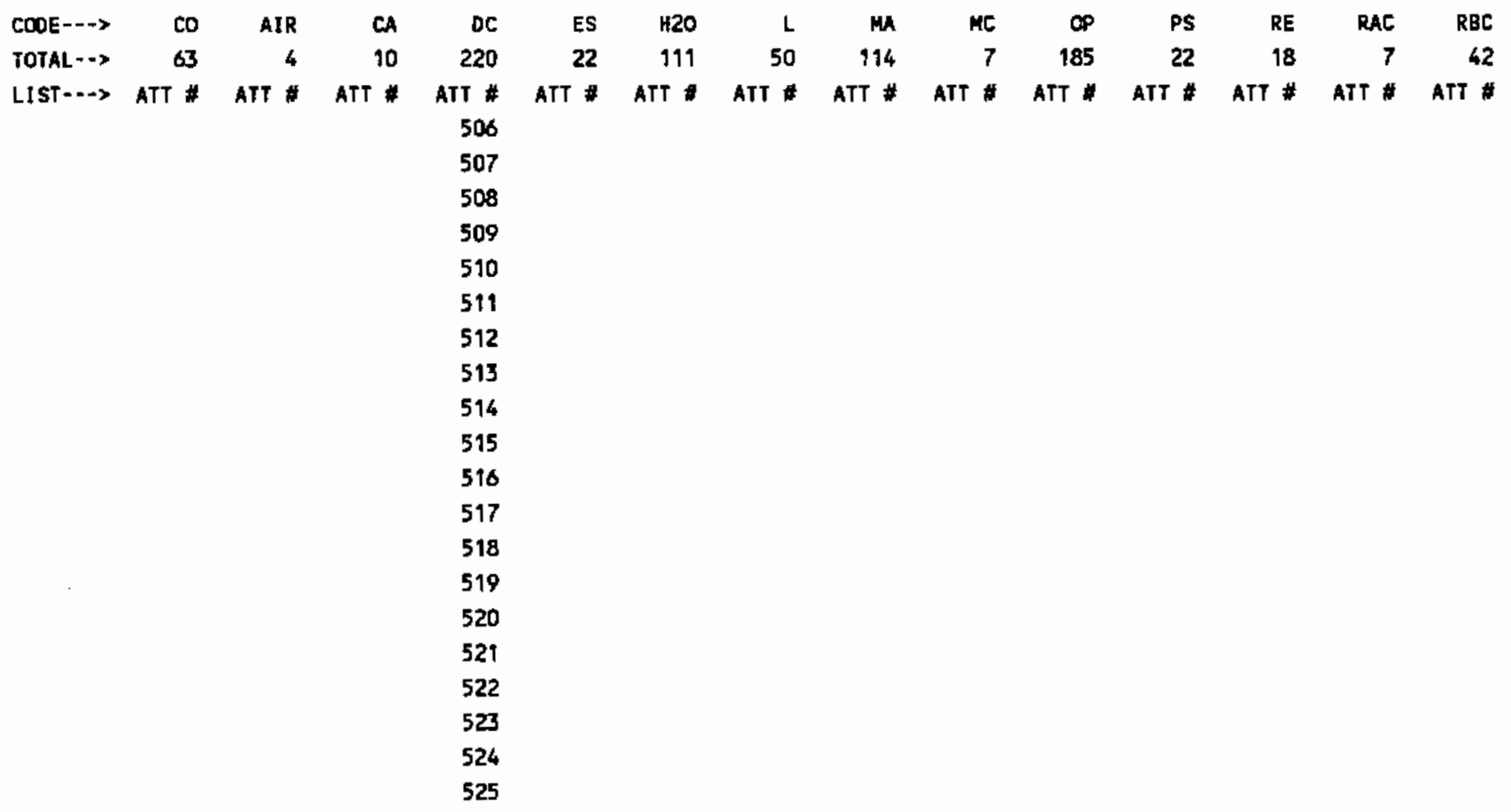




\section{APPENDIX C}

SOURCE DATA FOR REQUIREMENTS ANALYSIS - SECTION 9.0 
APPENDIX C

\section{SOURCE DATA FOR REQUIREMENTS ANALYSIS - SECTION 9.0}

This appendix contains the inputs for the requirements analysis of the SST system. The attribute descriptions are listed in Tables C.I and C.2. and are grouped into six major categories. Each category is subdivided further as described in the text. There 541 attributes, and each is given a number for identification.

In Table C.1, the attribute number, the attribute description, and the unit of measure for the attribute are listed respectively in the first three columns. In columns 4 and 5, the applicability of the attribute to the "Inplace," "Retrieve" or both options is indicated by a YES or NO 1abel. In column 6 the status of the attribute is indicated either blank if the choice of the value has not been made or by the letter " $C$ " if the attributes is a constraint designated in the regulatory statutes and DOE orders discussed in Section 8.0 of the text.

The last column of Table $C .1$ assigns each attribute to one or more of 14 categories defined in Section 8.0. These categories are used to connect the performance objectives and constraints to the attribute list.

In Table C.2, the attributes have been ranked in order of importance to each of the seven first-level functions. The ranking values range from 1 to 10 , with 10 being the most important to the function. A ranking of 1 signifies that the attribute has no importance to the function regardless of the stringency level assigned to it. Each function must have at least one attribute ranked as a 10. Intermediate rankings indicate a lesser degree of importance.

Table $C .2$ also shows the average value of the ranking by each function in the top row of the ranking matrix. The last column in the matrix lists the number of functions which ranked the attribute as "one" in importance. This term helps to understand the breadth of the importance of the attribute among the seven first-level functions. A few "number of ones" indicates that 
achieving a consensus wi1l involve many functions. A large "number of ones" indicates that the attribute has a narrow span of importance and that changes in its stringency level can be made with a lesser impact on the other functions. 
TABLE C.1. Listing of Attributes, Units of Measure as Potential Requirements for Final Disposition of the SST System

\begin{tabular}{|c|c|c|c|c|c|c|}
\hline \multirow{5}{*}{$\begin{array}{l}\text { ATTRIBUTE } \\
\text { No. } \\
=======\end{array}$} & \multirow{4}{*}{$\begin{array}{l}\text { 5/31/89 Update } \\
\text { ATTRIBUTE OESCRIPTIOH }\end{array}$} & \multirow{5}{*}{ 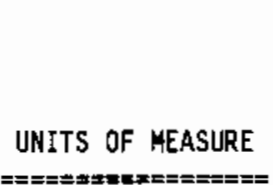 } & \multicolumn{4}{|c|}{ CLASSIFICATIONS OF ATTRIBUTES } \\
\hline & & & \multirow{2}{*}{\multicolumn{2}{|c|}{\begin{tabular}{|l} 
APPLICATION TO \\
OISPOSAL OPTION
\end{tabular}}} & \multirow{4}{*}{$\begin{array}{c}\text { STATUS: } \\
\text { "C" }= \\
\text { CONSTRAIKT } \\
==0= \pm====\end{array}$} & \multirow{4}{*}{$\begin{array}{c}\text { SOURCE } \\
\text { COOE } \\
\text { See APp B } \\
====== \pm\end{array}$} \\
\hline & & & & & & \\
\hline & & & IM-PLACE & :RETRIEYE & & \\
\hline & 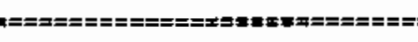 & & 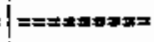 & : :========= & & \\
\hline & CHEMICAL ATTRIBUTES & & & : & & \\
\hline & Detection Limits & & & : & & \\
\hline & (for Groundwater, Leaching & & & $:$ & & \\
\hline & Tests, Process Samples, & & & : & & \\
\hline & etc.) & & & : & & \\
\hline & 1.1.1 Radionuclides & & & : & & \\
\hline 1 & $A c-227$ & $\mathrm{pC} \mathbf{i}$ & YES & NO & & $\mathrm{MA}, \mathrm{H} 2 \mathrm{O}$ \\
\hline 2 & $A m-241$ & $\mathrm{pC} \mathfrak{i}$ & YES & : YES & & MA, H2O \\
\hline 3 & Am-242 & $\mathrm{pC} i$ & YES & : NO & & MA, , $\mathrm{H} 2 \mathrm{O}$ \\
\hline 4 & Am-243 & $\mathrm{pCi}$ & YES & No & & $\mathrm{MA}, \mathrm{H} 2 \mathrm{O}$ \\
\hline 5 & $C-14$ & $\mathrm{pC} i$ & YES & YES & & $\mathrm{MA}, \mathrm{H} 2 \mathrm{O}$ \\
\hline 6 & $\mathrm{Cm}-242$ & $\mathrm{PC} i$ & YES & YES & & $\mathrm{MA}, \mathrm{HZO}$ \\
\hline 7 & $\mathrm{Cm}-244$ & $\mathrm{pCi}$ & YES & No & & $\mathrm{MA}, \mathrm{H} 2 \mathrm{O}$ \\
\hline 8 & $\mathrm{Cm}-245$ & $\mathrm{pCi}$ & YES & ND & & MA, H2O \\
\hline 9 & Co-66 & $\mathrm{pCi}$ & YES & YES & & $M A, H 2 O$ \\
\hline 10 & Cs -135 & $\mathrm{pCi}$ & YES & YES & & MA. $\mathrm{H} 2 \mathrm{O}$ \\
\hline 11 & Cs-137 & $\mathrm{pCi}$ & YES & YES & & $\mathrm{MA}, \mathrm{H} 2 \mathrm{O}$ \\
\hline 12 & $\mathrm{H}-3$ & $\mathrm{pC} i$ & YES & No & & MA, H2O \\
\hline 13 & I -129 & $\mathrm{pCi}$ & YES & YES & & MA, $\mathrm{H} 2 \mathrm{O}$ \\
\hline 14 & $\mathrm{Ni}-59$ & $\mathrm{pCi}$ & YES & NO & & $\mathrm{MA}, \mathrm{H} 2 \mathrm{O}$ \\
\hline 15 & $\mathrm{Ni} i-63$ & $\mathrm{pC} i$ & YES & YES & & $\mathrm{MA}, \mathrm{H} 2 \mathrm{O}$ \\
\hline 16 & $\mathrm{Nb}-94$ & $\mathrm{pCi}$ & YES & YES & & MA, H2O \\
\hline 17 & Np-237 & $\mathrm{pCi}$ & YES & YES & & $\mathrm{MA}, \mathrm{H} 2 \mathrm{O}$ \\
\hline 18 & $\mathrm{~Pa}-23 \mathrm{l}$ & $\mathrm{pCi}$ & YES & NO & & $\mathrm{MA}, \mathrm{H} 2 \mathrm{O}$ \\
\hline 19 & $\mathrm{~Pb}-210$ & $p C i$ & YES & No & & $\mathrm{MA}, \mathrm{H} 2 \mathrm{O}$ \\
\hline $2 \sigma$ & $P_{0}-210$ & $\mathrm{pCi}$ & YES & NO & & $M A, H 2 O$ \\
\hline 21 & Pu-238 & $\mathrm{pCi}$ & YES & No & & $\mathrm{MA}, \mathrm{H} 2 \mathrm{O}$ \\
\hline 22 & Pu-239 & $\mathrm{pCi}$ & YES & YES & & $\mathrm{MA}, \mathrm{H} 2 \mathrm{O}$ \\
\hline 23 & $P u-24 \sigma$ & $\mathrm{pCi}$ & YES & NO & & $\mathrm{MA}, \mathrm{H} 2 \mathrm{O}$ \\
\hline 24 & $P u-241$ & $\mathrm{pCi}$ & YES & NO & & $\mathrm{MA}, \mathrm{H} 2 \mathrm{O}$ \\
\hline 25 & Pu-242 & $\mathrm{pCi}$ & YES & NO & & $\mathrm{MA}, \mathrm{H} 2 \mathrm{O}$ \\
\hline 26 & $\operatorname{Ra}-226$ & $\mathrm{pC} ;$ & YES & No & & $\mathrm{MA}, \mathrm{H} 2 \mathrm{O}$ \\
\hline 27 & $\mathrm{Ra}-228$ & $\mathrm{pC}_{i}$ & YES & NO & & $\mathrm{MA}, \mathrm{H} 2 \mathrm{O}$ \\
\hline 28 & $R !-106$ & $\mathrm{pCi}$ & YES & No & & $\mathrm{MA}, \mathrm{H} 2 \mathrm{O}$ \\
\hline 29 & $\mathrm{Se}-79$ & $\mathrm{pCi}$ & YES & YES & & $\mathrm{MA}, \mathrm{H} 2 \mathrm{O}$ \\
\hline 30 & Sm-151 & $\mathrm{pCi}$ & YES & : NO & & MA.H2O \\
\hline 31 & $S n-126$ & $\mathrm{pCi}$ & YES & YES & & $\mathrm{MA}, \mathrm{H} 2 \mathrm{O}$ \\
\hline 32 & $\mathrm{Sr}-90$ & $\mathrm{pCi}$ & YES & YES & & $\mathrm{MA}, \mathrm{H} 2 \mathrm{O}$ \\
\hline 33 & Tc-99 & $\mathrm{pCi}$ & YES & : YES & & $\mathrm{MA}, \mathrm{H} 2 \mathrm{O}$ \\
\hline 34 & Th-229 & $\mathrm{pCi}$ & YES & NO & & MA, H2O \\
\hline 35 & Th-230 & $\mathrm{pCi}$ & YES & : NO & & $\mathrm{MA}, \mathrm{H} 2 \mathrm{O}$ \\
\hline 36 & Th-232 & $\mathrm{pC} i$ & YES & NO & & $\mathrm{MA}, \mathrm{H} 2 \mathrm{O}$ \\
\hline 37 & $\mathrm{U}-233$ & $\mathrm{pCi}$ & YES & : NO & & $\mathrm{MA}, \mathrm{H} 2 \mathrm{O}$ \\
\hline 38 & $U-234$ & $\mathrm{pCi}$ & YES & NO & & $\mathrm{MA}, \mathrm{H} 2 \mathrm{O}$ \\
\hline 39 & $U-235$ & $\mathrm{pCi}$ & YES & NO & & $\mathrm{MA}, \mathrm{H} 2 \mathrm{O}$ \\
\hline 40 & $U-236$ & $\mathrm{pCi}$ & YES & : NO & & $\mathrm{MA}, \mathrm{H} 2 \mathrm{O}$ \\
\hline 41 & U-238 & $\mathrm{pCi}$ & YES & $: \quad$ YES & & MA, $\mathrm{H} 2 \mathrm{O}$ \\
\hline 42 & $\mathrm{Zr}-93$ & $p C i$ & YES & YES & & $\mathrm{MA}, \mathrm{H} 2 \mathrm{O}$ \\
\hline
\end{tabular}


TABLE C.1. (contd)

\begin{tabular}{|c|c|c|c|c|c|c|}
\hline \multirow{4}{*}{$\begin{array}{l}\text { ATTRIBUTE } \\
\text { No. } \\
\text { a }===== \pm==\end{array}$} & \multirow{4}{*}{$\begin{array}{c}\text { 5/31/89 Update } \\
\text { ATTRIBLTE DESCRIPTION }\end{array}$} & \multirow{4}{*}{ UNITS OF MEASURE } & \multicolumn{4}{|c|}{ CLASSIFICATIONS OF ATTRIQUTES } \\
\hline & & & \multirow{2}{*}{\multicolumn{2}{|c|}{$\begin{array}{l}\text { APPLICATION TO } \\
\text { DISPOSAL OPTION }\end{array}$}} & \multirow{4}{*}{ 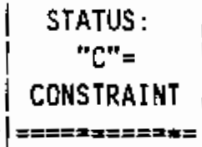 } & \multirow{4}{*}{$\begin{array}{c}\text { SOURCE } \\
\text { CODE } \\
\text { See App B } \\
\text { Sea }==== \pm=\end{array}$} \\
\hline & & & & & & \\
\hline & & & \multirow{2}{*}{ IN-PLACE } & & & \\
\hline$\Rightarrow *==== \pm \approx==-z *==$ & 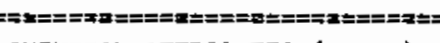 & $==\pi= \pm== \pm x====x===$ & & $x:==== \pm==8$ & & \\
\hline 1.8 & $\begin{array}{l}\text { CHEMICAL ATTRIBUTES (contd) } \\
1.1 .2 \text { Ionic Species }\end{array}$ & & & $:$ & & \\
\hline 43 & A Tuminum & $\mathrm{ppm}$ & NO & YES & & MA, H2O \\
\hline 44 & Arsen ic & pprn & YES & $: \quad$ NO & & $\mathrm{MA}, \mathrm{H} 2 \mathrm{O}$ \\
\hline 45 & Ammonia & ppm & YES & : NO & & $M A, H 2 O$ \\
\hline 46 & Barium & $p p m$ & YES & : NO & & MA, H2O \\
\hline 47 & Bery11ium & $\mathrm{ppm}$ & YES & : NO & & $\mathrm{MA}, \mathrm{H} 2 \mathrm{O}$ \\
\hline 48 & Bismuth & ppon & YES & : NO & & $\mathrm{MA}, \mathrm{H} 2 \mathrm{O}$ \\
\hline 49 & Boron & $\mathrm{ppm}$ & YES & : NO & & $\mathrm{MA}, \mathrm{H} 2 \mathrm{O}$ \\
\hline 50 & Carbonate & $\mathrm{gms} / 1$ & YES & : NO & & $M A, H 2 O$ \\
\hline 51 & Cadmitur & ppn & YES & YES & & $\mathrm{MA}, \mathrm{H} 2 \mathrm{O}$ \\
\hline 52 & Calcium & $\mathrm{ppm}$ & NO & YES & & $\mathrm{MA}, \mathrm{H} 2 \mathrm{O}$ \\
\hline 53 & Chloride & ppm & ผо & YES & & $\mathrm{MA}, \mathrm{H} 2 \mathrm{O}$ \\
\hline 54 & Chromium & $\mathrm{ppm}$ & YES & YES & & $M A, H 2 O$ \\
\hline 55 & Coba?t & ppm & YES & NO & & MA, H2O \\
\hline 56 & Copper & $\mathrm{ppm}$ & YES & YES & & $\mathrm{MA}, \mathrm{H} 2 \mathrm{O}$ \\
\hline 57 & Cyanide & $\mathrm{ppm}$ & YES & YES & & $M A, H 2 O$ \\
\hline 58 & Fluoride & ppm & YES & YES & & $\mathrm{MA}, \mathrm{H} 2 \mathrm{O}$ \\
\hline 59 & Free Hydroxide & $\mathrm{ppm}$ & YES & No & & $\mathrm{MA}, \mathrm{H} 2 \mathrm{O}$ \\
\hline 60 & Hypoch lorite & ppm & YES & NO & & $\mathrm{MA}, \mathrm{H} 2 \mathrm{O}$ \\
\hline 61 & I ron & ppm & YES & YES & & $\mathrm{MA}, \mathrm{H} 2 \mathrm{O}$ \\
\hline 62 & Lead & ppm & YES & HO & & $\mathrm{MA}, \mathrm{H} 2 \mathrm{O}$ \\
\hline 63 & Magnesium & ppm & YES & HO & & $\mathrm{MA}, \mathrm{H} 2 \mathrm{O}$ \\
\hline 64 & Manganese & ppm & YES & YES & & MA. H2O \\
\hline 65 & Mercury & ppin & YES & YES & & $\mathrm{MA}, \mathrm{H} 2 \mathrm{O}$ \\
\hline 66 & Hickel & ppm & YES & YES & & $\mathrm{MA}, \mathrm{H} 2 \mathrm{O}$ \\
\hline 67 & MoTybdenum & ppm & YES & NO & & $\mathrm{MA}, \mathrm{H} 2 \mathrm{O}$ \\
\hline 68 & Nitrate & $\mathrm{ppm}$ & YES & YES & & $\mathrm{MA}, \mathrm{H} 2 \mathrm{O}$ \\
\hline 69 & Nitrite & ppm & YES & YES & & MA, H2O \\
\hline 70 & Phosphorus & ppm & YES & YES & & $\mathrm{MA}, \mathrm{H} 2 \mathrm{O}$ \\
\hline 71 & Potassium & $\mathrm{ppm}$ & YES & No & & $M A, H 2 O$ \\
\hline 72 & Selenium & ppm & YES & YES & & $\mathrm{MA}, \mathrm{H} 2 \mathrm{O}$ \\
\hline 73 & Silicon & ppm & NO & YES & & $M A, H 2 O$ \\
\hline 74 & Silver & $\mathrm{ppm}$ & YES & NO & & $\mathrm{MA}, \mathrm{H} 2 \mathrm{O}$ \\
\hline 75 & Sodium & ppm & YES & YES & & MA, $\mathrm{H} 2 \mathrm{O}$ \\
\hline 76 & Stront ium & $\mathrm{ppm}$ & YES & NO & & $\mathrm{MA}, \mathrm{H} 2 \mathrm{O}$ \\
\hline 77 & Sulfate & ppm & YES & YES & & $\mathrm{MA}, \mathrm{H} 2 \mathrm{O}$ \\
\hline 78 & Sulfite & pa़ा & YES & NO & & $\mathrm{MA}, \mathrm{H} 2 \mathrm{O}$ \\
\hline 79 & Titanium & $\mathrm{ppm}$ & YES & No & & $\mathrm{MA}, \mathrm{H} 2 \mathrm{O}$ \\
\hline 80 & Uranium & ugm/gm & YES & YES & & $\mathrm{MA}, \mathrm{H} 2 \mathrm{O}$ \\
\hline 81 & Vanadium & $\mathrm{ppm}$ & YES & NE & & MA, $\mathrm{H} 2 \mathrm{O}$ \\
\hline 82 & Zinc & $\mathrm{ppm}$ & YES & NO & & $\mathrm{MA}, \mathrm{H} 2 \mathrm{O}$ \\
\hline 83 & Zirconium & $\mathrm{ppm}$ & YES & No & & $\mathrm{MA}, \mathrm{H} 2 \mathrm{O}$ \\
\hline 84 & Tota1 Organo-Ha] ides (TOX) & $g / 1$ & YES & NO & & MA, H2O \\
\hline 85 & TOX Species Identification & $\%$ & YES & NO & & MA, $\mathrm{H} 2 \mathrm{O}$ \\
\hline 86 & Tota 1 Organic Carbon (TOC) & $g / 1$ & YES & YES & & $\mathrm{MA}, \mathrm{H} 2 \mathrm{O}$ \\
\hline 87 & TOC Species Identification & $\%$ & YES & YES & & MA, H2O \\
\hline
\end{tabular}




\section{TABLE C.1. (contd)}

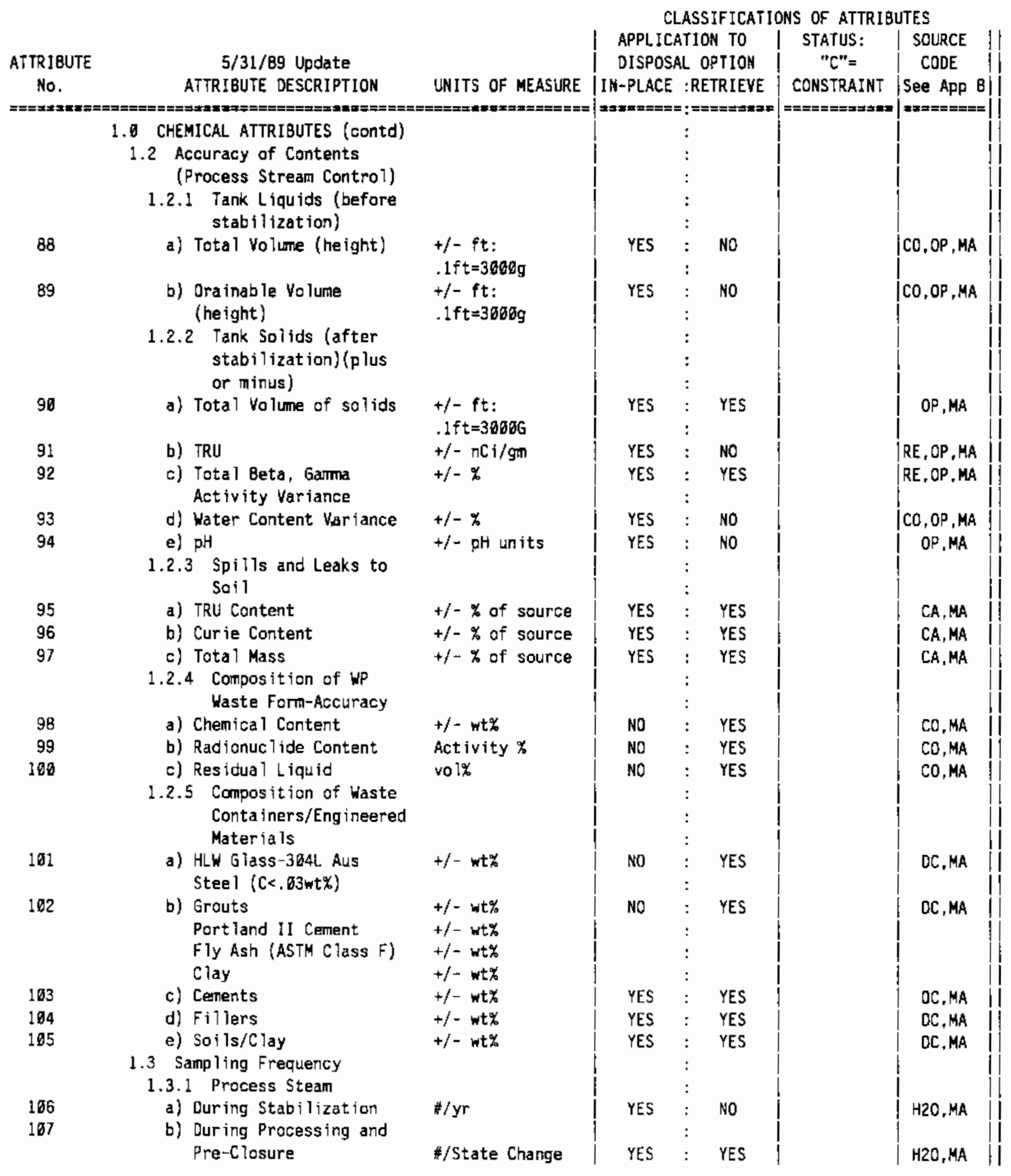


TABLE C.1. (contd)

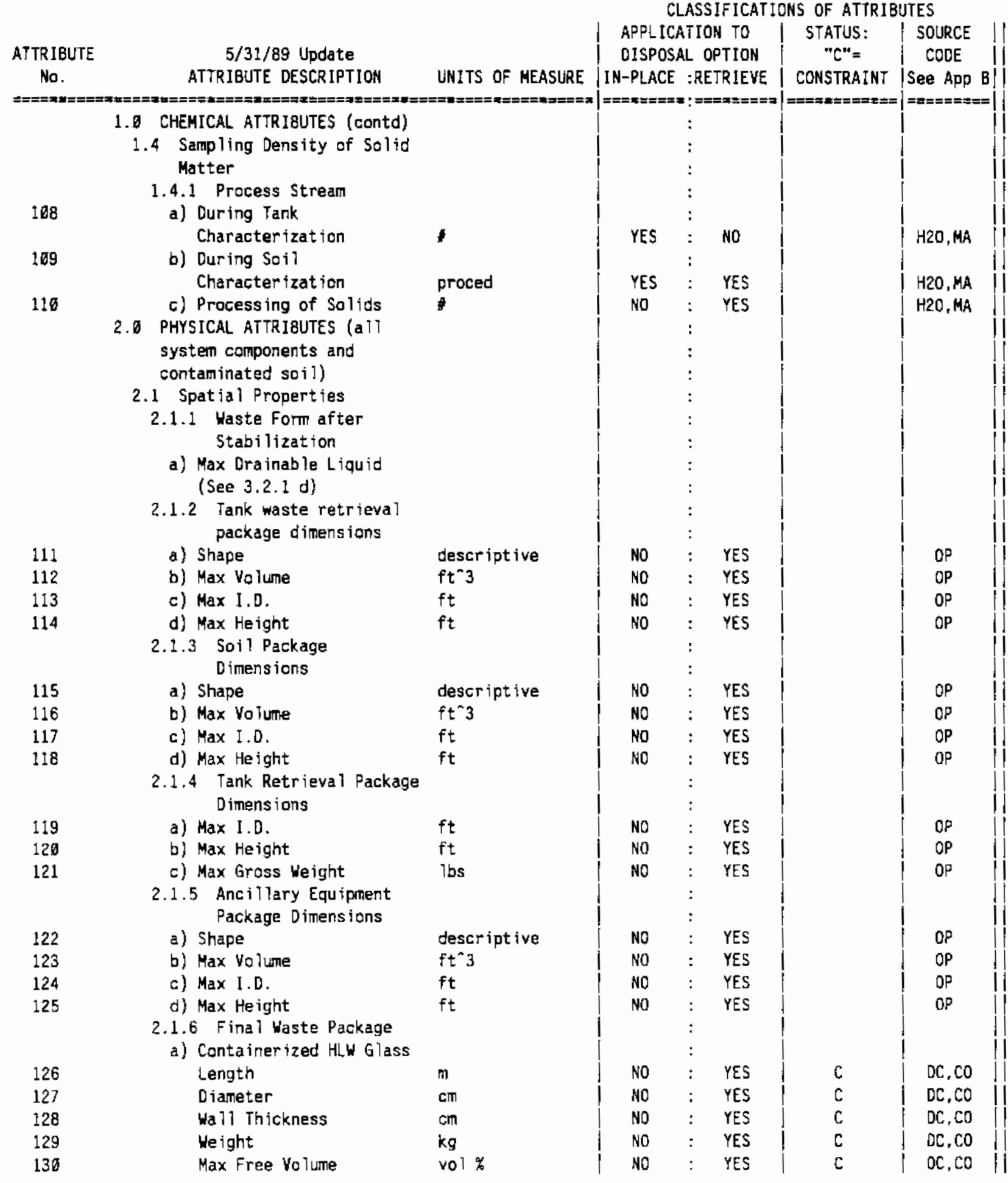


IABLE C.1. (contd)

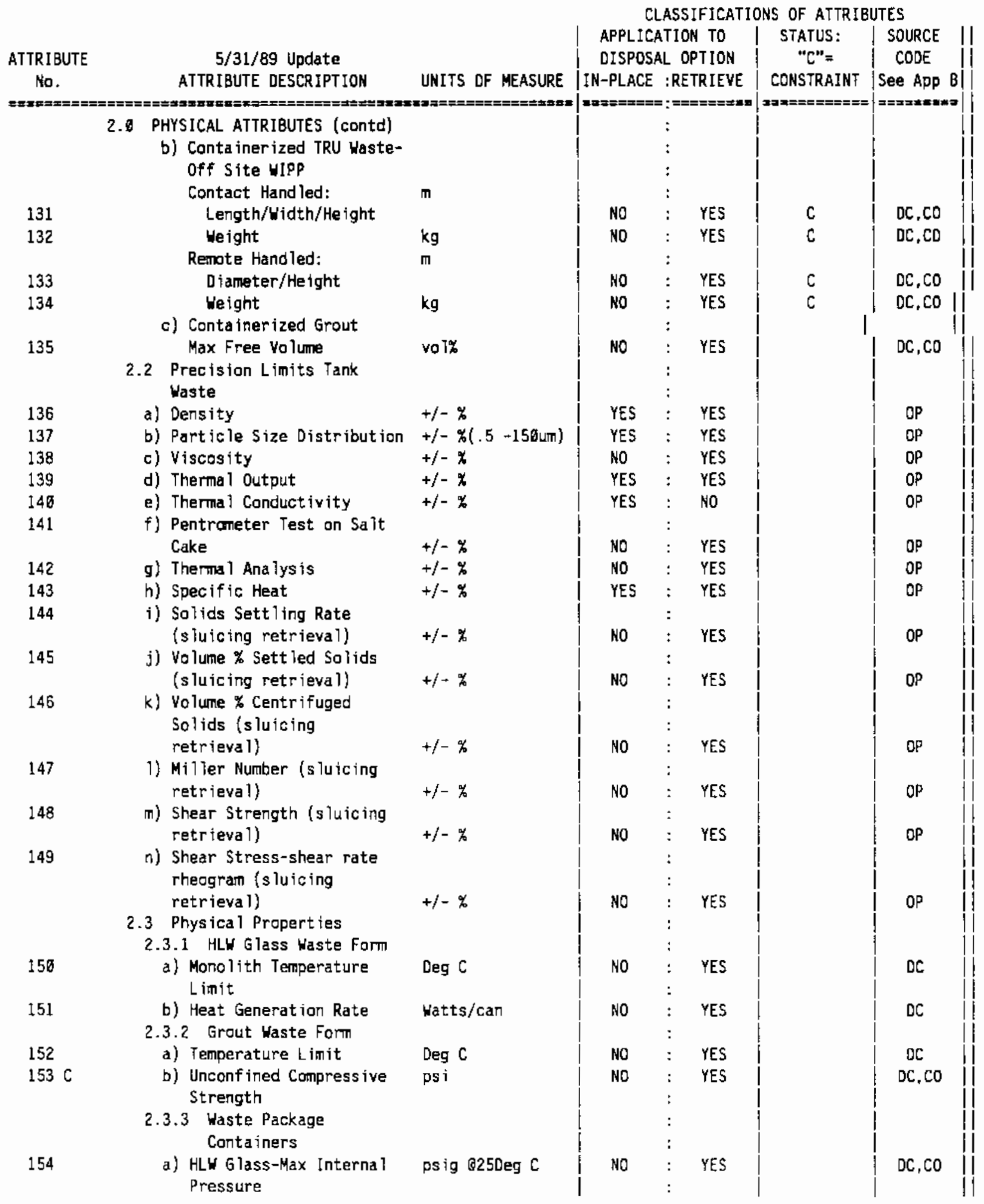




\section{IABLE C.1. (contd)}

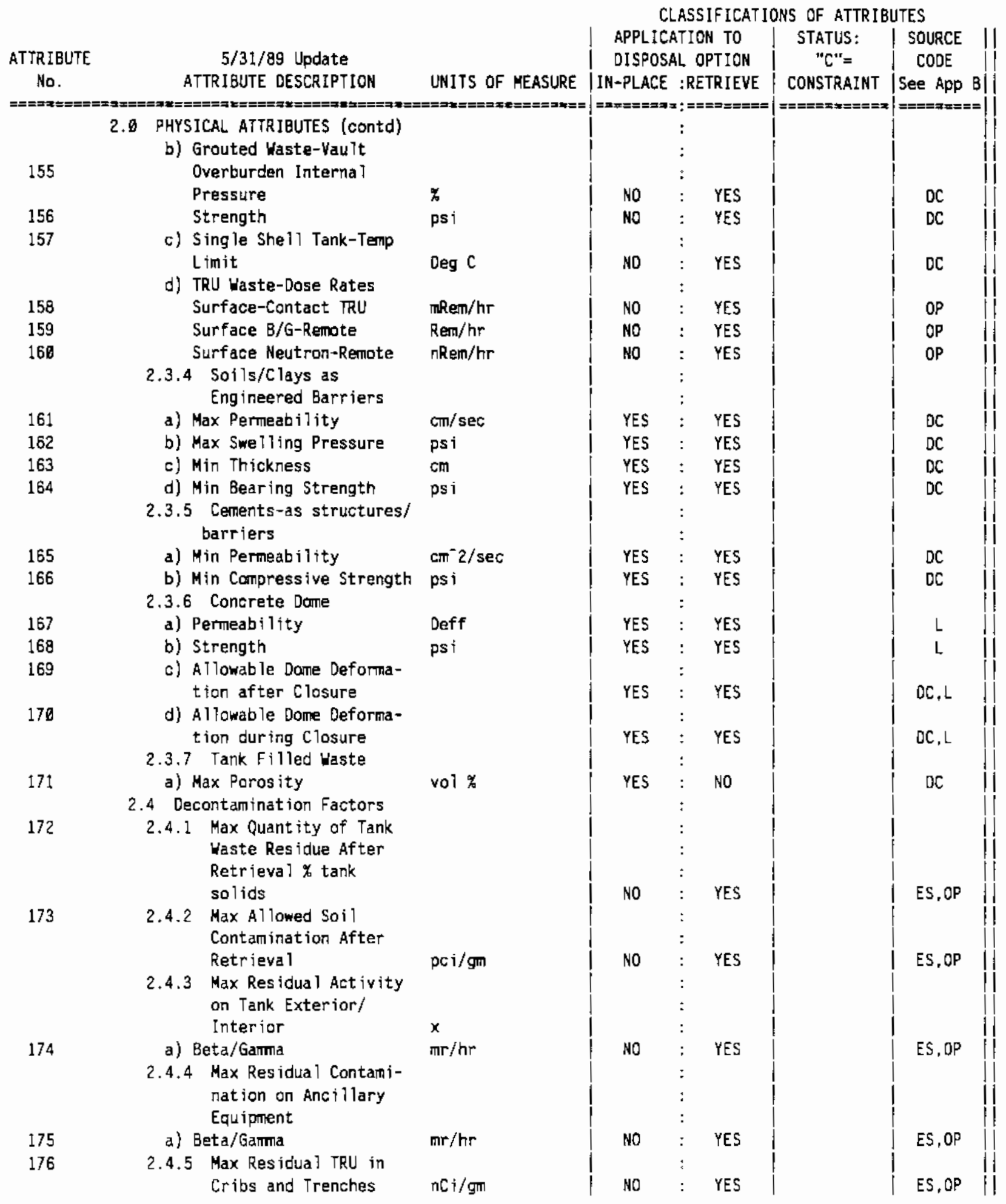


IABLE C.1. (contd)

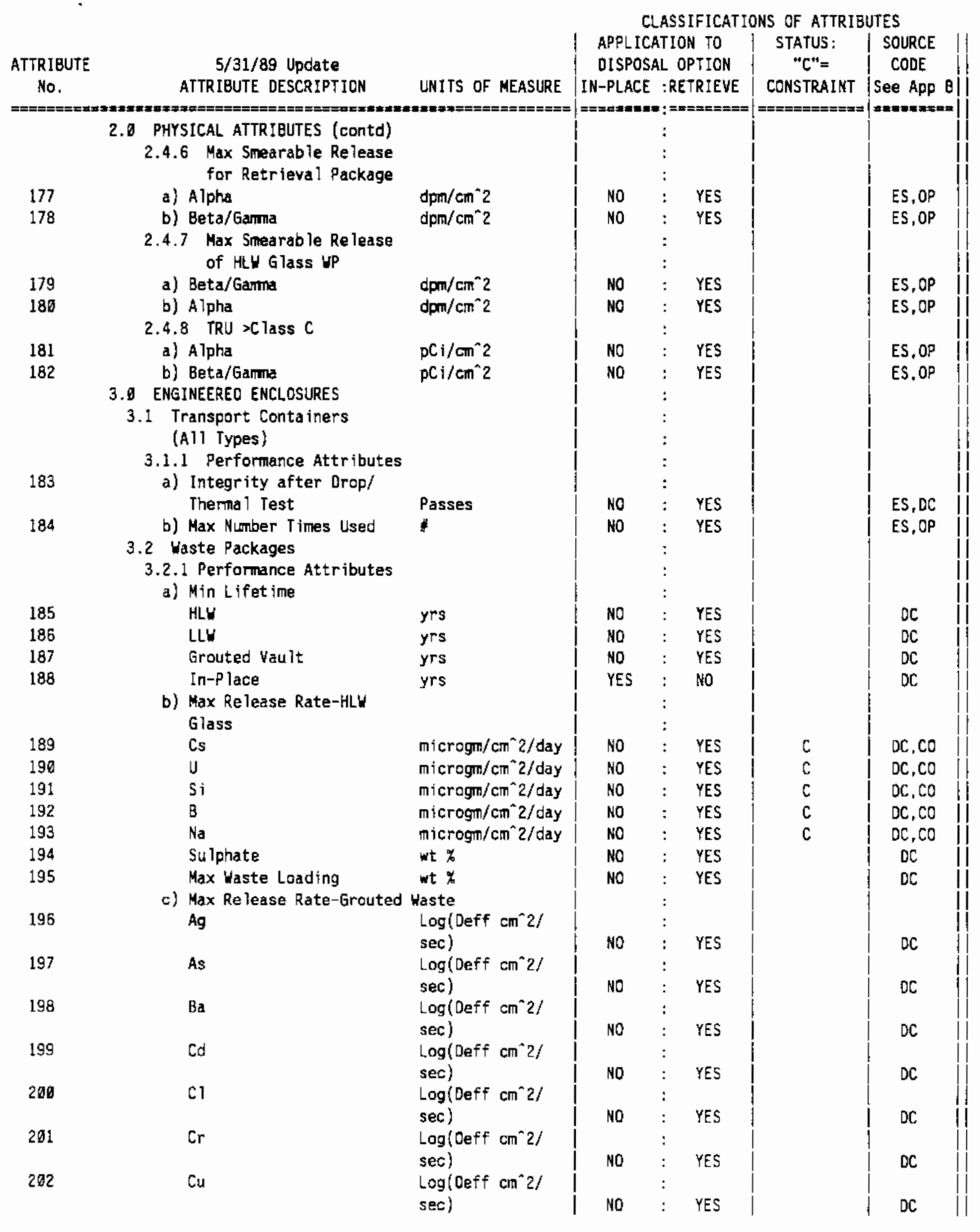


IABLE C.1. (contd)

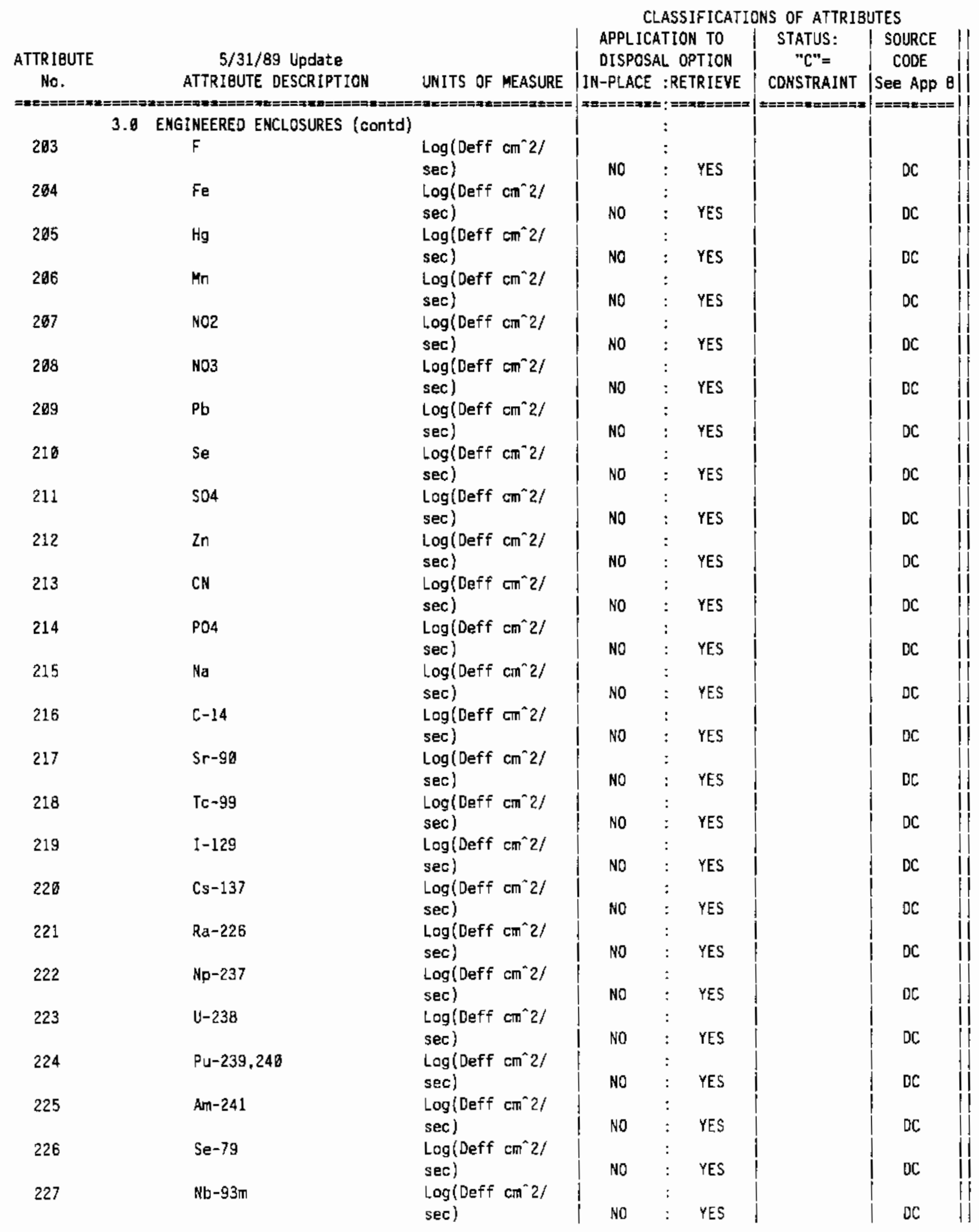


TABLE C.1. (contd)

\begin{tabular}{|c|c|c|c|c|c|c|}
\hline \multirow{5}{*}{ 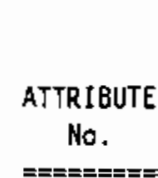 } & & & \multicolumn{4}{|c|}{ CLASSIFICATIONS OF ATTRIBUTES } \\
\hline & & \multirow{4}{*}{ 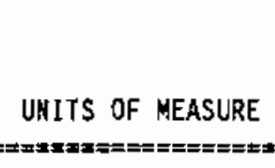 } & \multirow{4}{*}{\multicolumn{2}{|c|}{ 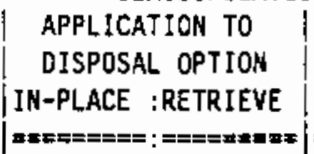 }} & \multirow{4}{*}{$\begin{array}{c}\text { STATUS: } \\
\text { "C"= } \\
\text { CONSTRAINT } \\
======== \pm \approx\end{array}$} & \multirow{4}{*}{$\begin{array}{c}\text { SOURCE } \\
\text { CODE } \\
\text { See App B } \\
==\pi \approx=x==\end{array}$} \\
\hline & 5/31/89 Update & & & & & \\
\hline & ATTRIBUTE DESCRIPTION & & & & & \\
\hline & 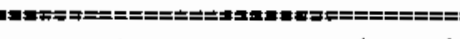 & & & & & \\
\hline & ENGINEERED ENCLOSURES (contd) & & & : & & \\
\hline 228 & Co-60 & $\log \left(\right.$ Deff $\left.\mathrm{cm}^{n} 2\right)$ & & : & & \\
\hline & & sec) & NO & YES & & $D C$ \\
\hline 229 & Ru-106 & $\log \left(\right.$ Deff $\left.\mathrm{cm}^{+} 2\right)$ & & : & & \\
\hline & & $\mathrm{sec})$ & ND & : YES & & DC \\
\hline 230 & Sb-126m & $\log \left(\right.$ Deff $\left.\mathrm{cm}^{\wedge} 2\right)$ & & : & & \\
\hline & & & No & YES & & $D C$ \\
\hline 231 & $C s-135$ & $\log \left(\right.$ Deff $\left.\mathrm{cm}^{*} 2\right)$ & & : & & \\
\hline & & sec) & No & YES & & $O C$ \\
\hline 232 & Ce-144 & $\log \left(\right.$ Deff $\mathrm{cm}^{\wedge} 2$ ) & & : & & \\
\hline & & sec) & NO & YES & & $D C$ \\
\hline 233 & Pu-241 & Log(Deff $\left.\mathrm{cm}^{*} 2\right)$ & & : & & \\
\hline & & sec) & NO & YES & & $D C$ \\
\hline 234 & $5 m-151$ & $\log \left(\right.$ Deff $\left.\mathrm{cm}^{\wedge} 2\right)$ & & : & & \\
\hline & & sec) & NO & YES & & DC \\
\hline 235 & $\mathrm{Ba}-137 \mathrm{~m}$ & $\log \left(\right.$ Deff $\left.\mathrm{cm}^{-2} 2\right)$ & & : & & \\
\hline & & $\mathrm{sec})$ & NO & YES & & DC \\
\hline 236 & $S n-126$ & $\log \left(\right.$ Deff $\operatorname{cm}^{\wedge} 2 /$ & & : & & \\
\hline & & $\mathrm{sec})$ & No & YES & & $D C$ \\
\hline 237 & $2 r-93$ & $\log \left(\right.$ Deff $\mathrm{cm}^{\wedge} 2 /$ & & : & & \\
\hline & & sec) & NO & YES & & $D C$ \\
\hline 238 & $\mathrm{Ni}-63$ & $\log \left(\operatorname{Deff} \mathrm{cm}{ }^{\wedge} 2 /\right.$ & & : & & \\
\hline & & sec) & NO & YES & & $D C$ \\
\hline 239 & $\mathrm{Cm}-242$ & Log(Beff $\left.\mathrm{cm}^{`} 2\right)$ & & : & & \\
\hline & & sec) & No & YES & & $\mathrm{OC}$ \\
\hline 240 & TOC Content & wt $\%$ & No & YES & & $D C$ \\
\hline 241 & Residual/Free Water & vol $\%$ & NO & YES & & $D C$ \\
\hline 242 & Ten min Gel Strength & $1 \mathrm{bs} / \mathrm{ft}^{\wedge} 2$ & NO & YES & & OC \\
\hline 243 & Critical Flow & $\mathrm{ga} 1 / \mathrm{min}$ & No & YES & & DC \\
\hline 244 & 30 Themal Cycles & ASTM test & NO & YES & & $D C$ \\
\hline 245 & B todegradation & ASTM test & \$0 & YES & & $D C$ \\
\hline & d) Max Release Rate & & & $:$ & & \\
\hline & In-Tank Waste Package & & & : & & \\
\hline 246 & Residual Water (up to & & & : & & \\
\hline & $300 \operatorname{deg} F)$ & vol $\%$ & YES & NO & & $\mathrm{CO}, \mathrm{DC}$ \\
\hline 247 & Total Organ ic Carbon & $\%$ & YES & NO & & $D C$ \\
\hline 248 & $\mathrm{Ag}$ & $g / \pi^{\wedge} 3$ & YES & : No & & $D C$ \\
\hline 249 & As & $g / m 3$ & YES & : NO & & $D C$ \\
\hline 250 & $B a$ & $g / \pi^{\wedge} 3$ & YES & : NO & & $O C$ \\
\hline 251 & $\mathrm{Cd}$ & $g / m^{3} 3$ & YES & : NO & & $O C$ \\
\hline 252 & C1 & $9 / m^{*} 3$ & YES & : NO & & $\mathrm{DC}$ \\
\hline 253 & $\mathrm{Cr}$ & $g / m^{3} 3$ & YES & ; NO & & OC \\
\hline 254 & $\mathrm{Cu}$ & $g / \pi^{\wedge} 3$ & YES & $: \quad$ NO & & $D C$ \\
\hline 255 & F & $g / \pi^{\wedge} 3$ & YES & : NO & & $D C$ \\
\hline 256 & $\mathrm{Fe}$ & $\mathrm{g} / \mathrm{m}^{\wedge} 3$ & YES & : No & & $\mathrm{OC}$ \\
\hline 257 & $\mathrm{Hg}$ & $g / \pi^{\wedge} 3$ & YES & NO & & $D C$ \\
\hline 258 & $M n$ & $g / \pi^{3} 3$ & YES & : ND & & $\mathrm{OC}$ \\
\hline 259 & NO2 & $g / m^{\wedge} 3$ & YES & : NO & & $\mathrm{DC}$ \\
\hline 260 & N03 & $g / \pi^{\wedge} 3$ & YES & : NO & & $D C$ \\
\hline 261 & $\mathrm{~Pb}$ & $g / \pi^{3} 3$ & YES & $:$ NO & & OC \\
\hline 262 & $\mathrm{Se}$ & $g / m \wedge 3$ & YES & : NO & & $D C$ \\
\hline
\end{tabular}


IABLE C.1. (contd)

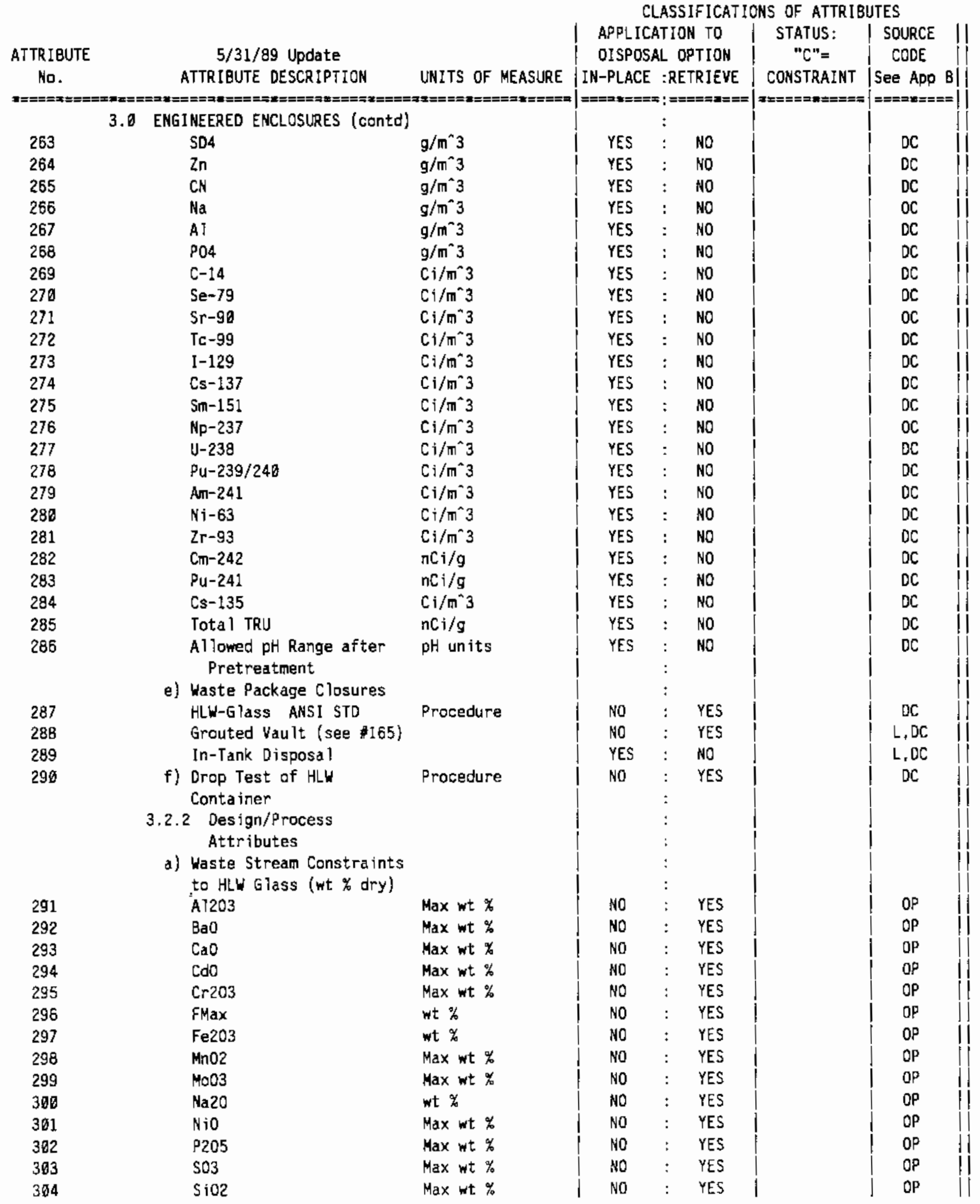


TABLE C.1. (contd)

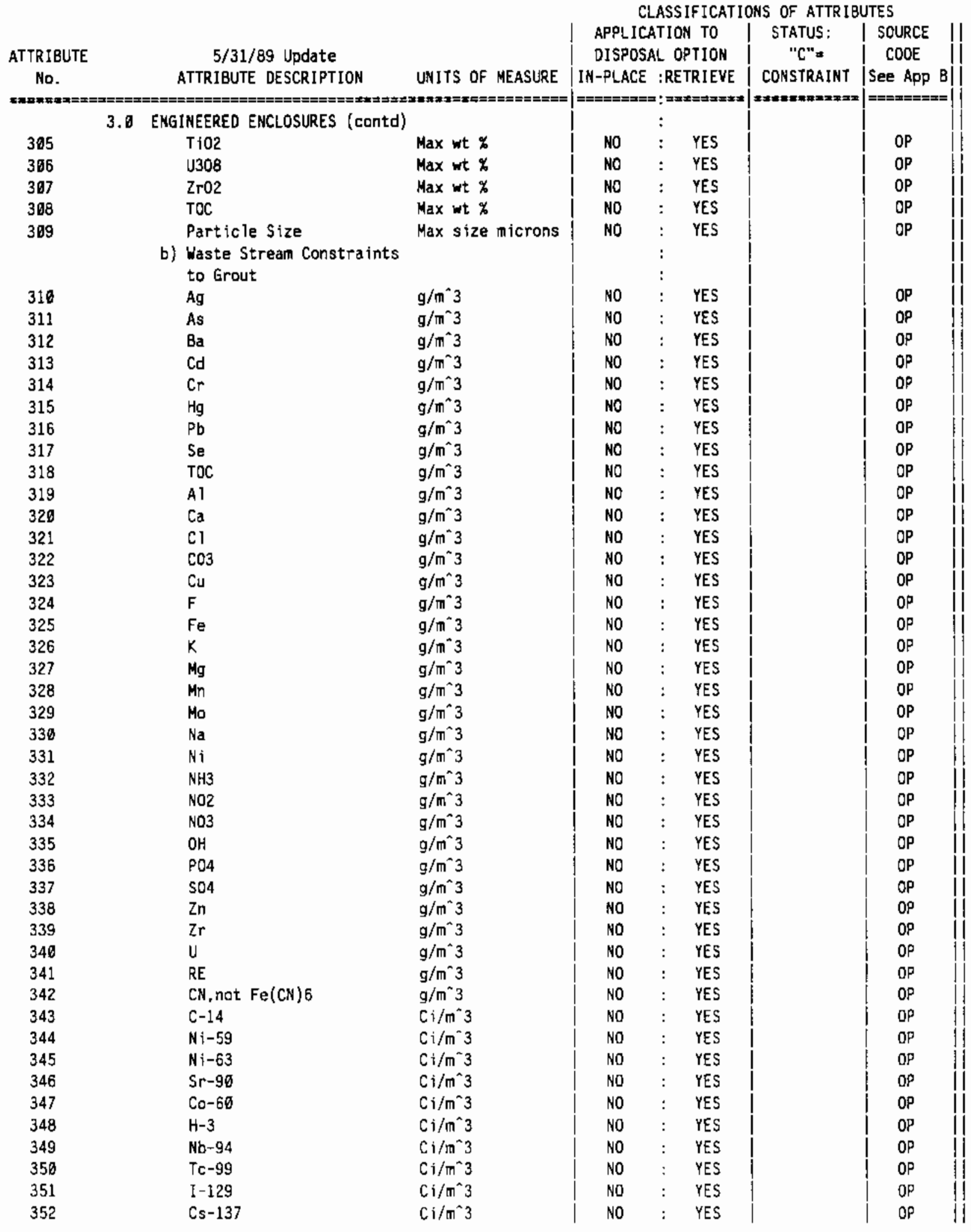


IABLE C.1. (contd)

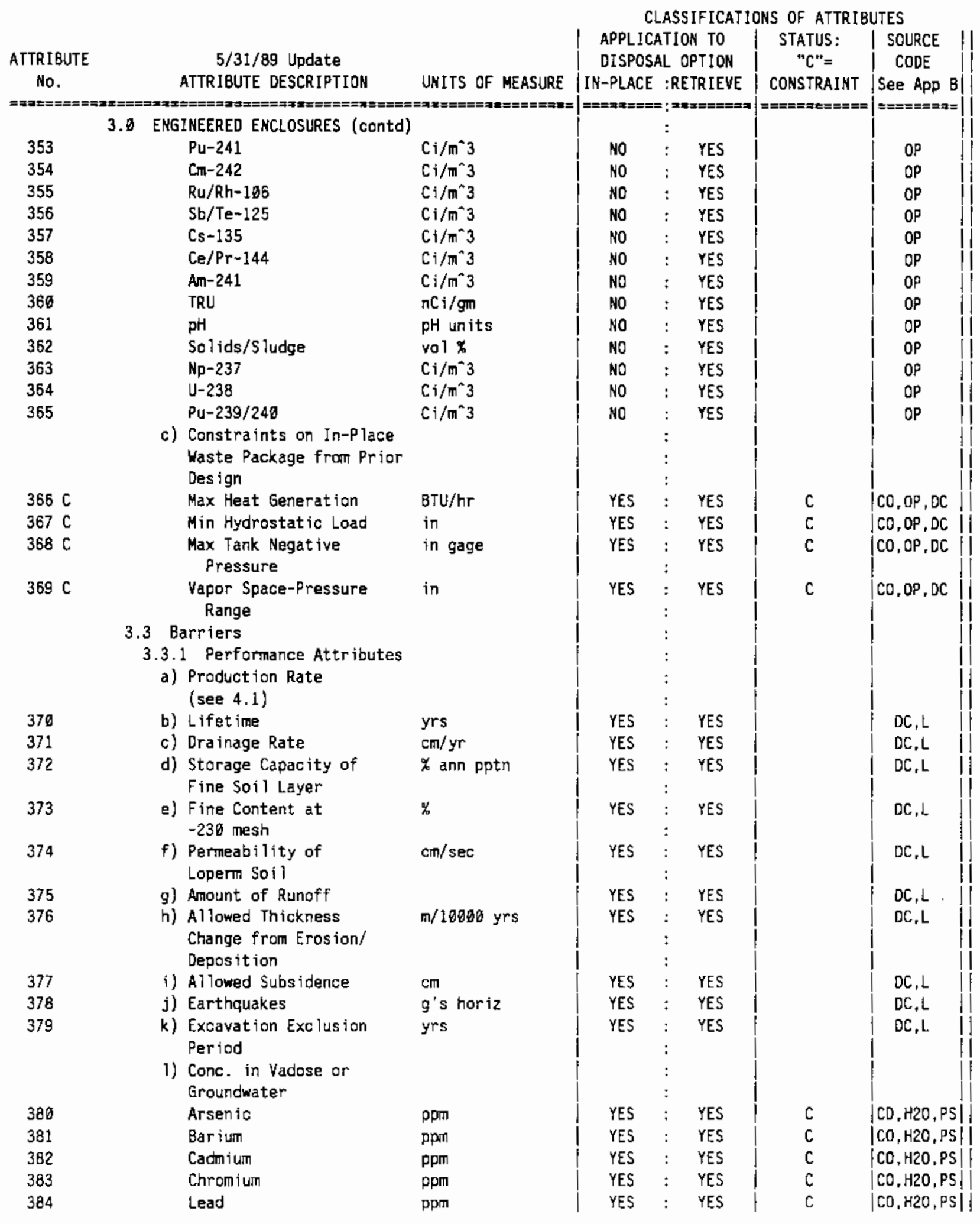


TABLE C.1. (contd)

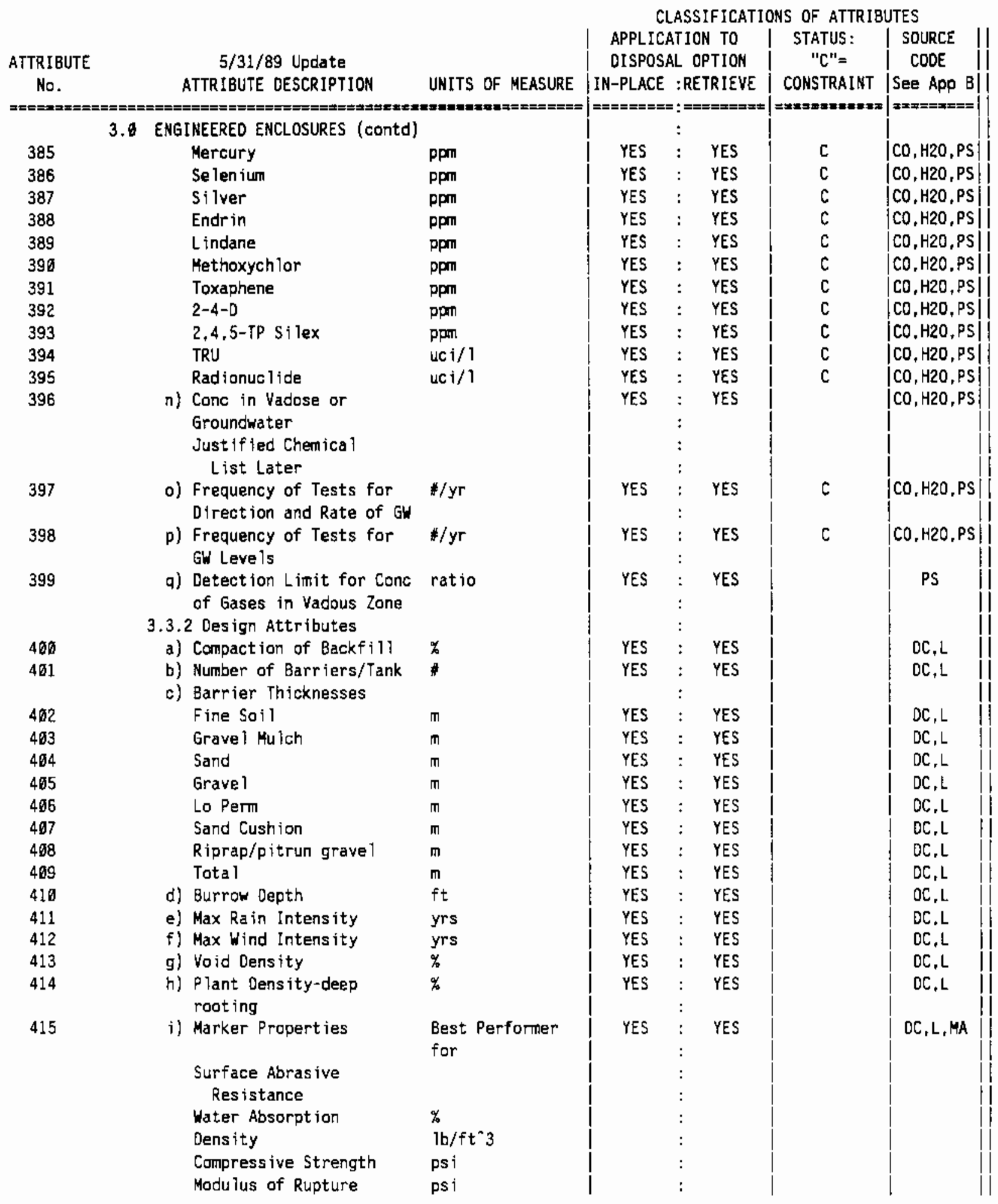


TABLE C.1. (contd)

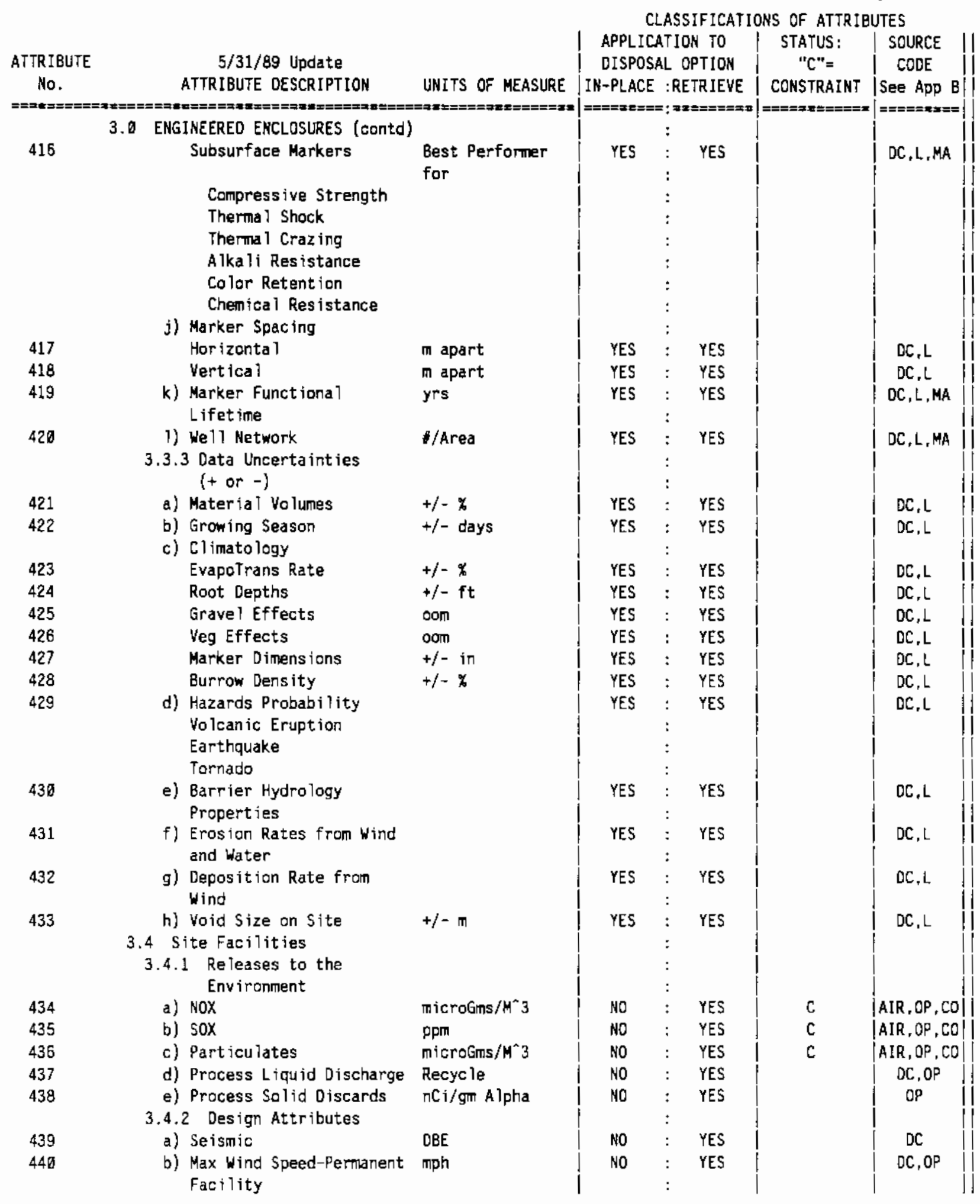

C. 16 
TABLE C.1. (contd)

\begin{tabular}{|c|c|c|c|c|c|c|}
\hline \multirow{4}{*}{$\begin{array}{l}\text { ATTR IBUTE } \\
\text { No. }\end{array}$} & \multirow{4}{*}{$\begin{array}{l}\text { 5/31/89 Update } \\
\text { ATTRIBUTE DESCRIPTION }\end{array}$} & \multirow[b]{4}{*}{ UNITS OF MEASURE } & \multicolumn{4}{|c|}{ CLASSIFICATIONS OF ATTRIBUTES } \\
\hline & & & \multirow{3}{*}{\multicolumn{2}{|c|}{ 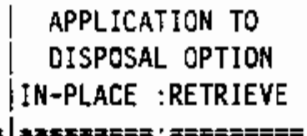 }} & \multirow{3}{*}{$\begin{array}{l}\text { STATUS: } \\
\text { "C" }= \\
\text { CON5TRAINT }\end{array}$} & \multirow{3}{*}{$\begin{array}{c}\text { SOURCE } \\
\text { CODE } \\
\text { See ApP B } \\
========\end{array}$} \\
\hline & & & & & & \\
\hline & & & & & & \\
\hline & 3.0 ENGIMEERED ENCLOSURES (contd) & & & $: \quad$ & & \\
\hline 441 & $\begin{array}{l}\text { c) Max wind Speed- } \\
\text { Transportable Facility } \\
\text { during op'ns }\end{array}$ & mph & NO & $\begin{array}{ll}: & \text { YES } \\
: & \end{array}$ & & $D C$ \\
\hline 442 & d) Factlity Operating Life & yrs & No & YES & & $D C$ \\
\hline 443 & e) Post-c losure Life & yrs & NO & YES & & DC \\
\hline & $\begin{array}{l}4.9 \text { OPERATING ATTRIBUTES } \\
\text { (Retrieve, Pretreat, waste } \\
\text { Package, On-site 8urial) }\end{array}$ & & & & & \\
\hline & $\begin{array}{l}\text { 4.1 Production/Process Rates } \\
\text { (System Level Dnly) }\end{array}$ & & & $\begin{array}{l}: \\
:\end{array}$ & & \\
\hline 444 & 4.1.1 Mean Disposition Rate & Tanks/yr & ND & YE5 & & $O P, R B C$ \\
\hline 445 & $\begin{array}{l}4.2 \text { Min In-Process Storage } \\
\text { Times }\end{array}$ & yrs & No & YES & & $\mathrm{OP}, \mathrm{RBC}$ \\
\hline & $\begin{array}{l}\text { 4.3 Process Water Utilization } \\
\text { Mgmit }\end{array}$ & & & $\begin{array}{l}: \\
:\end{array}$ & & \\
\hline 446 & 4.3.1 Retrieva 1 Output/Input & Fraction & No & YES & & $O P, R B C$ \\
\hline 447 & $\begin{array}{l}\text { 4.3.2 Processing Output/ } \\
\text { Input }\end{array}$ & Fraction & NO & YES & & OP.RBC \\
\hline 448 & $\begin{array}{l}4.3 .3 \text { Waste Packaging } \\
\text { Output/Input }\end{array}$ & Fraction & No & YES & & OP, RBC \\
\hline & 4.4 Acceptance Criteria & & & : & & \\
\hline & 4.4.1 Retrieval Package & & & : & & \\
\hline 449 & $\begin{array}{l}\text { a) Max Thermal Content/ } \\
\text { Package }\end{array}$ & Kw & NO & YES & & OP \\
\hline 450 & $\begin{array}{l}\text { b) Max Mass Content/Package } \\
4.5 \text { Process Separations }\end{array}$ & Kgs & NO & YES & & OP \\
\hline & 4.5.1 Species in Glass & & & : & & \\
\hline & Stream after & & & : & & \\
\hline & Pretreatment & & & : & & \\
\hline 451 & a) NaFrac of Input & & No & YES & & $O P, R 8 C$ \\
\hline 452 & b) $\mathrm{Al}, \mathrm{Fe}$ & Frac of Input & No & YES & & $O P, R B C$ \\
\hline 453 & c) SiFrac of Input & & No & YES & & $\mathrm{OP}, \mathrm{RBC}$ \\
\hline 454 & d) U Frac of Input & & NO & YES & & $O P, R B C$ \\
\hline 455 & e) $70 \mathrm{C}$. inc $1 \mathrm{CN}$ & Frac of Input & NO & YES & & $O P, R B C$ \\
\hline & $\begin{array}{l}\text { 4.5.2 Species in Grout } \\
\text { Stream after }\end{array}$ & & & & & \\
\hline & Pretreatme & & & : & & \\
\hline 456 & a) NaFrac of Input & & NO & YES & & $O P, R B C$ \\
\hline 457 & b) $\mathrm{NO}^{2}$ & Frac of Input & NO & YES & & $\mathrm{OP}, \mathrm{RBC}$ \\
\hline 458 & c) $C-14$ & Frac of Input & NO & YES & & $O P, R B C$ \\
\hline 459 & d) $N i-63$ & Frac of Input & NO & YES & & $\mathrm{OP}, \mathrm{RBC}$ \\
\hline 460 & e) $5 r-90$ & Frac of Input & NO & YES & & $O P, R B C$ \\
\hline 461 & f) Tc-99 & Frac of Input & NO & YES & & $\mathrm{OP}, \mathrm{RBC}$ \\
\hline 462 & g) $1-129$ & Frac of Input & NO & : YES & & $O P, R B C$ \\
\hline 463 & h) $\mathrm{Cs}-137$ & Frac of Input & NO & YES & & $\mathrm{OP}, \mathrm{RBC}$ \\
\hline 464 & i) U-235, 238 & Frac of Input & NO & YES & & $\mathrm{OP}, \mathrm{RBC}$ \\
\hline 465 & j) $\mathrm{Np}-237$ & Frac of Input & NO & YES & & $O P, R B C$ \\
\hline 466 & k) $P u-239.249$ & Frac of Input & NO & YES & & $\mathrm{OP}, \mathrm{RBC}$ \\
\hline 467 & 1) $A m-241$ & Frac of Input & NO & YES & & $O P, R B C$ \\
\hline
\end{tabular}


IABLE C.1. (contd)

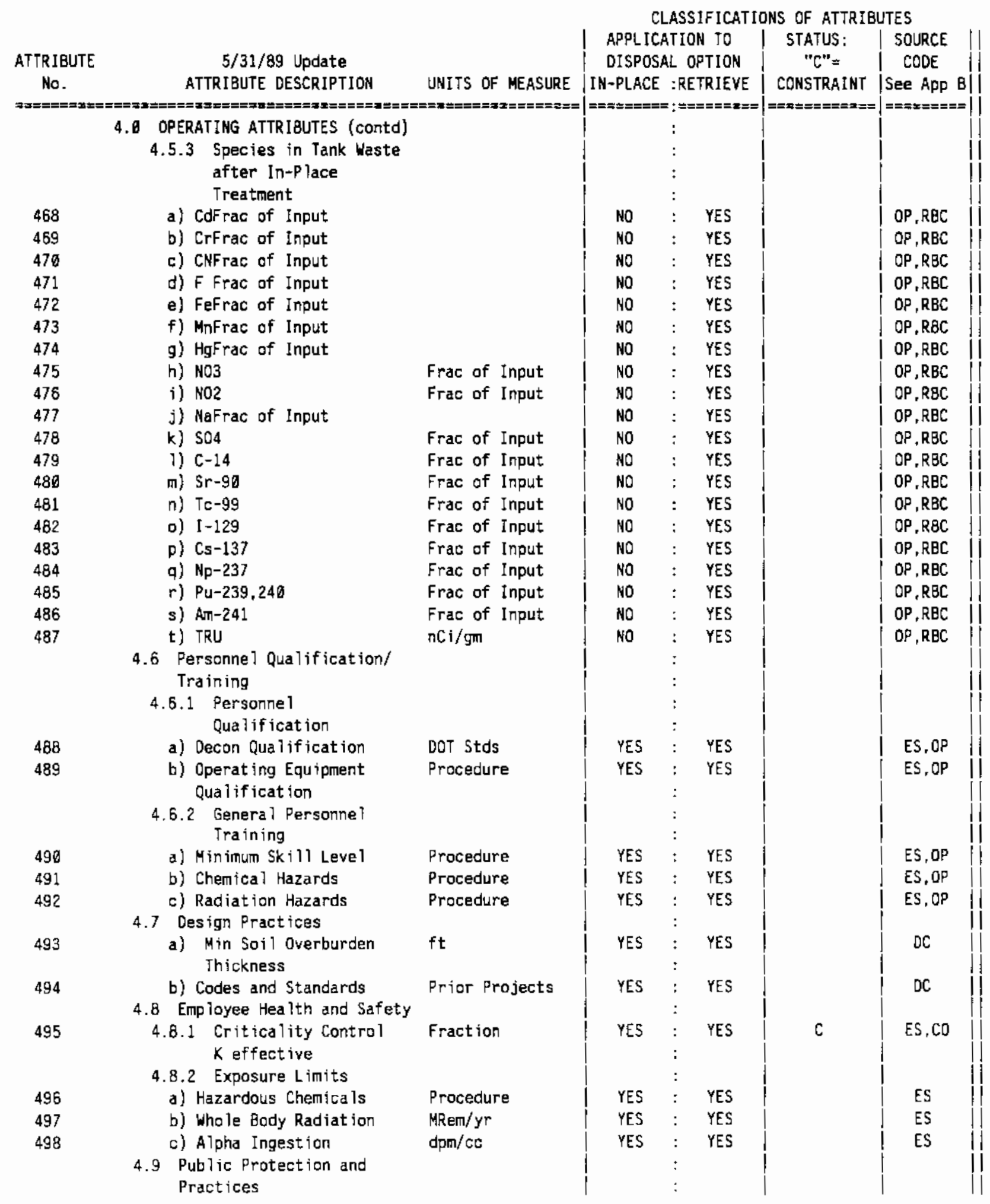


TABLE C.1. (contd)

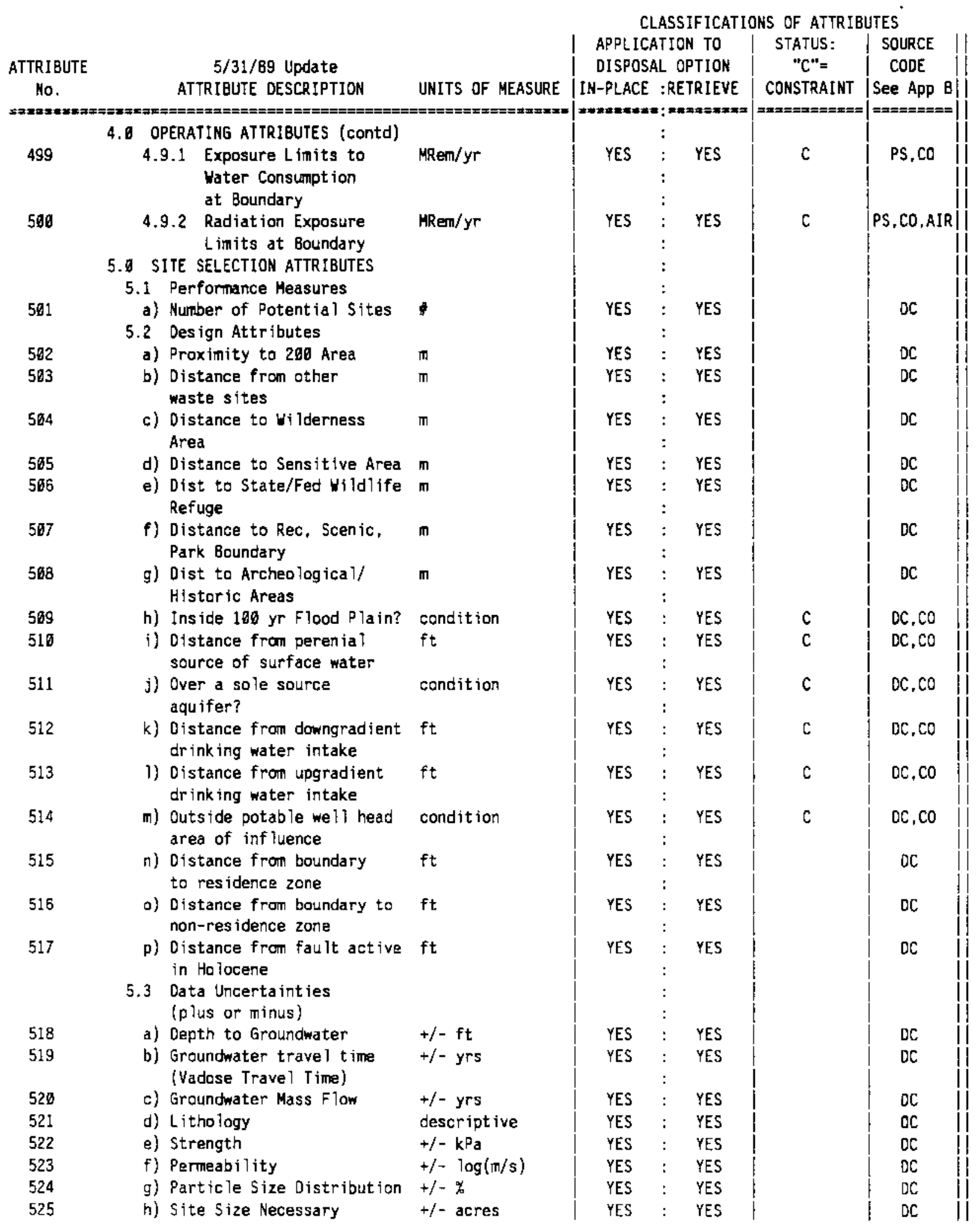


IABLE C.1. (contd)

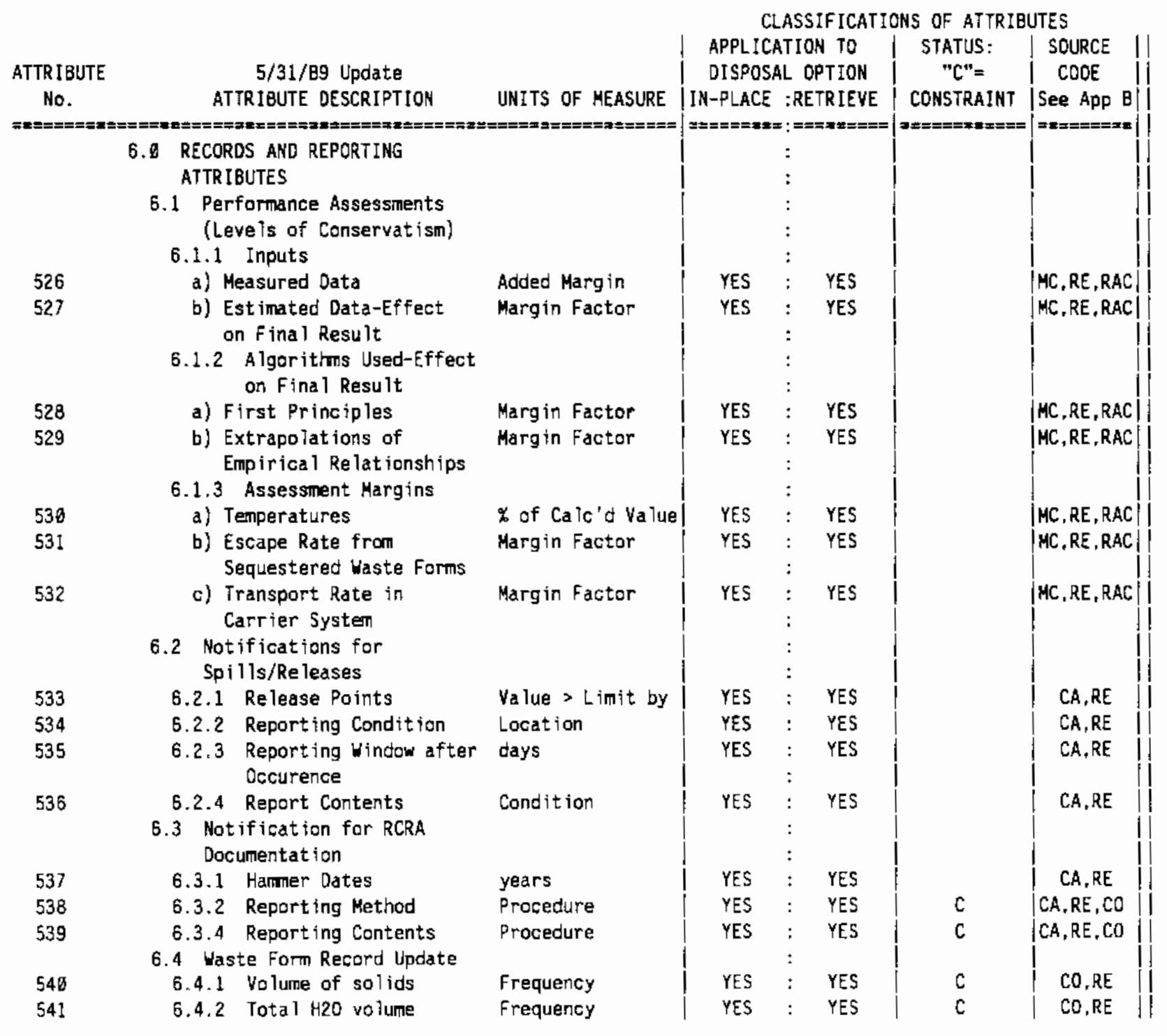




\section{TABLE C.2. Listing of Rankings of Attributes by Function}

ATTRIBUTE

No.

ATTRIBUTE OESCRIPTION
RANKINGS BY FUNCTION

1100120013001400150016001700 NUMBER

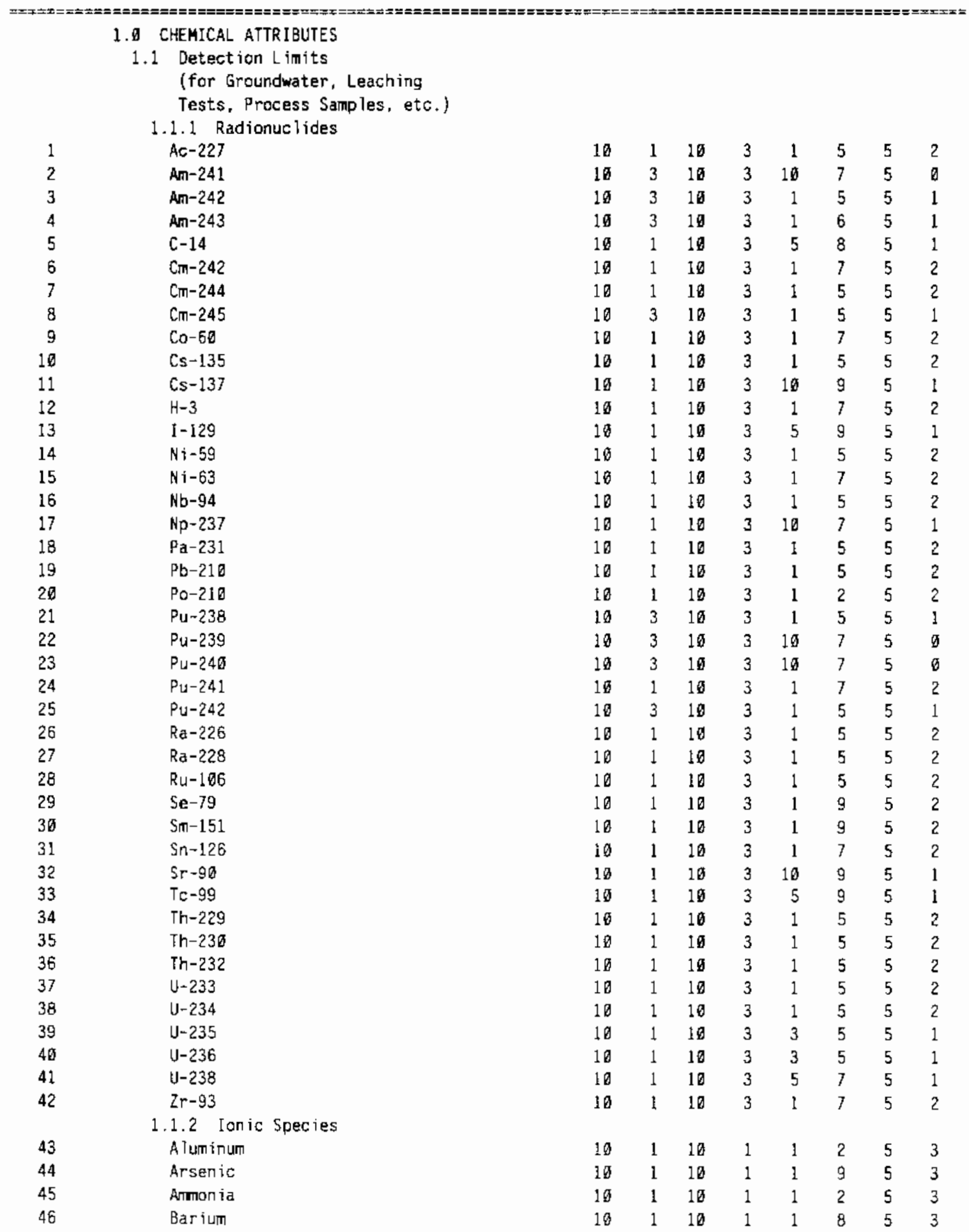


IABLE C.2. (contd)

ATTRIBUTE

RANKINGS BY FUNCTION

No.

ATTRIBUTE DESCRIPTION

$1100120013001400 \quad 150016801760$ NUMBER

A

47

48

49

50

51

52

53

54

55

56

57

58

59

60

61

62

63

64

65

66

67

68

69

79

71

72

73

74

75

76

77

78
1.ஏ CHEMICAL, ATTRIBUTES (contd)

Beryilium

Boron

Carbonate

Cadmium

Calc ium

Chloride

Chromium

Cobalt.

Copper

Cyanide

Fluoride

Free Hydroxide

Hypoch lor ite

Iron

Lead

Magnes ium

Manganese

Mercury

Nickel

Mo lybdenum

Nitrate

Nitrite

Phosphorus

Potass ium

Se 7enium

Silican

Silver

Sodium

Stront ium

Sulfate

Sulfite

Titanium

Uranium

Vanadium

Zinc

Zirconium

Total Organo-Halides(TO)

Tox Species Identification

Total Organic Carbon (TOC)

TOC Species Ident ification

1.2 Accuracy of Contents (Process Stream Contro?)

1.2.1 Tank Liquids (before stabilization)

a) Total volume (height)

b) Drainable volume (height) $\begin{array}{llllllll}10 & 1 & 10 & 1 & 1 & 2 & 5 & 3\end{array}$

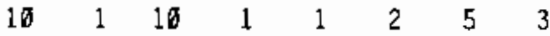

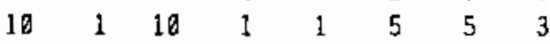

$\begin{array}{llllllll}10 & 1 & 10 & 1 & 1 & 5 & 5 & 3\end{array}$

$\begin{array}{llllllll}10 & 1 & 10 & 1 & 1 & 9 & 5 & 3\end{array}$

$\begin{array}{llllllll}10 & 1 & 10 & 1 & 1 & 2 & 5 & 3\end{array}$

$10 \quad 1 \quad 10 \quad 1 \quad 5 \quad 5 \quad 52$

101110101502

$101010101010 \begin{array}{lllll}10 & 1 & 1 & 5 & 3\end{array}$

$10 \quad 1 \quad 10 \quad 1 \quad 10 \begin{array}{lllll}10 & 5 & 5 & 3\end{array}$

$\begin{array}{llllllll}10 & 1 & 10 & 1 & 7 & 9 & 5 & 2\end{array}$

$\begin{array}{llllllll}10 & 1 & 10 & 1 & 5 & 7 & 5 & 2\end{array}$

$\begin{array}{llllllll}10 & 1 & 10 & 1 & 1 & 9 & 5 & 3\end{array}$

$\begin{array}{llllllll}10 & 1 & 10 & 1 & 1 & 2 & 5 & 3\end{array}$

$\begin{array}{llllllll}10 & 1 & 10 & 1 & 1 & 5 & 5 & 3\end{array}$

$\begin{array}{llllllll}10 & 1 & 10 & 1 & 1 & 9 & 5 & 3\end{array}$

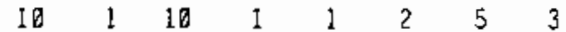

$\begin{array}{llllllll}10 & 1 & 10 & 1 & 1 & 5 & 5 & 3\end{array}$

$\begin{array}{llllllll}10 & 1 & 10 & 1 & 3 & 9 & 5 & 2\end{array}$

$\begin{array}{llllllll}10 & 1 & 10 & 1 & 3 & 5 & 5 & 2\end{array}$

$\begin{array}{llllllll}10 & 1 & 10 & 1 & 1 & 5 & 5 & 3\end{array}$

$\begin{array}{llllllll}16 & 2 & 10 & 1 & 5 & 9 & 5 & 1\end{array}$

$\begin{array}{llllllll}10 & 1 & 10 & 1 & 5 & 9 & 5 & 2\end{array}$

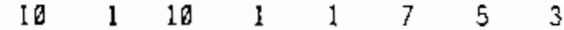

$\begin{array}{llllllll}10 & 1 & 10 & 1 & 1 & 2 & 5 & 3\end{array}$

$\begin{array}{llllllll}10 & 1 & 10 & 1 & 1 & 9 & 5 & 3\end{array}$

$\begin{array}{llllllll}10 & 1 & 10 & 1 & 1 & 2 & 5 & 3\end{array}$

$\begin{array}{llllllll}10 & 1 & 10 & 1 & 1 & 8 & 5 & 3\end{array}$

$\begin{array}{llllllll}10 & 2 & 10 & 1 & 1 & 8 & 5 & 2\end{array}$

$\begin{array}{llllllll}14 & 1 & 10 & 1 & 1 & 9 & 5 & 3\end{array}$

$\begin{array}{llllllll}10 & 1 & 10 & 1 & 5 & 9 & 5 & 2\end{array}$

$10 \quad 1 \quad 10 \quad 1 \quad 3 r \begin{array}{llll}10 & 9 & 5 & 2\end{array}$

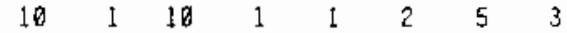

$\begin{array}{llllllll}10 & 1 & 10 & 1 & 5 & 7 & 5 & 2\end{array}$

$\begin{array}{llllllll}10 & 1 & 10 & 1 & 1 & 2 & 5 & 3\end{array}$

$101010 \quad 1 \quad 110503$

$\begin{array}{lllllll}10 & 1 & 10 & 1 & 3 & 5 & 5\end{array}$

$\begin{array}{llllllll}10 & 1 & 10 & 1 & 5 & 8 & 5 & 2\end{array}$

$\begin{array}{llllllll}10 & 1 & 10 & 1 & 3 & 8 & 5 & 2\end{array}$

$10 \quad 1 \quad 10 \quad 1 \quad 10 \quad 9 \quad 502$

$\begin{array}{llllllll}10 & 1 & 10 & 1 & 3 & 7 & 5 & 2\end{array}$




\section{TABLE C.2. (contd)}

RANKINGS BY FUNCTION

ATTR IBUTE

1100120013601460156016001790 NUMBER

No.

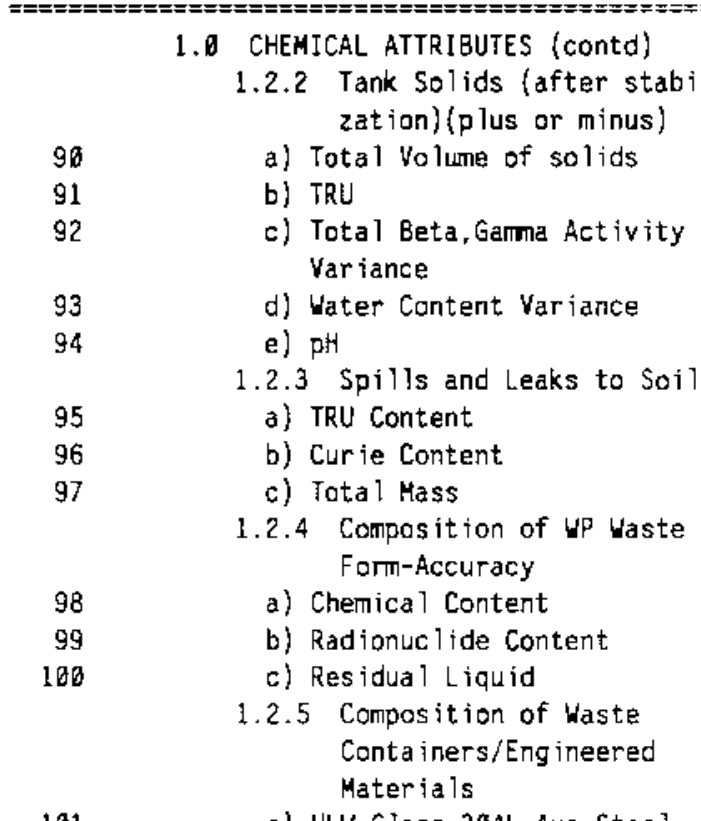

162

103

104

105

106

197

b) Grouts Portland II Cement Fly Ash (ASTM Class F) Clay

c) Cements

d) Fillers

e) Soils/Clay

1.3 Sampling Frequency

1.3.1 Process Stream

a) During Stabilization

b) During Processing and Pre-closure

1.4 Sampling Density of Solid Matter

1.4.1 Process Stream

a) During Tank Characterization

b) During Soil Characterization

c) Processing of Salids

$\begin{array}{lllllllll}\text { AVERAGE-> } & 4.5 & 2.6 & 6.4 & 2.4 & 3.7 & 6.3 & 4.7 & \text { OF ONES }\end{array}$

110

2.0 PHYSICAL ATTRIBUTES (a 11 system

components and contaminated soil)

2.1 Spatial Properties

2.1.1 Waste Form after Stabilization

a) Max Drainable Liquid

(See 3.2.1d) 


\section{TABLE C.2. (contd)}

RANKINGS BY FUNCTION

ATTRIBUTE

ATTRIEUTE DESCRIPTION

1100 $1200 \quad 1300146015001600 \quad 1700$ NUMBER

No.

4.5
2.0 $6.4 \quad 2.4 \quad 3.7 \quad 6.3 \quad 4.7$ OF ONES

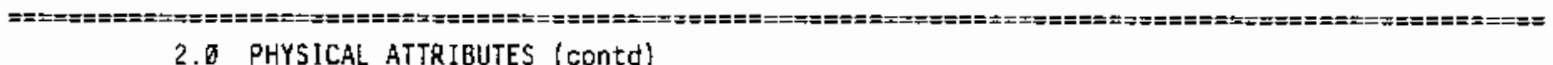

2.1.2 Tank waste retrieval

package dimensions

111

112

113

114

115

116

117

118

$\$ 19$

120

121

122

123

124

125

126

127

128

129

130

131

132

133

134

135

136

137

138

139

140

141

142

143

144
a) Shape
b) Max Volume
c) Max 1.0.
d) Max Height

2.1.3 Soil Package Oimensions

a) Shape

b) Max Volume

c) Max I.D.

d) Max Height

2.1.4 Tank Retrieval Package Dimensions

a) $\operatorname{Max}$ I.D.

b) Max Height

c) Max Gross Weight

2.1.5 Ancillary Equipment Package Oimensions

a) Shape

b) Max Volume

c) $\operatorname{Max}$ I. D.

d) Hax He ight

2.1.6 Final Waste Package

a) Containerized HLW Glass

Length

Diameter

Hall Thickness

Weight

Max Free Volume

b) Containerized TRU Waste-Off

Site WIPP

Contact Handled:

Length/Width/He ight

We ight

Rernote Handled: Diameter/Height

Weight

c) Containerized Grout

Max Free Yolume

2.2 Preciston Limits Tank Waste

a) Density

b) Particle Size Oistribution

c) Viscosity

d) Thermal Output

e) Therma 1 Conductivity

f) Pentraneter Test on Salt Cake

g) Therma 7 Analys is

h) Specific Heat

i) Solids Settiing Rate (sluicing retrieval)

$\begin{array}{rrrrrrrr}1 & 1 & 1 & 9 & 3 & 1 & 1 & 5 \\ 1 & 1 & 1 & 10 & 3 & 1 & 1 & 5 \\ 1 & 1 & 1 & 8 & 3 & 1 & 1 & 5 \\ 1 & 1 & 1 & 7 & 3 & 1 & 1 & 5 \\ 1 & 1 & 1 & 9 & 1 & 1 & 1 & 6 \\ 1 & 1 & 1 & 10 & 1 & 1 & 1 & 6 \\ 1 & 1 & 1 & 8 & 1 & 1 & 1 & 6 \\ 1 & 1 & 1 & 7 & 1 & 1 & 1 & 6\end{array}$

$\begin{array}{llllllll}1 & 1 & 1 & 8 & 1 & 1 & 1 & 6\end{array}$

$\begin{array}{rrrrrrrr}1 & 1 & 1 & 7 & 1 & 1 & 1 & 6 \\ 1 & 1 & 1 & 10 & 1 & 1 & 1 & 6\end{array}$

$\begin{array}{rrrrrrrr}1 & 3 & 1 & 10 & 1 & 1 & 1 & 5 \\ 1 & 3 & 1 & 8 & 1 & 1 & 1 & 5 \\ 1 & 3 & 1 & 8 & 1 & 1 & 1 & 5 \\ 1 & 3 & 1 & 10 & 1 & 1 & 1 & 5\end{array}$




\section{IABLE C.2. (contd)}

RANKINGS BY FINACTION

ATTRIBUTE

1100120013001400150016001700 NUMBER

No. ATTRIBUTE DESCRIPTION

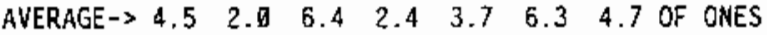

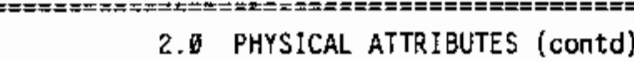

145 j) Volune \% Sett led Solids

(sluicing retrieval)

146 k) Volume * Centrifuged Solids (sluicing retrieval)

147 1) Miller Number (sluicing retrieva T)

148 m) Shear Strength (sluicing retrieval)

149 n) Shear Stress-shear rate rheogram (sluicing retrieval)

\subsection{Physical Properties}

2.3.1 HLW Glass Waste Form

150 a) Monalith Temperature Limit

151 b) Heat Generation Rate

2.3.2 Grout Waste Form

152 a) Temperature Limit

$153 \mathrm{C}$ b) Unconfined Campressive Strength

2.3.3 Waste Package Containers

a) HLW Glass-Max Interna] Pressure

b) Grouted Waste-Vault Overburden Interna? Pressure Strength

c) Single She1] Tank-Temp Limit

d) TRU Waste-Dose Rates

Surface-Contact TRU Surface B/G-Remote Surface Neutron-Remote

2.3.4 Soils/Clays as Engineered Barriers
a) Max Permeability
b) Max Swelling Pressure
c) Min Thickness
d) Min Bearing Strength

2.3.5 Cements-as structures/ barriers

a) Min Permeability

b) Min Compressive Strength

167

168

169

179

2.3.6 Concrete Dome

a) Permeability

b) Strength

c) Al lowable Dome Deformation after Closure

d) Al lowable Dome Defarmation during Closure

171

2.3.7 In-Tank Filled Waste

$\begin{array}{llllllll}10 & 1 & 1 & 7 & 5 & 1 & 1 & 4 \\ 10 & 1 & 1 & 6 & 3 & 1 & 1 & 4 \\ 10 & 1 & 1 & 7 & 3 & 1 & 1 & 4 \\ 10 & 1 & 1 & 8 & 3 & 1 & 1 & 4 \\ 10 & 1 & 1 & 8 & 3 & 1 & 1 & 4\end{array}$

$\begin{array}{llllllll}1 & 1 & 1 & 1 & 1 & 10 & 1 & 6\end{array}$

$\begin{array}{llllllll}1 & 1 & 1 & 1 & 1 & 10 & 1 & 6\end{array}$

$\begin{array}{llllllll}1 & 1 & 1 & 1 & 1 & 10 & 1 & 6\end{array}$

$\begin{array}{llllllll}1 & 1 & 1 & 1 & 1 & 10 & 1 & 6\end{array}$

$\begin{array}{llllllll}1 & 1 & 1 & 1 & 1 & 10 & 1 & 6\end{array}$

$\begin{array}{rrrrrrrr}1 & 1 & 1 & 1 & 1 & 10 & 1 & 6\end{array}$

$\begin{array}{llllllll}1 & 1 & 1 & 1 & 1 & 10 & 1 & 6\end{array}$

$\begin{array}{llllllll}1 & 1 & 1 & 1 & 1 & 10 & 1 & 6\end{array}$

$\begin{array}{llllllll}1 & 1 & 1 & 1 & 1 & 10 & 1 & 6\end{array}$

a) Max Porasity

2.4 Decontamination Factors

2.4.1 Max Quantity of Tank Waste Residue After Retrieval 


\section{IABLE C.2. (contd)}

RANKINGS BY FUNCIION

ATTR IBUTE

No.

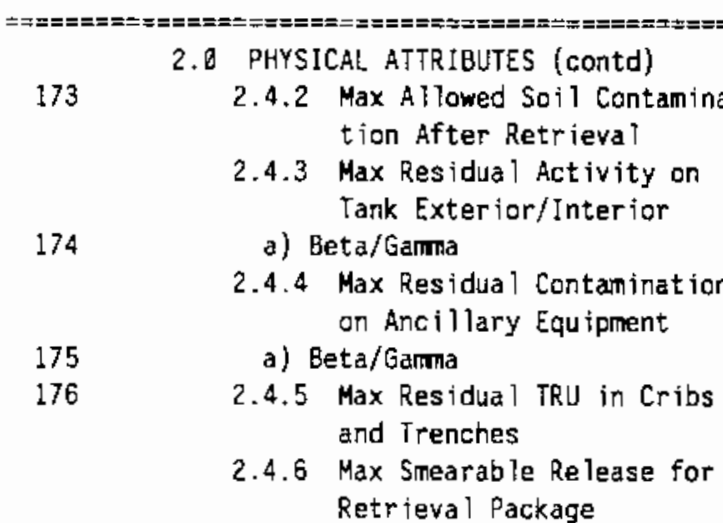

177

178

179

180

181

182

183

184

185

186

187

188

189

190

191

192

193

194

195

196

197

198

199 a) Aipha

b) Beta/Ganma

2.4.7 Max Sinearable Release of HLH Glass WP

a) Beta/Gaitma

b) Alpha

2.4.8 TRU >Class $C$

a) Aipha

b) Beta/Gamma

3. ENGINEERED ENCLOSURES

3.1 Transport Containers

(A11 Types)

3.1.1 Performance Attributes

a) Integrity after Drop/Thema I Test

b) Max Number Times Used

3.2 Waste Packages

3.2.1 Performance Attributes

a) Min Lifetime
$\mathrm{HLW}$
LLW
Grouted Vault
In-Place

b) Max Release Rate-HLH Glass

Cs

u

Si

8

$\mathrm{Na}$

Sulphate

Max Waste Loading

c) Max Release Rate-Grouted Waste

$\mathrm{Ag}$
$\mathrm{As}$
$\mathrm{Ba}$
$\mathrm{Cd}$

$\mathrm{Ag}$

As

Cd
$1100120013001400 \quad 1500 \quad 16001700$ MUMBER

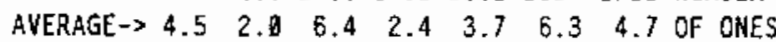

$\begin{array}{llllllll}1 & 1 & 8 & 9 & 1 & 2 & 1 & 4 \\ 1 & 1 & 8 & 9 & 1 & 2 & 1 & 4\end{array}$

$\begin{array}{llllllll}1 & 1 & 8 & 1 & 1 & 8 & 1 & 5 \\ 1 & 1 & 8 & 1 & 1 & 8 & 1 & 5 \\ 1 & 1 & 8 & 1 & 1 & 8 & 1 & 5 \\ 1 & 1 & 8 & 1 & 1 & 8 & 1 & 5\end{array}$


IABLE C.2. (contd)

\begin{tabular}{|c|c|c|c|c|c|c|c|c|c|c|c|}
\hline \multirow{3}{*}{$\begin{array}{c}\text { ATTRIBUTE } \\
\text { No. }\end{array}$} & \multirow{3}{*}{\multicolumn{2}{|c|}{ ATTRIBUTE DESCRIPTION }} & \multicolumn{9}{|c|}{ RANKINGS BY FUNCTION } \\
\hline & & & 1100 & \multirow{2}{*}{\multicolumn{2}{|c|}{$\begin{array}{rr}1200 & 1300 \\
2.0 & 6.4\end{array}$}} & 1400 & 1500 & 1660 & \multirow{2}{*}{$\begin{array}{r}1790 \\
4.7\end{array}$} & \multirow{2}{*}{\multicolumn{2}{|c|}{$\begin{array}{l}\text { NUMBER } \\
\text { OF ONES }\end{array}$}} \\
\hline & & & AVERAGE $\rightarrow 4.5$ & & & 2.4 & 3.7 & 6.3 & & & \\
\hline \multicolumn{12}{|c|}{ 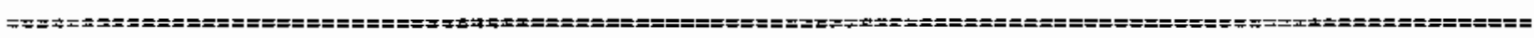 } \\
\hline & 3.0 & ENGIMEERED ENCLOSURES (contd) & & & & & & & & & \\
\hline 200 & & $\mathrm{Cl}$ & 1 & 1 & 9 & 1 & 1 & 5 & 7 & & 4 \\
\hline 201 & & $\mathrm{Cr}$ & 1 & 1 & 9 & 1 & 1 & 10 & 7 & & 4 \\
\hline 202 & & $\mathrm{Cu}$ & 1 & 1 & 9 & 1 & 1 & 5 & 7 & & 4 \\
\hline 203 & & $\mathrm{~F}$ & 1 & 1 & 9 & 1 & 1 & 9 & 7 & & 4 \\
\hline 204 & & $\mathrm{Fe}$ & 1 & 1 & 9 & 1 & 1 & 5 & 7 & & 4 \\
\hline 285 & & $\mathrm{Hg}$ & 1 & 1 & 9 & 1 & 1 & 9 & 7 & & 4 \\
\hline 296 & & $m_{n}$ & 1 & 1 & 9 & 1 & 1 & 5 & 7 & & 4 \\
\hline 297 & & $\mathrm{NO} 2$ & 1 & 1 & 9 & 1 & 1 & 10 & 7 & & 4 \\
\hline 208 & & $\mathrm{NO3}$ & 1 & 1 & 9 & 1 & 1 & 10 & 7 & & 4 \\
\hline 269 & & $\mathrm{~Pb}$ & 1 & 1 & 9 & 1 & 1 & 9 & 7 & & 4 \\
\hline 210 & & $\mathrm{Se}$ & 1 & 1 & 9 & 1 & 1 & 10 & 7 & & 4 \\
\hline 211 & & SO4 & 1 & 1 & 9 & 1 & 1 & 5 & 7 & & 4 \\
\hline 212 & & $Z n$ & 1 & 1 & 9 & 1 & 1 & 5 & 7 & & 4 \\
\hline 213 & & $\mathrm{CH}$ & 1 & 1 & 9 & 1 & 1 & 5 & 7 & & 4 \\
\hline 214. & & $\mathrm{PO4}$ & 1 & 1 & 9 & 1 & 1 & 10 & 7 & & 4 \\
\hline $215^{\circ}$ & & $\mathrm{Na}$ & $\downarrow$ & 1 & 9 & 1 & 1 & 10 & 7 & & 4 \\
\hline 216 & & $C-14$ & 1 & 1 & 9 & 1 & 1 & 10 & 7 & & 4 \\
\hline 217 & & $5 r-90$ & 1 & 1 & 9 & 1 & 1 & 7 & 7 & & 4 \\
\hline 218 & & TC-99 & 1 & 1 & 9 & 1 & 1 & 10 & 7 & & 4 \\
\hline 219 & & $I-129$ & 1 & 1 & 9 & 1 & 1 & 10 & 7 & & 4 \\
\hline 220 & & $C 5-137$ & 1 & 1 & 9 & 1 & 1 & 7 & 7 & & 4 \\
\hline 221 & & $\mathrm{Ra}-226$ & 1 & 1 & 9 & 1 & 1 & 5 & 7 & & 4 \\
\hline 222 & & $\mathrm{~Np}-237$ & 1 & 1 & 9 & 1 & 1 & 8 & 7 & & 4 \\
\hline 223 & & $\mathrm{U}-238$ & 1 & 1 & 9 & 1 & 1 & 5 & 7 & & 4 \\
\hline 224 & & $\mathrm{Pu}-239,240$ & 1 & 1 & 9 & 1 & 1 & 7 & 7 & & 4 \\
\hline 225 & & Am-241 & 1 & 1 & 9 & 1 & 1 & 7 & 7 & & 4 \\
\hline 226 & & $\mathrm{Se}-79$ & 1 & 1 & 9 & 1 & 1 & 7 & 7 & & 4 \\
\hline 227 & & $N b-93 m$ & 1 & 1 & 9 & 1 & 1 & 7 & 7 & & 4 \\
\hline 228 & & $C 0-60$ & 1 & 1 & 9 & 1 & 1 & 7 & 7 & & 4 \\
\hline 229 & & $R u-106$ & 1 & 1 & 9 & 1 & 1 & 7 & 7 & & 4 \\
\hline 230 & & $5 b-126 m$ & 1 & 1 & 9 & 1 & 1 & 7 & 7 & & 4 \\
\hline 231 & & $\mathrm{Cs}-135$ & 1 & 1 & 9 & 1 & 1 & 7 & 7 & & 4 \\
\hline 232 & & $\mathrm{Ce}-144$ & 1 & 1 & 9 & 1 & 1 & 7 & 7 & & 4 \\
\hline 233 & & $P_{u-241}$ & 1 & 1 & 9 & 1 & 1 & 7 & 7 & & 4 \\
\hline 234 & & $S m-151$ & 1 & 2 & 9 & 1 & 1 & 7 & 7 & & 4 \\
\hline 235 & & $8 a-137 m$ & 1 & 1 & 9 & 1 & 1 & 7 & 7 & & 4 \\
\hline 236 & & $S n-126$ & 1 & 1 & 9 & 1 & 1 & 7 & 7 & & 4 \\
\hline 237 & & $2 r-93$ & 1 & 1 & 9 & 1 & I & 7 & 7 & & 4 \\
\hline 238 & & $N i-63$ & 1 & 1 & 9 & 1 & I & 7 & 7 & & 4 \\
\hline 239 & & $\mathrm{C} m-242$ & 1 & 1 & 9 & 1 & 1 & 7 & 7 & & 4 \\
\hline 240 & & TOC Content & 1 & 1 & 9 & 1 & 5 & 7 & 7 & & 3 \\
\hline 241 & & Residua 1/Free Water & 1 & 1 & 9 & 1 & 1 & 7 & 7 & & 4 \\
\hline 242 & & Ten min Gel Strength & 1 & 1 & 9 & ! & 1 & 7 & 7 & & 4 \\
\hline 243 & & Critical Flow & 1 & 1 & 9 & 1 & 1 & 7 & 7 & & 4 \\
\hline 244 & & 30 Thermal Cycles & $i$ & $i$ & 9 & 1 & 1 & 7 & 7 & & 4 \\
\hline 245 & & Biodegradation & 1 & 1 & 9 & 1 & 1 & 7 & 7 & & 4 \\
\hline & & $\begin{array}{l}\text { d) Max Re lease Rate In-Tank } \\
\text { Waste Package }\end{array}$ & & & & & & & & & \\
\hline 246 & & $\begin{array}{l}\text { Residual water (up to } \\
300 \text { deg F) }\end{array}$ & 10 & 10 & 9 & 2 & 1 & 9 & 7 & & 1 \\
\hline
\end{tabular}


IABLE C.2. (contd)

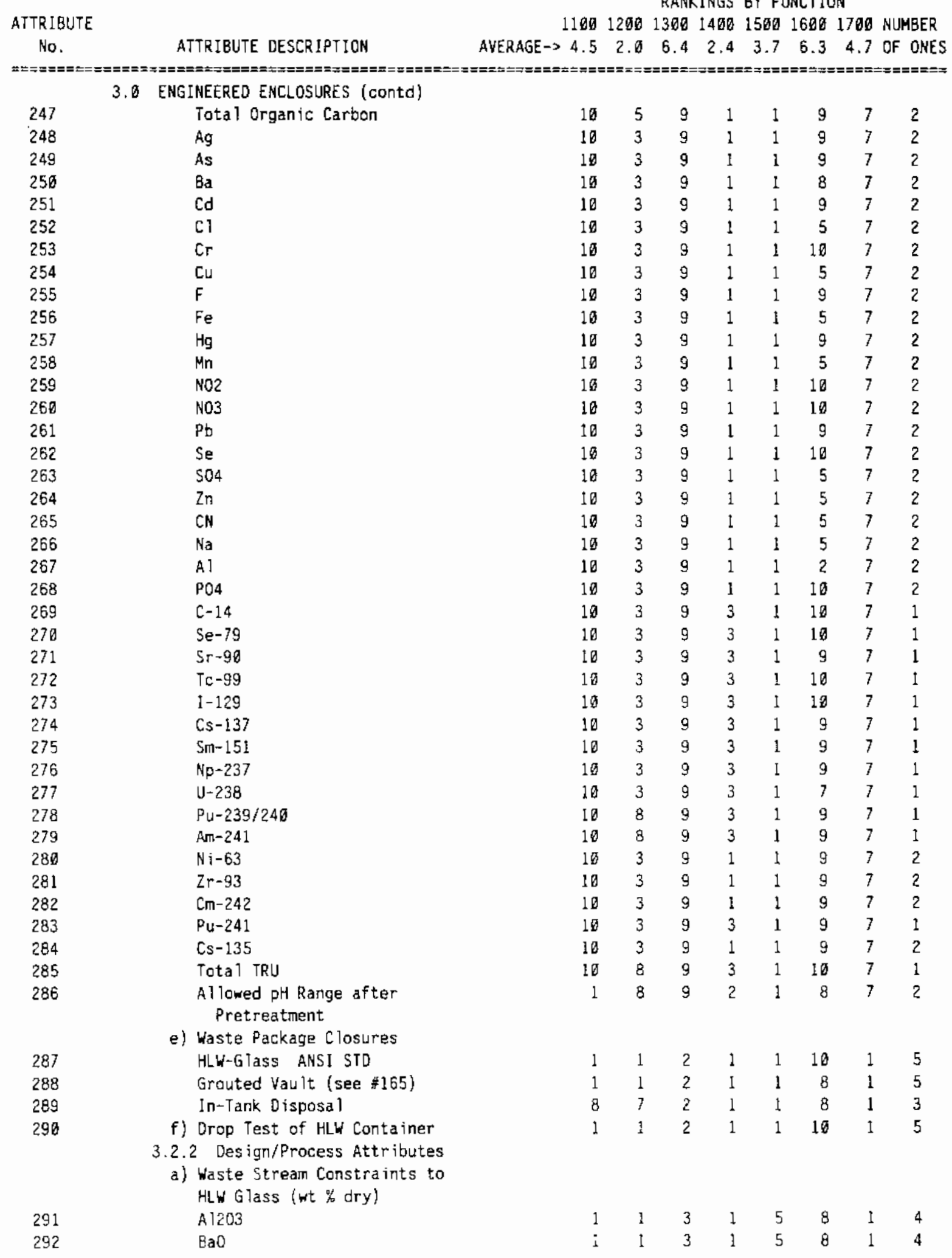


TABLE C.2. (contd)

RANKINGS BY FUNCTION

ATTRIBUTE

$11001200 \quad 13001400150016001700$ NUMBER

No.

ATTRIBUTE DESCRIPTION

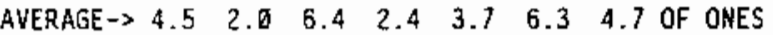

3. 8 ENGINEERED ENCLOSURES (contd)

293
294
295
296
297
298
299
306
301
362
303
304
305
306
307
308
309

310

311

312

313

314

315

316

317

318

319

320

321

322

323

324

325

326

327

328

329

330

331

332

333

334

335

336

337

338

339

340

341

$\mathrm{CaO}$
$\mathrm{CdO}$
$\mathrm{Cr} 203$
$\mathrm{~F}$
$\mathrm{Fe} 2 \mathrm{O3}$
$\mathrm{MnO2}$
$\mathrm{MoO3}$
$\mathrm{Ha} 2 \mathrm{O}$
$\mathrm{Ni0}$
$\mathrm{P} 205$
$\mathrm{SO3}$
$\mathrm{Si02}$
$\mathrm{Ti02}$
U308
Zr02
TOC
Partic le Size

b) Waste Stream Constraints to Grout

$\mathrm{Ag}$
$\mathrm{As}$
$\mathrm{Ba}$
$\mathrm{Cd}$
$\mathrm{Cr}$
$\mathrm{Hg}$
$\mathrm{Pb}$
$\mathrm{Se}$
$\mathrm{TOC}$
$\mathrm{Al}$
$\mathrm{Ca}$
$\mathrm{C} 1$
$\mathrm{CO} 3$
$\mathrm{Cu}$
$\mathrm{F}$
$\mathrm{Fe}$
$\mathrm{K}$
$\mathrm{Mg}$
$\mathrm{Mn}$
$\mathrm{Mo}$
$\mathrm{Na}$
$\mathrm{Ni}$
$\mathrm{NH} 3$
$\mathrm{NO2}$
$\mathrm{NO3}$
$\mathrm{OH}$
$\mathrm{PO} 4$
$\mathrm{SO} 4$
$\mathrm{Zn}$
$\mathrm{Zr}$
$\mathrm{U}$
$\mathrm{RE}$

$\begin{array}{rrrrrrrr}1 & 1 & 3 & 1 & 5 & 8 & 1 & 4 \\ 1 & 1 & 3 & 1 & 5 & 9 & 1 & 4 \\ 1 & 1 & 3 & 1 & 5 & 10 & 1 & 4 \\ 1 & 1 & 3 & 1 & 5 & 9 & 1 & 4 \\ 1 & 1 & 3 & 1 & 5 & 9 & 1 & 4 \\ 1 & 1 & 3 & 1 & 5 & 9 & 1 & 4 \\ 1 & 1 & 3 & 1 & 5 & 9 & 1 & 4 \\ 1 & 1 & 3 & 1 & 5 & 10 & 1 & 4 \\ 1 & 1 & 3 & 1 & 5 & 8 & 1 & 4 \\ 1 & 1 & 3 & 1 & 5 & 9 & 1 & 4 \\ 1 & 1 & 3 & 1 & 5 & 9 & 1 & 4 \\ 1 & 1 & 3 & 1 & 5 & 5 & 1 & 4 \\ 1 & 1 & 3 & 1 & 5 & 7 & 1 & 4 \\ 1 & 1 & 3 & 1 & 5 & 7 & 1 & 4 \\ 1 & 1 & 3 & 1 & 5 & 7 & 1 & 4 \\ 1 & 1 & 3 & 1 & 5 & 10 & 1 & 4 \\ 1 & 1 & 3 & 1 & 5 & 8 & 1 & 4\end{array}$

$\begin{array}{rrrrrrrr}1 & 1 & 3 & 1 & 3 & 9 & 1 & 4 \\ 1 & 1 & 3 & 1 & 3 & 9 & 1 & 4 \\ 1 & 1 & 3 & 1 & 3 & 8 & 1 & 4 \\ 1 & 1 & 3 & 1 & 3 & 10 & 1 & 4 \\ 1 & 1 & 3 & 1 & 7 & 10 & 1 & 4 \\ 1 & 1 & 3 & 1 & 3 & 9 & 1 & 4 \\ 1 & 1 & 3 & 1 & 3 & 9 & 1 & 4 \\ 1 & 1 & 3 & 1 & 3 & 10 & 1 & 4 \\ 1 & 1 & 3 & 1 & 3 & 7 & 1 & 4 \\ 1 & 1 & 3 & 1 & 3 & 2 & 1 & 4 \\ 1 & 1 & 3 & 1 & 3 & 2 & 1 & 4 \\ 1 & 1 & 3 & 1 & 3 & 5 & 1 & 4 \\ 1 & 1 & 3 & 1 & 3 & 5 & 1 & 4 \\ 1 & 1 & 3 & 1 & 3 & 5 & 1 & 4 \\ 1 & 1 & 3 & 1 & 3 & 5 & 1 & 4 \\ 1 & 1 & 3 & 1 & 3 & 5 & 1 & 4 \\ 1 & 1 & 3 & 1 & 3 & 5 & 1 & 4 \\ 1 & 1 & 3 & 1 & 3 & 5 & 1 & 4 \\ 1 & 1 & 3 & 1 & 3 & 5 & 1 & 4 \\ 1 & 1 & 3 & 1 & 3 & 5 & 1 & 4 \\ 1 & 1 & 3 & 1 & 3 & 10 & 1 & 4 \\ 1 & 1 & 3 & 1 & 3 & 5 & 1 & 4 \\ 1 & 1 & 3 & 1 & 3 & 7 & 1 & 4 \\ 1 & 1 & 3 & 1 & 7 & 10 & 1 & 4 \\ 1 & 1 & 3 & 1 & 7 & 10 & 1 & 4 \\ 1 & 1 & 3 & 1 & 3 & 9 & 1 & 4 \\ 1 & 1 & 3 & 1 & 3 & 9 & 1 & 4 \\ 1 & 1 & 3 & 1 & 3 & 9 & 1 & 4 \\ 1 & 1 & 3 & 1 & 3 & 5 & 1 & 4 \\ 1 & 1 & 3 & 1 & 3 & 5 & 1 & 4 \\ 1 & 1 & 3 & 1 & 3 & 5 & 1 & 4 \\ 1 & 1 & 3 & 1 & 3 & 5 & 1 & 4\end{array}$




\section{TABLE C.2. (contd)}

ATTRIBUTE

No.
RANKINGS BY FUNCTION

$1100120013001400 \quad 150016001700$ NUMBER

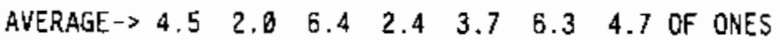

342

343

344

345

346

347

348

349

350

351

352

353

354

355

356

357

358

359

360

361

362

363

364

365

$366 \mathrm{C}$

$367 \mathrm{C}$

$368 \mathrm{C}$

$369 \lessdot$

370

371

372

373

374

375

376

377

378

379

380

381

382
ATTRIBUTE DESCRIPTION

3. ENGINEERED ENCLOSURES (contd)

$\mathrm{CN}$, not $\mathrm{Fe}(\mathrm{CN}) 6$

$\mathrm{C}-14$

$\mathrm{Ni}-59$

$\mathrm{Ni}-63$

$\mathrm{Sr}-9 \mathrm{G}$

Co-60

$\mathrm{H}-3$

$\mathrm{Nb}-94$

Tc-99

I -129

Cs-137

Pu-241

$\mathrm{Cm}-242$

$\mathrm{Ru} / \mathrm{Rh}-106$

$\mathrm{Sb} / \mathrm{Te}-125$

Cs-135

$\mathrm{Ce} / \mathrm{Pr}-144$

An-241

TRU

$\mathrm{pH}$

Solids/S tudge

$\mathrm{Np}-237$

$\mathrm{U}-238$

$\mathrm{Pu}-239 / 240$

c) Constraints on In-P lace

Waste Package from Prior

Design

Max Heat Generation

$M$ in Hydrostatic Load

Max Tank Negative Pressure

Vapor Space-Pressure Range

\subsection{Barriers}

3.3.1 Performance Attributes

a) Production Rate (see 4.1)

b) Lifetime

c) Orainage Rate

d) Storage Capacity of Fine Soil Layer

e) Fine Content at -236 mesh

f) Permeability of Loperm So 1

g) Amount of Runoff

h) Allowed Thickness Change from Erosion/Deposition

i) Allowed Subsidence

j) Earthquakes

k) Excavation Exclusion Period

1) Conc. in Vadose or

Groundwater

Arsenic

Barium

Cadmi ium

$\begin{array}{rrrrrrrr}1 & 1 & 3 & 1 & 3 & 5 & 1 & 4 \\ 1 & 1 & 3 & 1 & 5 & 10 & 1 & 4 \\ 1 & 1 & 3 & 1 & 1 & 5 & 1 & 5 \\ 1 & 1 & 3 & 1 & 1 & 9 & 1 & 5 \\ 1 & 1 & 3 & 1 & 10 & 10 & 1 & 4 \\ 1 & 1 & 3 & 1 & 1 & 9 & 1 & 5 \\ 1 & 1 & 3 & 1 & 1 & 10 & 1 & 5 \\ 1 & 1 & 3 & 1 & 1 & 5 & 1 & 5 \\ 1 & 1 & 3 & 1 & 5 & 10 & 1 & 4 \\ 1 & 1 & 3 & 1 & 5 & 10 & 1 & 4 \\ 1 & 1 & 3 & 1 & 10 & 10 & 1 & 4 \\ 1 & 1 & 3 & 1 & 5 & 9 & 1 & 4 \\ 1 & 1 & 3 & 1 & 1 & 9 & 1 & 5 \\ 1 & 1 & 3 & 1 & 1 & 5 & 1 & 5 \\ 1 & 1 & 3 & 1 & 1 & 5 & 1 & 5 \\ 1 & 1 & 3 & 1 & 1 & 5 & 1 & 5 \\ 1 & 1 & 3 & 1 & 1 & 5 & 1 & 5 \\ 1 & 1 & 3 & 1 & 10 & 9 & 1 & 4 \\ 1 & 1 & 3 & 1 & 10 & 10 & 1 & 4 \\ 1 & 1 & 3 & 1 & 3 & 8 & 1 & 4 \\ 1 & 1 & 3 & 1 & 3 & 8 & 1 & 4 \\ 1 & 1 & 3 & 1 & 10 & 9 & 1 & 4 \\ 1 & 1 & 3 & 1 & 5 & 7 & 1 & 4 \\ 1 & 1 & 3 & 1 & 10 & 9 & 1 & 4\end{array}$

$\begin{array}{llllllll}8 & 10 & 2 & 8 & 1 & 8 & 1 & 2 \\ 1 & 10 & 2 & 8 & 1 & 5 & 1 & 3 \\ 1 & 10 & 2 & 9 & 1 & 2 & 1 & 3 \\ 1 & 10 & 2 & 7 & 1 & 2 & 1 & 3\end{array}$


TABLE C.2. (contd)

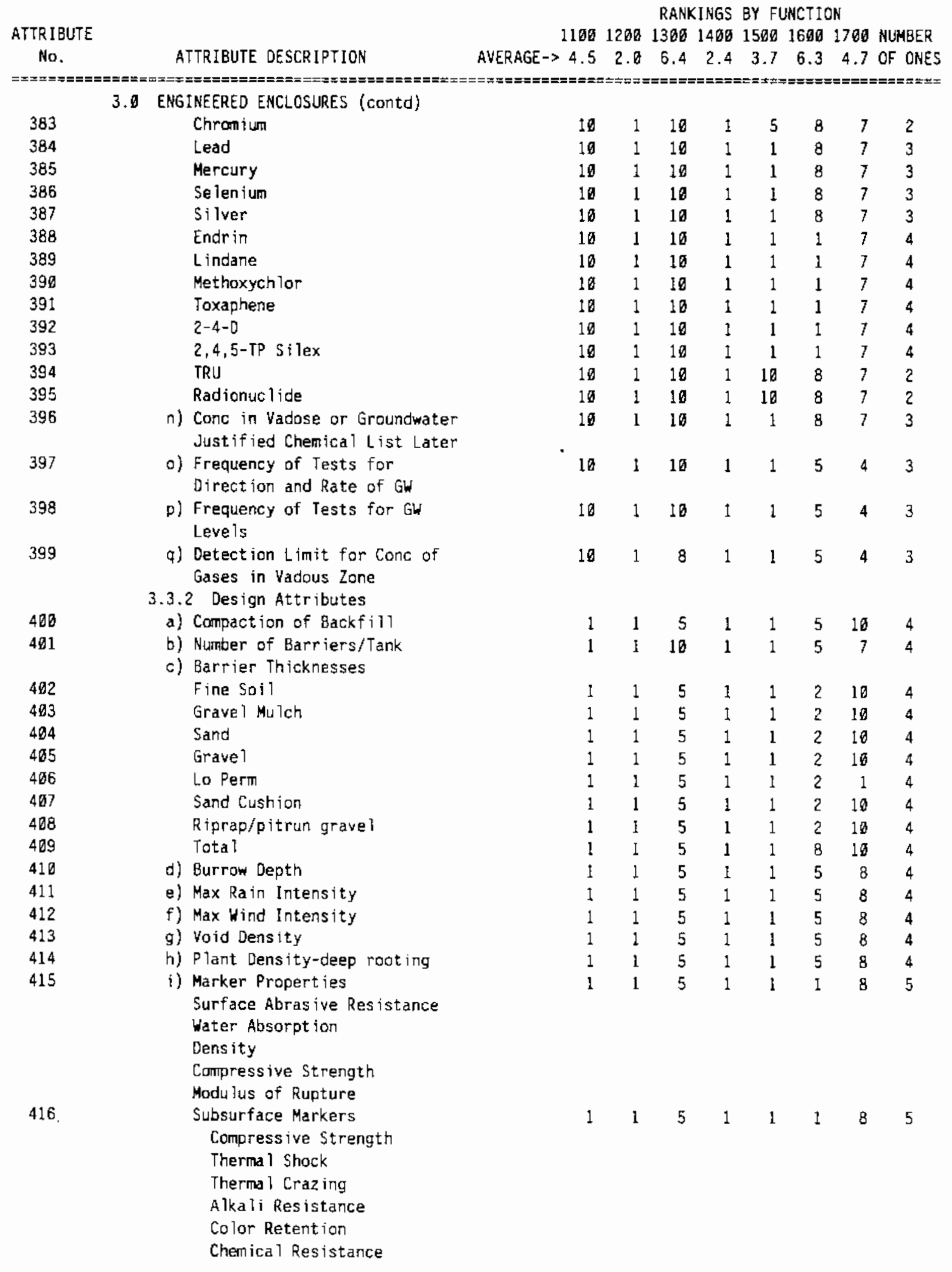


TABLE C.2. (contd)

ATTRIBUTE

Na.

ATTRIBUTE DESCRIPTION

RANKINGS BY FUNCTION

1100120013001400150016001700 NUMAER

(1)

3. 0 ENGINEERED ENCLOSURES (contd)

j) Marker Spacing

417

418

419

420

421

422

423

424

425

426

427

428

429

436

431

432

433

434

435

436

437

438

439

440

441

442

443

444

445

446

447

448
Horizontal

Vertical

k) Marker Functiona 1 Lifetime

1) Well Network

3.3.3 Data Uncertainties (+ or -)

a) Material Volumes

b) Growing Season

c) Climatology

EvapoTrans Rate

Root Depths

Grave 1 Effects

Veg Effects

Marker Dimensions

Burrow Density

d) Hazards Probability

Volcan ic Eruption

Earthquake

Tornado

e) Barrier Hydrology Properties

f) Erosion Rates from wind and Water

g) Deposition Rate from wind

h) Void Size on Site

3.4 Site Facilities

3.4.1 Releases to the Environment

a) $N O X$

b) $50 x$

c) Particulates

d) Process Liquid Discharge

e) Process Solid Discards

3.4.2 Design Attributes

a) Seismic

b) Max Wind Speed-Permanent Factility

c) Max Wind Speed-Transportable Facility during op'ns

d) Facility Operating Life

e) Post-closure Life

4. D OPERATING ATTRIBUTES (Retrieve,

Pretreat, Waste Package. On-site Burial)

4.1 Production/Process Rates (System Level only)

4.1.1 Mean Disposition Rate

4.2 Min In-Process Storage Times

4.3 Process Water Jti i ization Mgmt

4.3.1 Retrieval Output/Input

4.3.2 Processing Output/Input.

4.3.3 Waste Packaging Output/ input

$\begin{array}{rrrrrrrr}1 & 1 & 5 & 1 & 1 & 1 & 8 & 5 \\ 1 & 1 & 5 & 1 & 1 & 1 & 8 & 5 \\ 1 & 1 & 10 & 1 & 1 & 1 & 8 & 5 \\ 1 & 1 & 16 & 1 & 1 & 1 & 8 & 5 \\ 1 & 1 & 5 & 1 & 1 & 1 & 5 & 5 \\ 1 & 1 & 5 & 1 & 1 & 1 & 5 & 5 \\ 1 & 1 & 7 & 1 & 1 & 5 & 9 & 4 \\ 1 & 1 & 7 & 1 & 1 & 5 & 9 & 4 \\ 1 & 1 & 7 & 1 & 1 & 5 & 9 & 4 \\ 1 & 1 & 7 & 1 & 1 & 1 & 9 & 5 \\ 1 & 1 & 7 & 1 & 1 & 1 & 9 & 5 \\ 1 & 1 & 7 & 1 & 1 & 1 & 9 & 5 \\ 1 & 1 & 7 & 1 & 1 & 1 & 9 & 5\end{array}$

$\begin{array}{llllllll}1 & 1 & 7 & 1 & 1 & 8 & 9 & 4 \\ 1 & 1 & 7 & 1 & 1 & 5 & 9 & 4 \\ 1 & 1 & 7 & 1 & 1 & 1 & 9 & 5 \\ 1 & 1 & 7 & 1 & 1 & 1 & 9 & 5\end{array}$

$\begin{array}{rrrrrrrr}7 & 1 & 10 & 10 & 10 & 1 & 1 & 3 \\ 7 & 1 & 10 & 10 & 5 & 1 & 1 & 3 \\ 7 & 1 & 10 & 10 & 3 & 1 & 1 & 3 \\ 1 & 1 & 10 & 10 & 5 & 5 & 1 & 3 \\ 1 & 1 & 10 & 10 & 10 & 5 & 1 & 3 \\ 1 & 1 & 5 & 5 & 3 & 1 & 1 & 4 \\ 1 & 1 & 5 & 1 & 3 & 1 & 1 & 5 \\ 1 & 1 & 5 & 8 & 3 & 1 & 1 & 4 \\ 1 & 1 & 5 & 5 & 3 & 1 & 1 & 4 \\ 1 & 1 & 10 & 1 & 3 & 1 & 1 & 5\end{array}$


TABLE C.2. (contd)

RANKINGS BY FUNCTION

ATTRIBUTE

No.

ATTRIBUTE DESCRIPTION

$110012001360 \quad 1400150016001700$ NUMBER

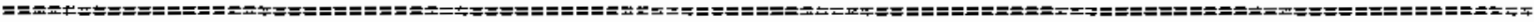

4.6 DPERATING ATTRIBUTES (contd)

4.4 Acceptance Criteria

4.4.1 Retrieval Package

449

450

a) Max Themal Content/Package

b) Max Mass Content/Package

\subsection{Process Separations}

4.5.1 Species in Glass Stream

451

452

453

454

455

456

457

458

459

460

461

462

463

464

465

466

467

468

469

470

471

472

473

474

475

476

477

478

479

480

481

482

483

484

485

486

487 a) $\mathrm{Na}$

b) Al. $\mathrm{Fe}$

c) $\mathrm{Si}$

d) $\mathrm{U}$

e) TOC, incl $\mathrm{CN}$

4.5.2 Species in Grout Stream after Pretreatment
a) $\mathrm{Na}$
b) $\mathrm{NO3}$
c) $\mathrm{C}-14$
d) $N i-63$
e) $\mathrm{S} r-90$
f) $\mathrm{Tc}-99$
g) $I-129$
h) $[s-137$
i) U-235.238
j) $\mathrm{Np}-237$
k) $P u-239,240$
1) A $\mathrm{A}-241$

4.5.3 Species in Tank waste after In-Place Treatment

a) $\mathrm{Cd}$

b) $\mathrm{Cr}$

c) $\mathrm{CN}$

d) $\mathrm{F}$

e) $\mathrm{Fe}$

f) $\mathrm{Mn}$

g) $\mathrm{Hg}$

h) $\mathrm{NOO}$

i) $\mathrm{NO2}$

j) $\mathrm{Na}$

k) $\mathrm{SO4}$

1) $\mathrm{C}-14$

m) $\mathrm{Sr}-90$

n) $T c-99$

o) $[-129$

p) $\mathrm{Cs}-137$

q) $\mathrm{Np}-237$

r) $P u-239,240$

s) $A m-241$

t) TRU

$\begin{array}{rrrrrrrr}1 & 1 & 1 & 9 & 1 & 1 & 1 & 6 \\ 1 & 1 & 1 & 10 & 1 & 1 & 1 & 6\end{array}$

$\begin{array}{llllllll}1 & 1 & 5 & 1 & 10 & 10 & 7 & 3 \\ 1 & 1 & 5 & 1 & 10 & 10 & 7 & 3 \\ 1 & 1 & 5 & 1 & 10 & 10 & 7 & 3 \\ 1 & 1 & 5 & 1 & 10 & 10 & 7 & 3 \\ 1 & 1 & 5 & 1 & 10 & 10 & 7 & 3\end{array}$

$\begin{array}{rrrrrrrr}1 & 1 & 5 & 1 & 10 & 10 & 7 & 3 \\ 1 & 1 & 5 & 1 & 10 & 10 & 7 & 3 \\ 1 & 1 & 5 & 1 & 10 & 10 & 7 & 3 \\ 1 & 1 & 5 & 1 & 10 & 8 & 7 & 3 \\ 1 & 1 & 5 & 1 & 10 & 9 & 7 & 3 \\ 1 & 1 & 5 & 1 & 10 & 10 & 7 & 3 \\ 1 & 1 & 5 & 1 & 10 & 10 & 7 & 3 \\ 1 & 1 & 5 & 1 & 10 & 9 & 7 & 3 \\ 1 & 1 & 5 & 1 & 10 & 8 & 7 & 3 \\ 1 & 1 & 5 & 1 & 10 & 8 & 7 & 3 \\ 1 & 1 & 5 & 1 & 10 & 8 & 7 & 3 \\ 1 & 1 & 5 & 1 & 10 & 8 & 7 & 3\end{array}$

$\begin{array}{rrrrrrrr}8 & 2 & 5 & 1 & 1 & 10 & 7 & 2 \\ 8 & 2 & 5 & 1 & 10 & 10 & 7 & 1 \\ 8 & 2 & 5 & 1 & 10 & 8 & 7 & 1 \\ 8 & 2 & 5 & 1 & 10 & 8 & 7 & 1 \\ 8 & 2 & 5 & 1 & 1 & 5 & 7 & 2 \\ 8 & 2 & 5 & 1 & 1 & 5 & 7 & 2 \\ 8 & 2 & 5 & 1 & 1 & 8 & 7 & 2 \\ 8 & 2 & 5 & 1 & 1 & 10 & 7 & 2 \\ 8 & 2 & 5 & 1 & 1 & 10 & 7 & 2 \\ 8 & 2 & 5 & 1 & 1 & 5 & 7 & 2 \\ 8 & 2 & 5 & 1 & 1 & 7 & 7 & 2 \\ 8 & 2 & 5 & 3 & 5 & 10 & 7 & 0 \\ 8 & 2 & 5 & 3 & 10 & 9 & 7 & 0 \\ 8 & 2 & 5 & 3 & 5 & 10 & 7 & 0 \\ 8 & 2 & 5 & 3 & 5 & 10 & 7 & 0 \\ 8 & 2 & 5 & 3 & 10 & 9 & 7 & 0 \\ 8 & 2 & 5 & 3 & 10 & 7 & 7 & 0 \\ 8 & 3 & 5 & 3 & 10 & 7 & 7 & 0 \\ 8 & 3 & 5 & 3 & 10 & 7 & 7 & 0 \\ 8 & 3 & 5 & 3 & 10 & 10 & 7 & 0\end{array}$




\section{IABLE C.2. (contd)}

RANKINGS BY FUNCTION

ATTRIBUTE

No.

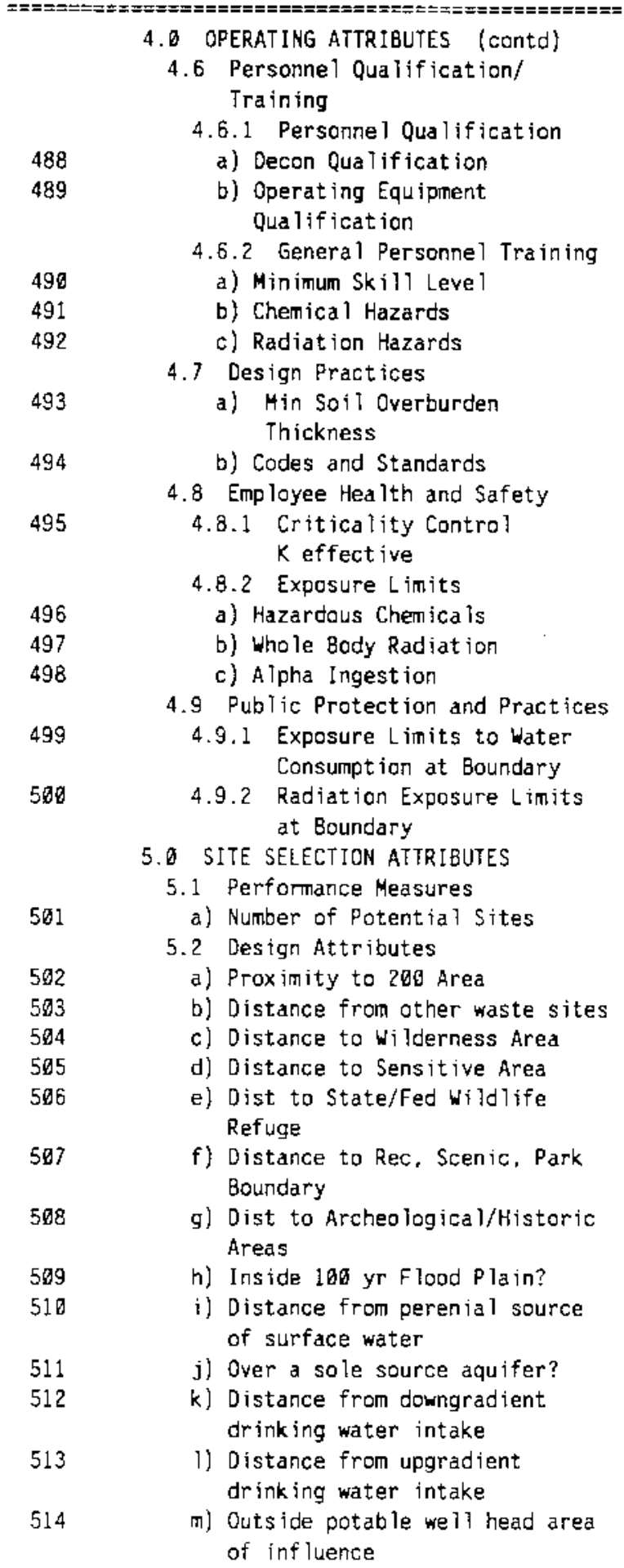

$110012001300 \quad 1400150016001760$ NUMBER

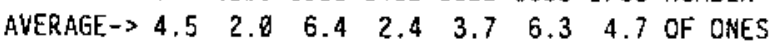

$\begin{array}{rrrrrrrr}10 & 10 & 7 & 10 & 3 & 1 & 1 & 2 \\ 10 & 10 & 7 & 9 & 5 & 5 & 1 & 1 \\ & & & & & & & \\ 10 & 10 & 7 & 7 & 5 & 5 & 1 & 1 \\ 10 & 10 & 7 & 8 & 5 & 5 & 1 & 1 \\ 10 & 10 & 7 & 8 & 5 & 5 & 1 & 1 \\ 1 & 1 & 2 & 7 & 1 & 9 & 1 & 4 \\ 1 & 1 & 2 & 2 & 5 & 5 & 1 & 3 \\ 10 & 5 & 8 & 5 & 5 & 10 & 1 & 1 \\ & & & & & & & \\ 10 & 10 & 8 & 9 & 5 & 9 & 1 & 1 \\ 10 & 10 & 8 & 10 & 5 & 9 & 1 & 1 \\ 10 & 10 & 8 & 10 & 5 & 9 & 1 & 1 \\ 3 & 10 & 9 & 2 & 5 & 9 & 10 & 0 \\ 3 & 10 & 9 & 2 & 5 & 9 & 10 & 0\end{array}$

$\begin{array}{llllllll}3 & 10 & 9 & 2 & 5 & 9 & 19 & 0\end{array}$ 


\section{TABLE C.2. (contd)}

RANKINGS BY FUNCTION

ATTR I BUTE

No.

ATTRIBUTE DESCRIPTION

$11001200 \quad 13001490 \quad 150016001700$ NUMBER

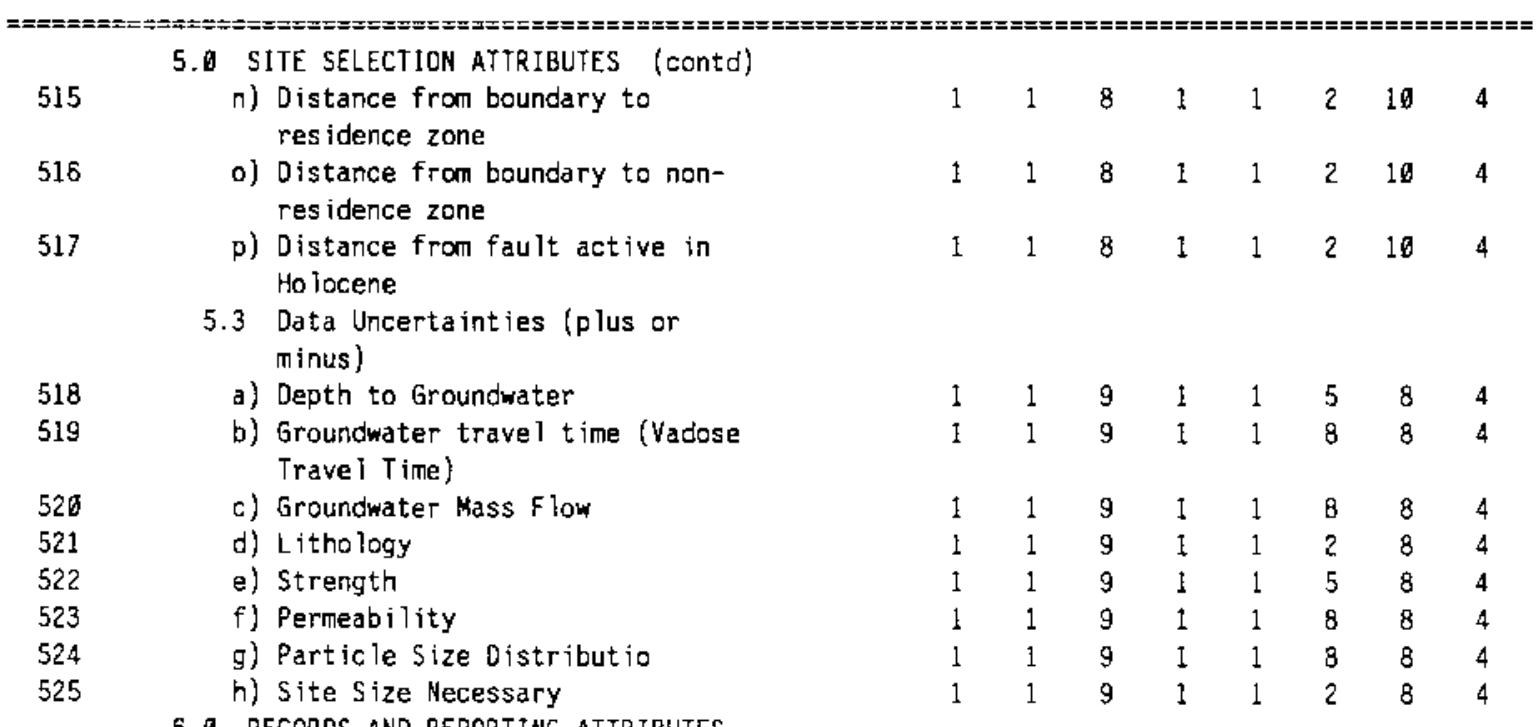

6. RECOROS AND REPORTING ATTRIBUTES

6.1 Performance Assessments (Levels of Conservatism)

526

527
6.1 .1 inputs

a) Measured Data

b) Estimated Data-Effect on Final Result.

6.1.2 Algorithns Used-Effect on Final Result

a) First Principles

b) Extrapolations of Empirical Relationships

6.1.3 Assessment Margins

a) Temperatures

b) Escape Rate from Sequestered Waste Forms

c) Transport Rate in Carrier Systern

6.2 Not if ications for $\$ p i l l s /$ Re leases

6.2.1 Release Points

6.2.2 Reporting Condition

6.2.3 Reporting Window after Occurence

6.2.4 Report Contents

6.3 Natification for RCRA

Documentation

6.3.1 Hammer Dates

6.3.2 Reporting Method

6.3.4 Reporting Contents

6.4 Waste Form Record Update

6.4 .1 Volume of solids

6.4.2 Total H2O volume

$\begin{array}{rrrrrrrr}10 & 10 & 9 & 10 & 3 & 5 & 1 & 1 \\ 10 & 3 & 9 & 10 & 3 & 5 & 1 & 1 \\ 10 & 10 & 9 & 10 & 3 & 5 & 1 & 1 \\ 8 & 8 & 9 & 10 & 3 & 5 & 1 & 1 \\ & & & & & & & \\ 3 & 3 & 9 & 1 & 3 & 5 & 1 & 2 \\ 3 & 3 & 9 & 1 & 3 & 5 & 1 & 2 \\ 3 & 3 & 9 & 1 & 3 & 5 & 1 & 2 \\ 10 & 10 & 5 & 3 & 1 & 2 & 1 & 2 \\ 10 & 10 & 5 & 3 & 1 & 7 & 1 & 2\end{array}$




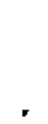

- 


\section{DISTRIBUTION}

No. of

Copies

OFFSITE

\section{DOE Headquarters}

J. C. Lehr

On-site Remediation Branch

U.S. Department of Energy

EM-442

Germantown

Washington, DC 20545

Other

2 ICF Inc.

591 Camino de La Reina, Suite 418

San Diego, CA 92108

ATTN: Martin Letourneau Rod Lorang

5 E. A. Aitken

54-829 Firestone

PGA West

La Quinta, CA 92253

\section{ONSITE}

8 DOE Richland Operations Office

M. J. Anthony

P. K. Clark

A6-95

R. D. Freeberg

A5-21

R. E. Gerton

A6-95

J. M. Hennig

A5-21

J. E. Newson

A5-21

A5-21

Public Reading Room (2) Al-65

84 Westinghouse Hanford Company

M. R. Adams

H4-55

H. Babad

B2-15

D. E. Bal1

A. L. Boldt

K. D. Boomer

L. C. Brown
No. of

Copies

J. W. Cammann H4-54

N. R. Croskrey H5-12

A. J. DiLiberto R2-12

J. R. Freeman-Pollard H4-55

J. S. Garfield Rl-16

K. A. Giese R2-12

C. E. GoTberg R2-12

V. W. Hall B2-15

B. A. Higley R3-63

J. 0. Honeyman B1-41

L. J. Johnson Rl-16

R. T. Kimura R1-49

M. J. Klem R2-12

L. E. Jusler R3-63

R. J. Landon B2-19

J. S. Layman H5-12

R. E. Lerch B2-35

R. M. Marusich R3-02

H. E. McGuire B2-35

B. E. Opitz (30) R1-19

S. M. O'Toole B2-20

R. J. Parazin H5-12

C. A. Petersen N1-34

S. J. Phillips 17-10

R. E. Raymond R1-62

R. C. Roal S6-08

F. A. Ruck H4-57

W. G. Ruff R2-50

L. M. Sasaki R2-12

E. J. Shen H5-08

E. M. Smith B2-19

J. C. Sonnichsen H4-50

J. D. Thomson H5-01

N. R. Wing H4-54

D. D. Wodrich R2-23

R. D. Wojtasek B2-15

J. C. Womack R2-18

D. D. Wood B2-19

K. A. Woodworth H4-55

Central Files L8-15

Environmental Data

Management Center (6) H4-22

Publications Services (3) L8-07 
No. of

Copies

24 Pacific Northwest Laboratory

E. G. Baker

W. F. Bonner

J. F. Fletcher

G. M. Holter

G. W. McNair

G. B. MeTlinger

D. R. Payson
$\mathrm{K} 2-12$

$\mathrm{K} 4-13$

$K 6-25$

$K 6-28$

$\mathrm{K} 6-25$

P7-18

K6-35
No. of

Copies

M. S. Peffers

K6-28

P. F. Salter

J. D. Smyth

T. L. Stewart

K. M. Tominey

R. S. Wegeng (5)

K. D. Wiemers

Publishing Coordination

Technical Report Files (5)
P8-01

$\cdot \mathrm{K} 6-25$

$\mathrm{K} 2-12$

$\mathrm{K} 6-25$

$\mathrm{K} 6-28$

P7-14 